\title{
Resurrection and emendation of the Hypoxylaceae, recognised from a multigene phylogeny of the Xylariales
}

\author{
Lucile Wendt ${ }^{1,2} \cdot$ Esteban Benjamin $\mathrm{Sir}^{3} \cdot$ Eric Kuhnert $^{1,2}$ • Simone Heitkämper ${ }^{1,2}$. \\ Christopher Lambert $^{1,2}$ - Adriana I. Hladki ${ }^{3}$ Andrea I. Romero ${ }^{4,5}$. \\ J. Jennifer Luangsa-ard ${ }^{6} \cdot$ Prasert Srikitikulchai $^{6} \cdot$ Derek Peršoh $^{7} \cdot$ Marc Stadler $^{1,2}$ (i)
}

Received: 21 February 2017 / Revised: 12 April 2017 / Accepted: 19 April 2017 / Published online: 10 June 2017

(C) The Author(s) 2017. This article is an open access publication

\begin{abstract}
A multigene phylogeny was constructed, including a significant number of representative species of the main lineages in the Xylariaceae and four DNA loci the internal transcribed spacer region (ITS), the large subunit (LSU) of the nuclear rDNA, the second largest subunit of the RNA
\end{abstract}

This article is part of the "Special Issue on ascomycete systematics in honor of Richard P. Korf who died in August 2016".

The present paper is dedicated to Prof. Jack D. Rogers, on the occasion of his fortcoming 80th birthday.

Section Editor: Teresa Iturriaga and Marc Stadler

Electronic supplementary material The online version of this article (doi:10.1007/s11557-017-1311-3) contains supplementary material, which is available to authorized users.

Marc Stadler

marc.stadler@helmholtz-hzi.de

1 Department of Microbial Drugs, Helmholtz-Zentrum für Infektionsforschung $\mathrm{GmbH}$, Inhoffenstrasse 7, 38124 Braunschweig, Germany

2 German Centre for Infection Research (DZIF), partner site Hannover-Braunschweig, 38124 Braunschweig, Germany

3 Fundación Miguel Lillo, CONICET, Institute of Mycology, Miguel Lillo 251, 4000 San Miguel de Tucumán, Tucumán, Argentina

4 Facultad de Ciencias Exactas y Naturales, Departamento de Biodiversidad y Biología Experimental, Universidad de Buenos Aires, C1428 EHA Buenos Aires, Argentina

5 Instituto de Micología y Botánica (INMIBO), CONICET-Universidad de Buenos Aires, C1428 EHA Buenos Aires, Argentina

6 National Center for Genetic Engineering and Biotechnology (BIOTEC), 113 Thailand Science Park, Phaholyothin Road, Klong Luang, Pathumthani 12120, Thailand

7 Department of Geobotany, Ruhr-Universität Bochum, Universitätsstraße 150, 44780 Bochum, Germany polymerase II (RPB2), and beta-tubulin (TUB2). Specimens were selected based on more than a decade of intensive morphological and chemotaxonomic work, and cautious taxon sampling was performed to cover the major lineages of the Xylariaceae; however, with emphasis on hypoxyloid species. The comprehensive phylogenetic analysis revealed a clear-cut segregation of the Xylariaceae into several major clades, which was well in accordance with previously established morphological and chemotaxonomic concepts. One of these clades contained Annulohypoxylon, Hypoxylon, Daldinia, and other related genera that have stromatal pigments and a nodulisporium-like anamorph. They are accommodated in the family Hypoxylaceae, which is resurrected and emended. Representatives of genera with a nodulisporium-like anamorph and bipartite stromata, lacking stromatal pigments (i.e. Biscogniauxia, Camillea, and Obolarina) appeared in a clade basal to the xylarioid taxa. As they clustered with Graphostroma platystomum, they are accommodated in the Graphostromataceae. The new genus Jackrogersella with $J$. multiformis as type species is segregated from Annulohypoxylon. The genus Pyrenopolyporus is resurrected for Hypoxylon polyporus and allied species. The genus Daldinia and its allies Entonaema, Rhopalostroma, Ruwenzoria, and Thamnomyces appeared in two separate subclades, which may warrant further splitting of Daldinia in the future, and even Hypoxylon was divided in several clades. However, more species of these genera need to be studied before a conclusive taxonomic rearrangement can be envisaged. Epitypes were designated for several important species in which living cultures and molecular data are available, in order to stabilise the taxonomy of the Xylariales.

Keywords Ascomycota · Biodiversity · Evolution · Gen. nov. $\cdot$ Sordariomycetes $\cdot$ Secondary metabolites $\cdot$

Xylariomycetideae 


\section{Introduction}

The Xylariaceae comprises one of the core families of the Sordariomycetes and is the largest family of the Xylariomycetideae that are known as cosmopolitan, ubiquitous wood degraders and predominant endophytes (Stadler 2011). The family is located within the Xylariales - the only order of the Xylariomycetidae (Eriksson and Winka 1997; see Senanayake et al. 2015 and Jaklitsch et al. 2016 for the current organisation of this order). It has always been recognised to comprise a homogenous evolutionary lineage based on its ascal and ascospore morphology (typically having eightspored asci with an amyloid ascal apical apparatus and brown to dark brown, ellipsoid ascospores; cf. Rogers 1979).

The prototype of a xylariaceous fungus is Xylaria hypoxylon (L.) Grev., the type species of the genus Xylaria Hill ex Schrank, which is probably the largest genus within the family, according to the current classification. The taxonomy of this fungus has only recently been stabilised by a lecto- and epitypification (Stadler et al. 2014b), following an extensive polyphasic study by Fournier et al. (2011).

Related families in the Xylariales/Xylariomycetideae such as the Diatrypaceae and Graphostromataceae have historically been distinguished from the Xylariaceae by having allantoid ascospores (Barr et al. 1993; Stadler et al. 2013). However, since about 50 years ago, the morphological characters of the asexual morph have been taken into account more seriously in the taxonomy of the Ascomycota. This has resulted in the restriction of the genus Hypoxylon Bull. for those taxa that have nodulisporium-like asexual stages. Genera such as Entoleuca Syd. and Nemania S. F. Gray were segregated from Hypoxylon as they produce geniculosporium-like asexual morphs (Rogers and Ju 1996; Ju and Rogers 2002).

An attempt to classify the larger groups in this highly diverse group of Ascomycota by Dennis (1961) into "Xylarioideae", "Hypoxyloideae", and "Thamnomycetideae" proved invalid because these "subfamilies" have not been formally erected following the rules of botanical nomenclature (cf. Bitzer et al. 2008). Moreover, the "Thamnomycetideae", which Dennis (1961) had mainly based on the aberrant stromatal morphology of Thamnomyces Ehrenb., was recently proven obsolete. It was clearly shown that the phylogenetic and chemotaxonomic affinities of typical Thamnomyces are with Daldinia Ces. \& De Not. and other "hypoxyloid" genera (Stadler et al. 2010b).

The first comprehensive classification of the Xylariaceae based on holomorphic concept was proposed by $\mathrm{Ju}$ and Rogers (1996), who divided the Xylariaceae into two major groups: the genera related to Xylaria with "geniculosporiumlike anamorphs" vs. the genera related to Hypoxylon, featuring "nodulisporium-like anamorphs". Ju and Rogers (1996) did not actually attempt formally to circumscribe these major groups by erecting subfamiliar taxa, but only listed the respective genera. Some authors have nevertheless used the taxonomically invalid terms "Xylarioideae" (for the former) and "Hypoxyloideae" (for the latter). Interestingly, these differences in anamorphic morphology also coincide with the presence of other features (e.g. inverse hat-shaped apical apparatus in many genera of the "Xylarioideae"; presence of stromatal pigments in Hypoxylon and allies). However, the immense morphological and phenotypic plasticity of the Xylariales has so far precluded a clear-cut segregation at the subfamiliar ranks, and even the definition of Hypoxylon by Ju and Rogers (1996) was still mainly based on gross stromatal morphology. Interfaces to other xylarialean families were also occasionally observed (cf. treatment of Creosphaeria, Lopadostoma, Jumillera and Whalleya below), but never taken seriously into consideration to remove any of the respective genera from the Xylariaceae, because the ascospore morphology was still regarded as a major discriminative character at this taxonomic level.

Starting from the work of Whalley and Edwards (1995), mycologists have begun to appreciate the value of chemotaxonomic data as complementary phenotype-based characters, which can be used to verify taxonomic concepts in the Xylariaceae. The latter authors mainly studied mycelial cultures of these fungi and identified their characteristic secondary metabolites after tedious chromatography work and extensive characterisation of the purified products, but did not have any high-throughput analytical methods at their disposal to screen numerous specimens for their occurrence to provide sound data on the distribution of the compounds in the family. While their work did not immediately result in taxonomic conclusions, this was later made possible by the advent of analytical techniques based on high performance liquid chromatography coupled with diode array detection and mass spectrometric detection (HPLC-DAD/MS). This technique, paired with extensive preparative chromatography work, has led to the discovery of over 150 secondary metabolites, most of which were new to science at the time of their discovery (Stadler and Hellwig 2005; Stadler 2011; Kuhnert et al. 2015). Recent studies have shown that in particular the metabolite profiles from cultures are strongly in agreement with molecular phylogenetic data (Bitzer et al. 2008; Stadler et al. 2010a, b, c), whereas the stromatal HPLC profiles proved highly valuable for delimitation of species in those genera that have so far been extensively studied (Stadler et al. 2008a, b, 2014a, Kuhnert et al. 2016).

Comprehensive molecular phylogenetic investigations of the Xylariaceae using data from reliably identified specimens have been rather scarce until very recently. The studies by Sánchez-Ballesteros et al. (2000), Triebel et al. (2005) and Pelaez et al. (2008) exclusively used DNA loci such as the internal transcribed spacer region (ITS) of the nuclear ribosomal DNA (rDNA) that is widely accepted by the community as standard barcode of fungi (Schoch et al. 2012), but 
failed to resolve the taxa in the hypoxyloid clades, due to its limitations as phylogenetically informative locus. The studies by Hsieh et al. (2005, with focus on Hypoxylon and allies), and Hsieh et al. (2010, with focus on the xylarioid clades) provided a better resolution based on the protein-coding genes alpha-actin (ACT) and beta-tubulin (TUB2). Both genes exhibit intron-rich $5^{\prime}$ primed ends and thus met ideal requirements for phylogenetically informative loci, but are - as non-universal regions - only of limited use for phylogenetic analyes (Tang et al. 2007; Stielow et al. 2015). Interestingly, Hsieh et al. (2005) already chose to abandon ITS data from their great experience with comparative morphology as phylogenetically valid criterion at a time when many other mycologists promoted them, and some even proposed that this DNA locus can serve as "sole means of identification of a fungus". The development in fungal taxonomy and phylogeny that followed in the past decade certainly proved the latter authors right!

Tang et al. (2009) were the first to attempt a multigene phylogeny derived from a combination of rRNA and protein-coding genes. Besides ITS, LSU, and TUB2, Tang et al. used the section " $6-7$ " of the second largest subunit of the RNA-polymerase II gene (RPB2) that is commonly used for both barcoding and phylogenetic purposes within the fungal kingdom. Unfortunately, their phylogeny had many gaps and several data sets were derived from different specimens of the same taxon or came from non-verifiable sources (e.g. sequence data in GenBank retrieved from material that is not available in the public domain for verification of the taxonomy). Recent work by Daranagama et al. (2014, 2015) provided additional rDNA and RPB2 sequence data, in particular for important Anthostomella species and other related taxa. Because of these studies, and comprehensive treatments of the Xylariaceae in phylogenies obtained exclusively from housekeeping gene sequences by Hsieh et al. (2005, 2010), the data matrix for a multigene genealogy has steadily increased over the past decade. Notably, several of the genera that were regarded as xylariaceous by Ju and Rogers (1996) and earlier workers are characterised by libertella-like asexual stages (cf. Ju et al. 1993 for Creosphaeria; Rogers et al. 1997 for Jumillera and Whalleya), revealing affinities to the Diatrypaceae.

Jaklitsch et al. (2014) provided a comprehensive polythetic study on the genus Lopadostoma based on rDNA and RPB2 data, revealing that these fungi appear rather distantly related to the core of Xylariaceae. Accordingly, Senanayake et al. (2015) placed Lopadostoma and Creosphaeria in the new family Lopadostomataceae, which was confirmed in a subsequent study by Jaklitsch et al. (2016). Concurrently and subsequently, several other studies have been initiated in order to classify the non-stromatic taxa of the Xylariales (Jaklitsch and Voglmayr 2012; Daranagama et al. 2015, 2016; Maharachchikumbura et al. 2016), sometimes resulting in incongruent concepts according to the standpoint of the authors.
In particular the study of Jaklitsch et al. (2016) provided several examples that undermined the classical concepts of ascomycete taxonomy, because they proved conclusively that it is not feasible to rely on old herbarium specimens and morphological descriptions, unless the respective species have been recollected, cultured, studied in detail for their morphological characters, and sequenced by means of a multi-locus approach. The other above mentioned studies, however, heavily relied on collection of fresh material during field work in tropical areas and many non-stromatic Xylariales with affinities to the Xylariaceae in the classical sense were recovered and sequenced, but they could not be assigned to one of the existing teleomorph-based genera.

As a consequence, the number of genera and even families has been steadily increasing, while the core taxa of the Xylariaceae, i.e. arguably the largest and most important family, remain to be re-organised.

The present paper was dedicated to a multigene genealogy of the family, with emphasis on Hypoxylon and its allies and their affinities to the xylarioid clades. We selected numerous representative specimens and cultures from extensive taxonomic work in the past decade and hope to fill some gaps in our knowledge on the phylogenetic affinities of this family. We concentrated on the phylogenetic and chemotaxonomic aspects, because a concurrent comprehensive study giving an account on all xylariaceous genera is presently under preparation.

\section{Materials and methods}

Except for the typification details in the taxonomic part, all fungal names are given without authorities or publication details, in accordance with Index Fungorum (http://www. indexfungorum.org) and Mycobank (http://www.mycobank. org/).

With respect to the terminology of sexual vs. asexual structures, we have explicitly decided to treat the "old-fashioned" expressions (anamorph/teleomorph) as synonyms of the more modern terms asexual vs. sexual morph. The reason is that, particularly in the Xylariaceae and related taxa, the conidial states of most of the species are not yet known, or it has not been possible to obtain them in culture. Therefore, the characteristics of the teleomorph are thus by far more informative.

\section{Taxon selection}

All taxa were selected from previous work as indicated in Table 1, which also contains all references from which sequence data were derived. Representatives of Diatrypaceae (Diatrype disciformis), Lopadostomataceae (Creosphaeria sassafras), and the anthostomella-like Pyriformiascoma trilobatum were selected as outgroup. The type strain of 


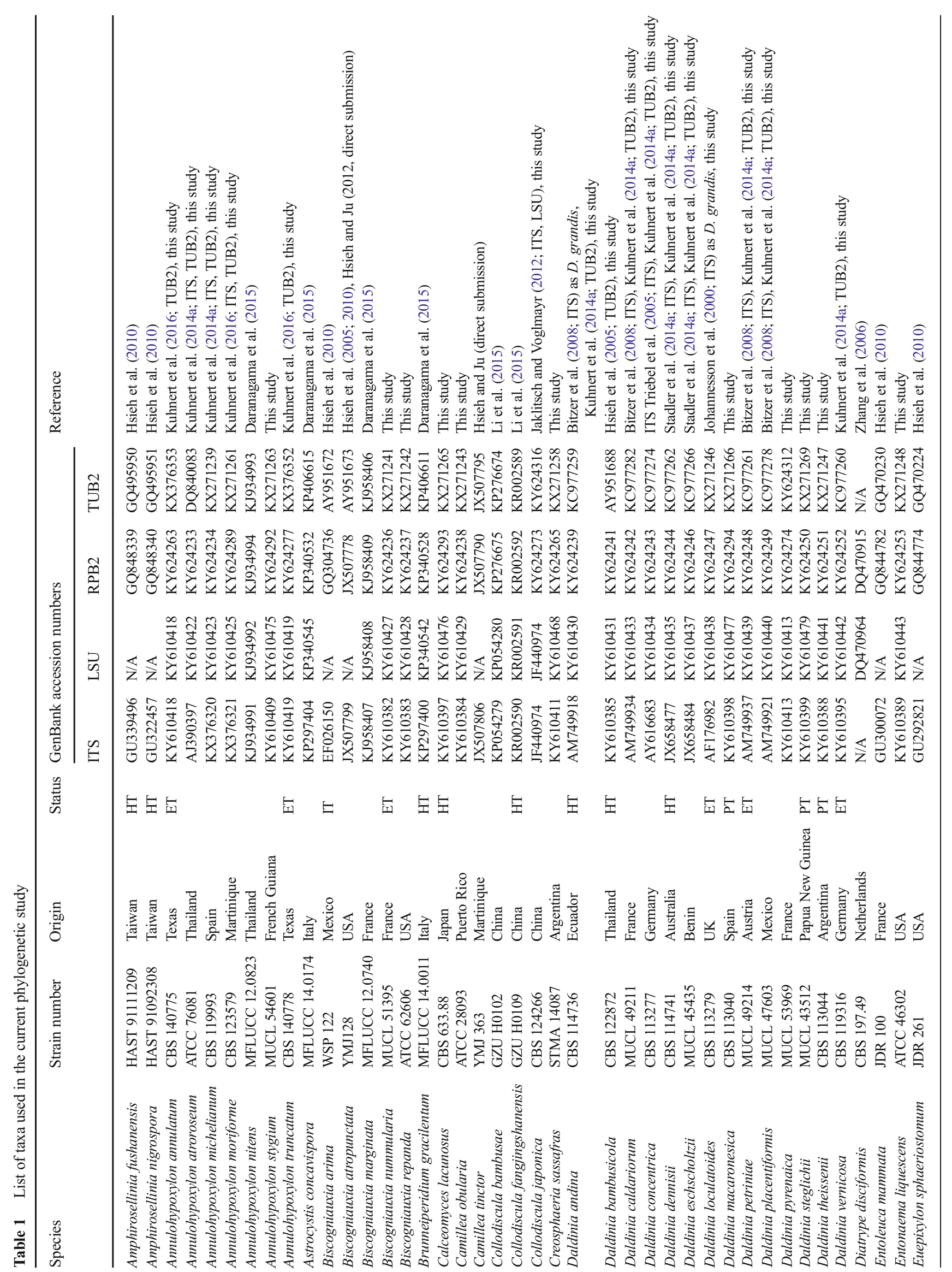



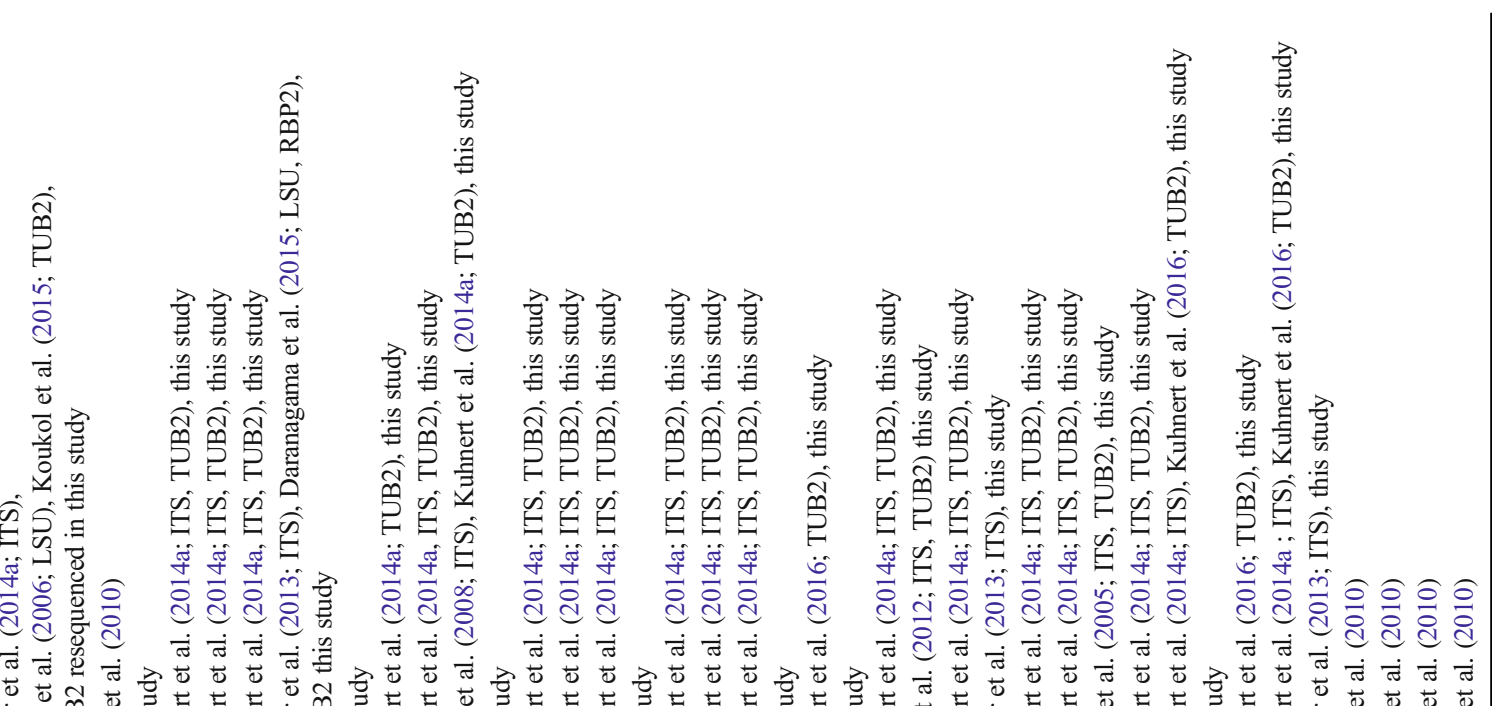

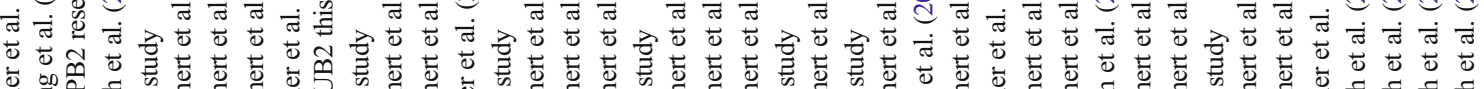

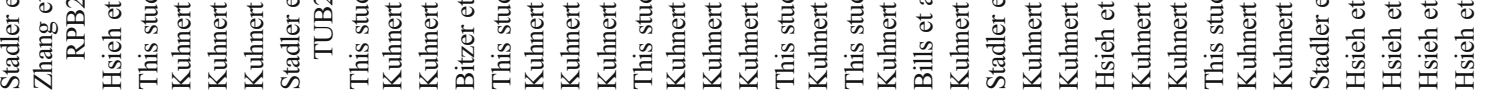

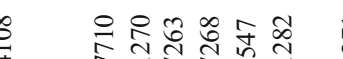

m-noommoonom

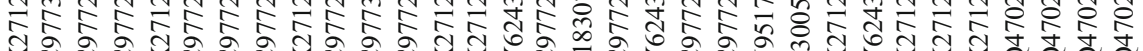

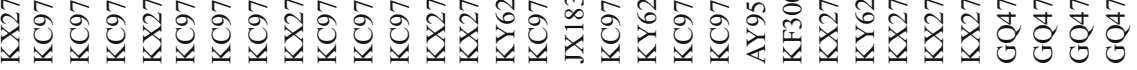

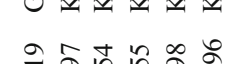

के 훙

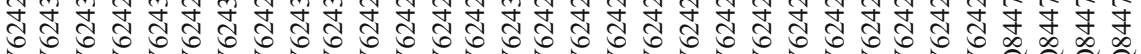

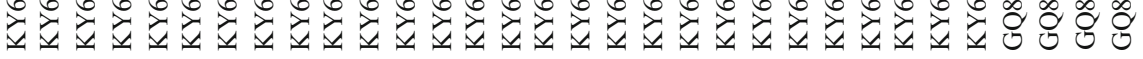

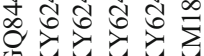

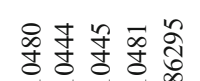

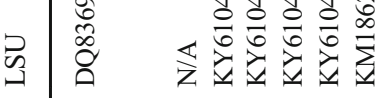

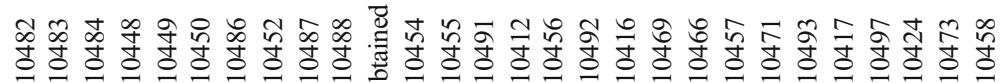

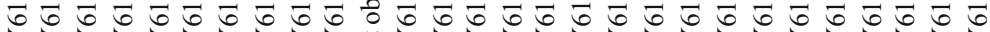

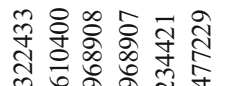

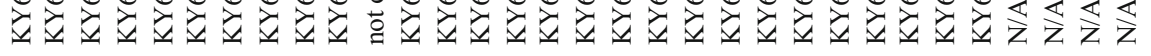

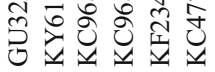

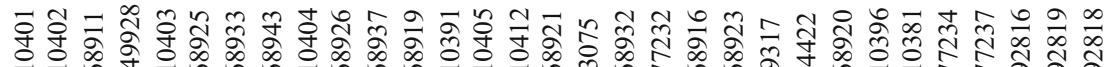

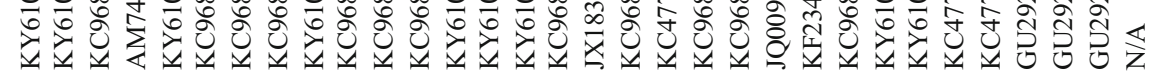

它

旨是芒

吉

占至包

是画画

画圼

兵

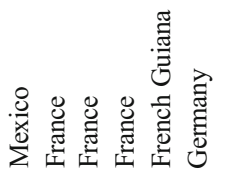

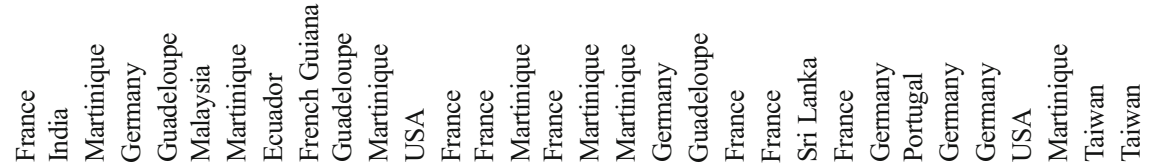

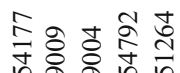

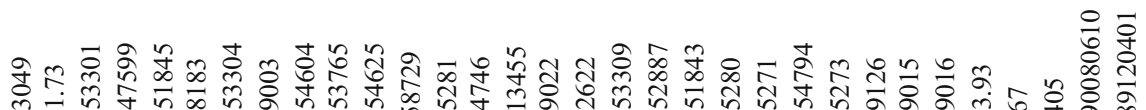

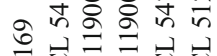

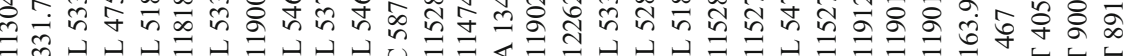

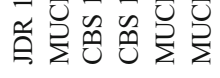

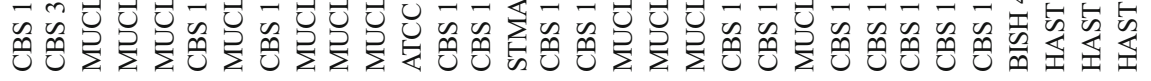

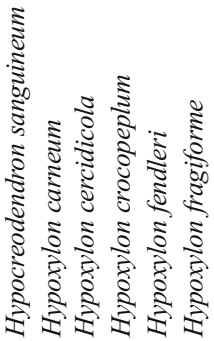

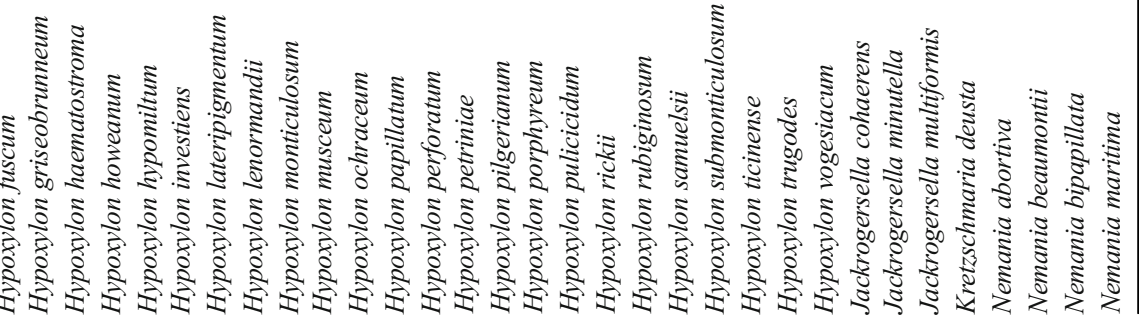




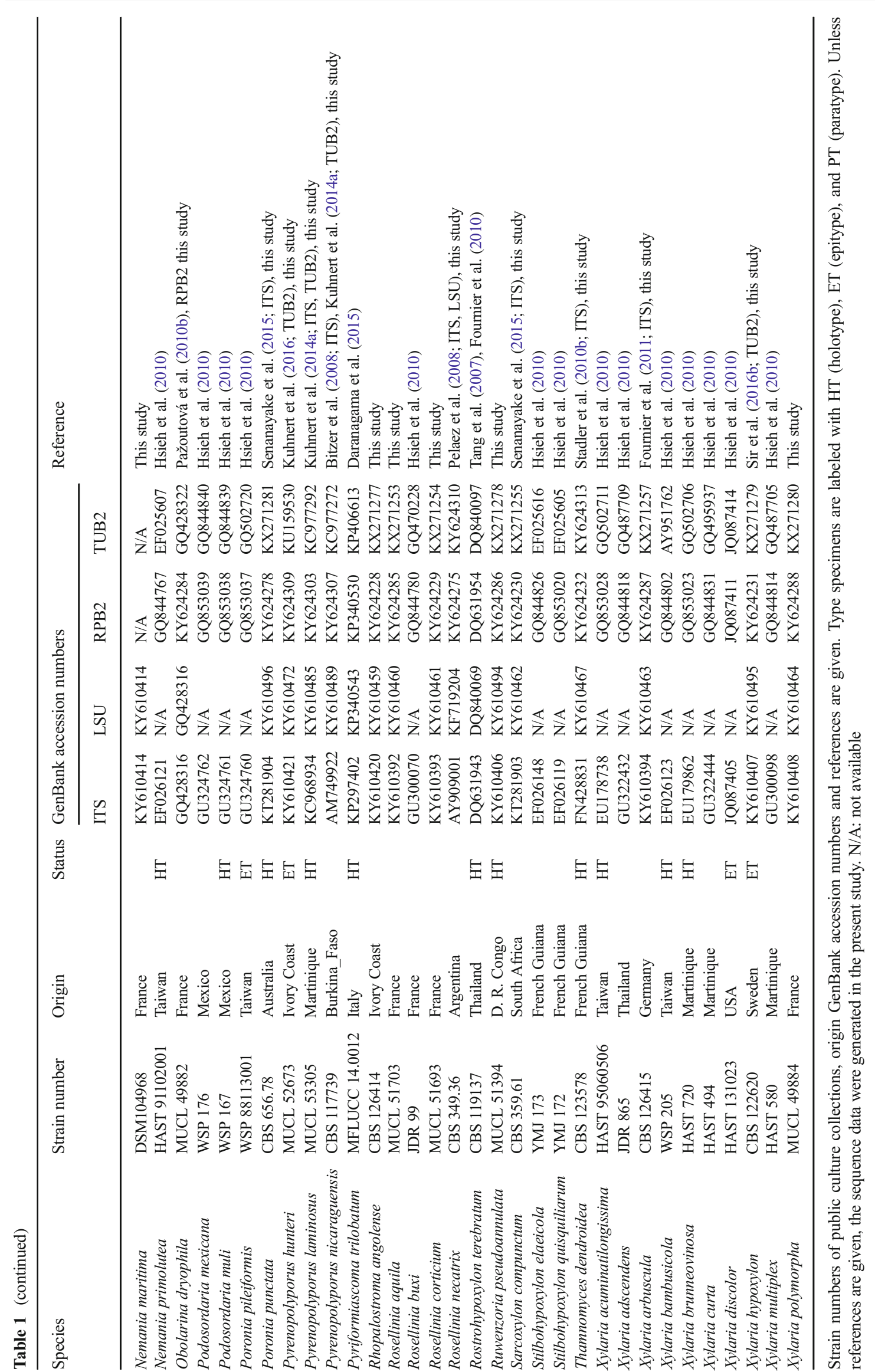


Calceomyces lacunosus was added, because it was reported to have a nodulisporium-like asexual morph and shoe-shaped ascospores and its phylogenetic affinities remained to be settled. The bulk of the taxa was selected from the large stromatic genera that comprise the Xylariaceae in the traditional sense, and for which numerous data derived from well-characterised specimens are available. The selection criteria included both morphological and chemotaxonomic characters. Type material or at least specimens representing the type species of the respective genera and some important other species were included whenever possible.

\section{Molecular phylogenetic analyses}

DNA was extracted from mycelial cultures using protocols and genomic DNA extraction kits described in Læssøe et al. (2010), Kuhnert et al. (2014a), and Otto et al. (2016). Partial sequences of four DNA loci were used as phylogenetic markers, namely a) internal transcribed spacer region (ITS); b) 28S large subunit (LSU) of ribosomal DNA; c) second largest subunit of the DNA-directed RNA polymerase II (RPB2); and d) beta-tubulin (TUB2) were generated using standard primers introduced by White et al. (1990; ITS4), Gardes and Bruns (1993; ITS1F), O’Donnell (1993; NL4), Vilgalys and Hester (1990; LR07 and LR0R), Liu et al. (1999; RPB2-5F, $-7 \mathrm{cF}$, and $-7 \mathrm{cR}$ ), and O'Donnell and Cigelnik (1997; T1, T2, T11, T21, T22, T121, T222, and T224), Glass and Donaldson (1995; Bt2b), and protocols as described by Læssøe et al. (2010) and Otto et al. (2016). PCR products were also purified and sequenced as described in Læssøe et al. (2010) and Otto et al. (2016).

Sequences were analyzed and processed in Geneious $\circledR$ 7.1 .9 (http://www.geneious.com, Kearse et al. 2012). Raw sequence files were trimmed automatically to exclude flanking regions and bases with error probabilities above $1 \%$ and double-stranded sequences were compiled. The generated sequence data were complemented by available sequence data from GenBank and the data sets for each genetic marker were aligned using MAFFT 7.017 with GINS-I as algorithm and default settings for gap open and gap extension penalties (Katoh and Kuma 2002). The constructed alignments were processed via the Castresana Lab Gblocks Server at low stringency settings (allowing smaller final blocks and gap positions within the final blocks; see Talavera and Castresana 2007; Castresana 2000) and the multigene alignment (MGA) was created by concatenation of all genetic markers in Geneious. The best fitting substitution model for each single gene alignment and the MGA was determined using jModeltest 2.1.7 (Darriba et al. 2012; Guindon and
Gascuel 2003). Phylogenetic relationships were inferred using neighbor-Joining with Tamura-Nei as distance model (NJ, Saitou and Nei 1987) in Geneious Tree Builder, Maximum Parsimony (MP), and tree bisection and reconnection (TBR) as branch swapping algorithm in PAUP 4. 0a151 (Swofford 2002), maximum likelihood (ML) with GTR + G + I as substitution model in RAxML 7.2.8 (Stamatakis 2006, 2014; Stamatakis and Alachiotis 2010). Bootstrap support (BS) values in NJ, MP, and ML analysis were calculated from 500 replicates. Prior to MP analysis, the consistency index (CI), retention index (RI), and homoplasy index (HI) were calculated.

In the Bayesian analysis, carried out in Mr. Bayes 3.2.6 (Huelsenbeck and Ronquist 2001), GTR+G was used as substitution model and four MCMC chains were sampled over 3,000,000 generations, sampling every 1000 generations and applying a burn-in of $10 \%$. All phylogenetic trees were rooted with Calceomyces lacunosus, Creosphaeria sassafras (Lopadostomataceae), Diatrype disciformis (Diatrypaceae), and Pyriformiascoma trilobatum.

\section{Results}

\section{Molecular phylogeny}

One-hundred and twelve fungal strains of 34 different genera were used in the analysis, of which 77 contained at least one sequence of the considered DNA loci. The five most species-rich genera were Hypoxylon with 29, Daldinia with 14, Xylaria with 10, Annulohypoxylon with seven, and Nemania with six included species. In total, 224 sequences were generated (36 ITS, 71 LSU, 75 RPB2, and 42 TUB2 sequences) and complemented with 206 sequences from GenBank. We used four different molecular markers and applied four tree reconstruction methods, which enabled us to make robust assumptions about the phylogenetic relationships of the studied taxa, but also led to substantial output data. Additional data files, e.g. the unprocessed MAFFT alignments, excluded data blocks, estimated model parameters or additional tree files have been provided in the Supplementary Information.

The calculated MAFFT alignments consisted of 1623 character positions in the ITS alignment, 2456 in the LSU alignment, 2335 in the TUB2 alignment, and 1325 in the RPB2 alignment. After curing - which is required to exclude poorly aligned areas and positions of low informative characters within the alignments the constructed multigene alignment (MGA) consisted of 2911 characters (314 of which were derived from the ITS alignment, 794 from LSU, 821 from RPB2, 
and 982 from TUB2). Of the MGA, 1082 characters were considered parsimony-informative.

The results of all phylogenetic tree constructions were superimposed on the Bayesian tree and support values that pose statistical support $[\geq 0.95$ for posterior probability (PP) and $\geq 50 \%$ bootstrap support (BS)] were indicated above the respective branches. However, significant support was assumed for BS values $\geq 70 \%$ and/ or PP values of $\geq 0.98$.

Representatives of the type species of the Diatrypaceae (Diatrype disciformis) and the most commonly reported species of the Lopadostomataceae (Creosphaeria sassafras), were initially designated as outgroup, because they are supposed to be close relatives of Xylariaceae in the classical sense. However, our analyses revealed that two further "xylariaceous" representatives, namely Calceomyces lacunosus and Pyriformiascoma trilobatum also clustered with this outgroup. Separation of the extended outgroup clade to the remaining taxa was fully supported in all phylogenetic trees.

Three major clades were observed: the first of those, clade (I) comprised Xylaria and all other genera studied with geniculosporium-like anamorphs (Fig. 1). Accordingly, clade I is from here on regarded to represent the Xylariaceae s. str. In the second major clade (II), Graphostroma platystomum clustered with Biscogniauxia, Camillea, and Obolarina as sister group to clade I, while Hypoxylon and all other genera with nodulisporium-like anamorphs appeared in a welldefined separate clade (III). This finding led us to abandon the conventional terminology concerning the classification of Xylariaceae. We will from here on use the newly introduced taxonomic terms that are explained in the taxonomic part further below.

Within clade I (Fig. 1), monophyletic clades of the coprophilous genera Podosordaria (PS) and Poronia (P) clustered with Sarcoxylon compunctum as sister to the remaining Xylariaceae s. str. clades. These included two Xylaria clades (X1 and X2), with X2 comprising Kretzschmaria deusta and Brunneiperidium gracilentum along with several other Xylaria spp., including the type species of the genus, Xylaria hypoxylon. A third clade (X3) was not supported and contained Xylaria polymorpha and further representatives of Xylaria and of the genera Amphirosellinia, Astrocystis, Collodiscula, and Stilbohypoxlon. The last clade of Xylariaceae s. str. split into clade $\mathbf{N}$ that comprised representatives of the genus Nemania and Euepixylon, and clade $\mathbf{R}$ with species of the genus Rosellinia and Entoleuca mammata. The latter clustered with non-pathogenic Rosellinia species that appeared in a sister clade to the two included plant-pathogens $R$. buxi and $R$. necatrix.
Within clade G, Graphostroma platystomum clustered in a well-supported subclade G1 with several species of Biscogniauxia. The second subclade $\mathbf{G 2}$ contained different species of Biscogniauxia (including the type species, B. nummularia), Camillea and Obolarina species.

Most representatives chosen for the current study were selected from the taxa with nodulisporium-like anamorphs and accordingly, clustered in Clade III. The topology of these clades was not consistently supported, but the backbone topology was characterised by distinct and strongly supported clades (Fig. 2). The genus Hypoxylon was divided into several subclades, sometimes only represented by one or two species, indicating that the taxon sampling may still be too low. Hypoxylon papillatum was the basalmost taxon of Clade III, followed by five well-supported clades comprising species of the genus Hypoxylon (H1-H5). H5 was a sister to a clade of the genera Jackrogersella (J) and Annulohypoxylon (A). And a sixth Hypoxylon clade (H6) formed the most derived monophyletic group of Hypoxylon as sister taxon to a clade comprising Pyrenopolyporus (Py) and Daldinia (D1-D2).

The separation of $H$. papillatum and the nodes of the basal sister clades $\mathbf{H} 1 \& \mathbf{H} 2$ were fully supported by the calculated support values of all phylogenetic tree algorithms. The clade H1 contained the frequent species H. fuscum, along with $H$. porphyreum and $H$. vogesiacum and was strongly supported, whereas clade $\mathbf{H} \mathbf{2}$ consisted of two well-supported subclades and an unsupported subclade. Hypoxylon hypomiltum and $H$. samuelsii formed one of the supported subclades and the second supported subclade consisted of $H$. rubiginosum - a common species of the Northern temperate hemisphere - and several other taxa that had previously been synonymised with this species, including $H$. cercidicola and $H$. petriniae. The unsupported $\mathbf{H 2}$ subclade comprised $H$. carneum, $H$. ochraceum, $H$. perforatum, $H$. musceum, and $H$. pilgerianum. The $\mathbf{H 3}$ clade was fully supported by NJ, Bayesian and RAxML analysis, but the node of $H$. crocopeplum and $H$. fendleri was not significantly supported, as only the NJ-BS value of $79 \%$ and a posterior probability value of 0.98 met the demanded threshold for statistical support. Nonetheless, the shown topology was predominantly observed in the phylogenetic analyses.

H4 comprised the generic type species, H. fragiforme, along with $H$. haematostroma, $H$. rickii, $H$. howeanum, and $H$. ticinense, and although the positions of H. haematostroma and $H$. rickii were not supported statistically, the clade was fully supported by NJ, MP, ML, and Bayesian analysis. The remaining clades split into two sister clades; one of those consisted of a multifurcated and poorly supported clade of $H$. griseobrunneum, $H$ trugodes, and a subclade comprising the genera Hypoxylon (H5), Jackrogersella (J), and Annulohypoxylon (A); the other clade comprised a fully supported clade of the "basal" Hypoxylon species 


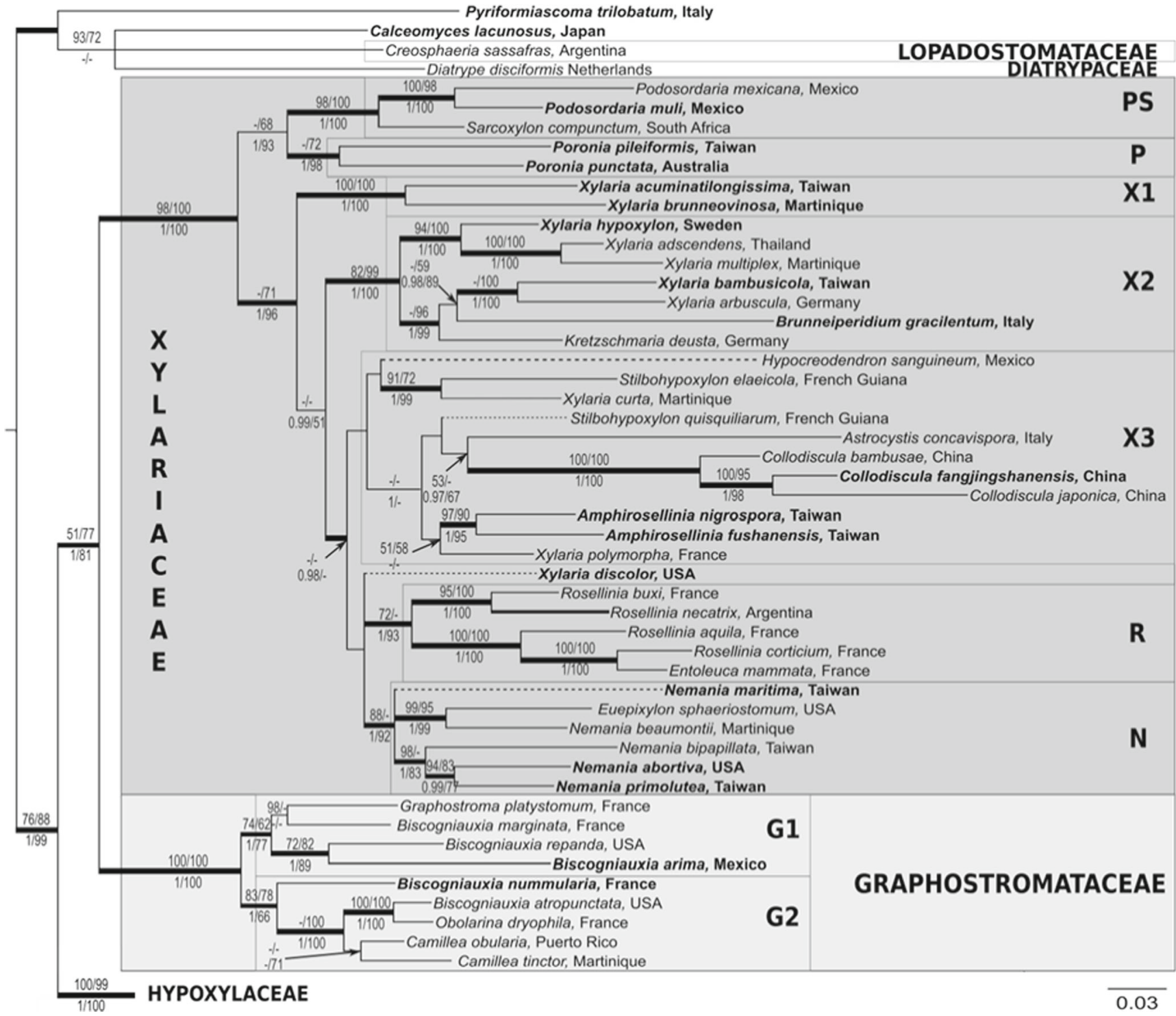

Fig. 1 Phylogeny of the Graphostromataceae and Xylariaceae sensu stricto. The phylogenetic relationships are depicted as Bayesian tree, inferred from a multigene alignment of ribosomal (ITS and LSU) and proteinogenic (TUB2 and RPB2) sequence information. In the Maximum Parsimony analysis a CI of 0.161 , a RI of 0.524 , and a HI of 0.839 was estimated, and yielded five most parsimonious trees with a length of 15,094 changes. The phylogenetic tree inferred by RAxML had a likelihood of $-65,444.25$ and the likelihood of the Bayesian tree

H. monticulosum and H. submonticulosum (H6), a monophyletic clade comprising species of the resurrected (see taxonomic part) genus Pyrenopolyporus (Py) and a clade comprising daldinoid species and closely related genera (D1-D2).

Clade $\mathbf{H 5}$ consisted of the species $H$. lateripigmentum, $H$. investiens, and H. pulicicidum and was mostly well supported and was shown as a sister taxon to a clade comprising the genera Jackrogersella, Rostrohypoxylon and Annulohypoxylon. Although this topology was only supported by Bayesian and ML analysis, the subdivision was $-65,951.87$. Support values were calculated via neighbor-joining (NJ), maximum parsimony (MP), Bayesian (B), and maximum likelihood (MA) analysis and are indicated above (NJ/MP) and below (B/ML) the respective branches, if the bootstrap support (BS) values exceeded $50 \%$ or the posterior probability (PP) value was 0.95 or higher. Branches of significant support ( $\mathrm{BS} \geq 70 \%$ and $\mathrm{PP} \geq 0.98$ ) are thickened; accessions representing type material are highlighted in bold letters

of the latter genera into two clades $(\mathbf{J} \& \mathbf{A})$ - with Rostrohypoxylon terebratum in an intermediate position - was strongly supported.

The fully supported genus Pyrenopolyporus (Py) was represented by the species P. laminosus, P. hunteri, and $P$. nicaraguensis. The sister taxon to clade Py split into three, mostly strong supported clades: clade D1 comprised the sister clades of $D$. andina, D. concentrica, D. dennisii, $D$. loculatoides, D. macaronesica, D. petriniae, D. pyrenaica, $D$. steglichii, and D. vernicosa (which are either temperate/ 


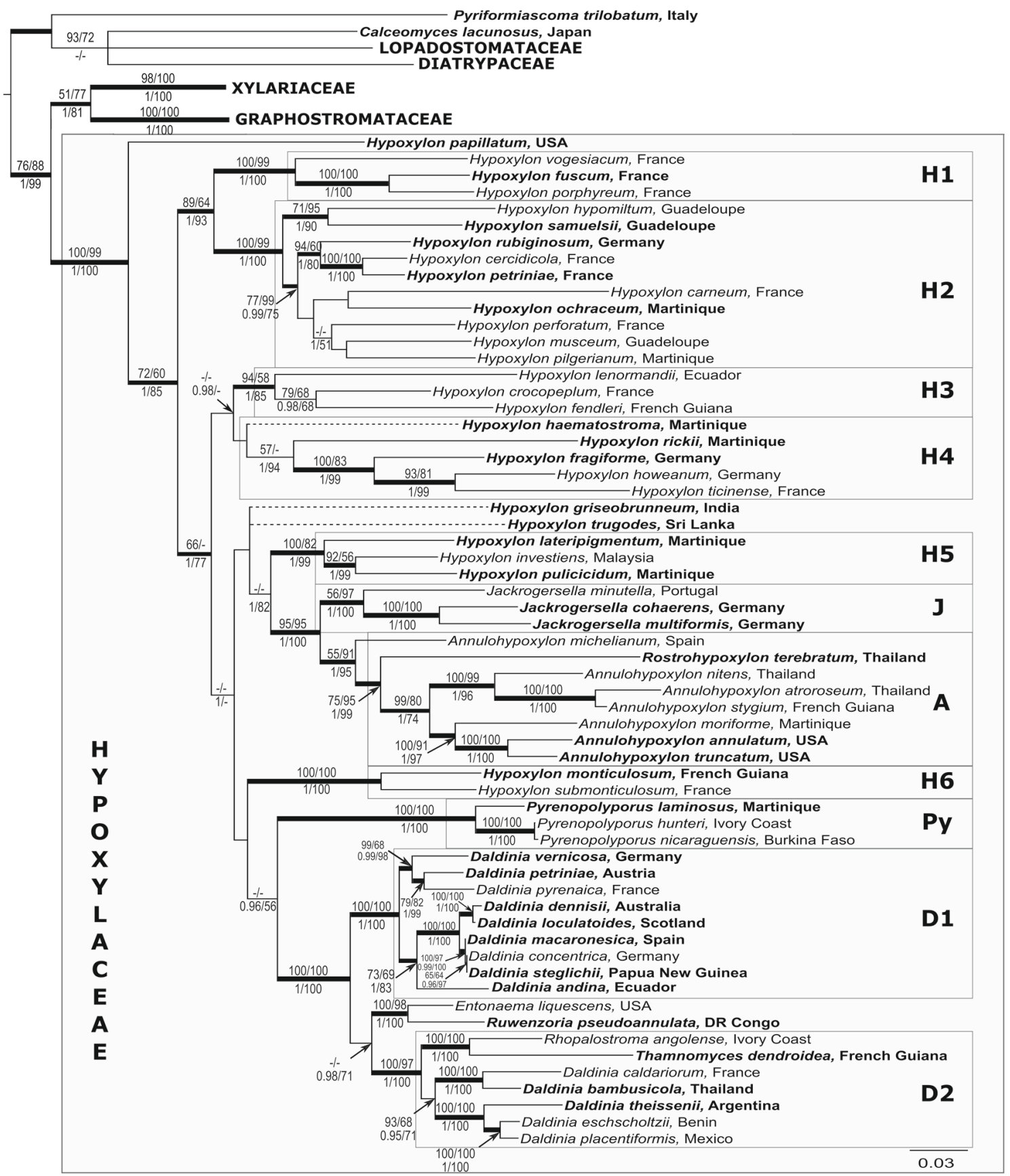

Fig. 2 Phylogeny of the Hypoxylaceae. For details, see legend of Fig. 1

subtropical taxa or like $D$. andina, have been found in the tropics, but at very high altitudes). The second Daldinia clade D2 embodied two fully supported subclades of Rhopalostroma angolense and Thamnomyces dendroidea on one branch, and the predominantly tropical D. bambusicola, Daldinia caldariorum, D. eschscholtzii, D. theissenii, and $D$. placentiformis on the other. The third clade of Entonaema liquescens and Ruwenzoria pseudoannulata showed full statistical support, but the relative position of this clade to the Daldinia clades D1 and D2 was not supported sufficiently.
These data led us to propose significant changes in the taxonomy of the Xylariales. Below we propose a new scheme that takes the current molecular phylogenetic data into account and is congruent with the morphological concepts at the same time. As will become evident in the following taxonomic part, the reorganisation of the taxonomy was often found to be congruent with the morphology of the conidial states, which are compiled based on representative taxa in Figs. 3 and 4. 


\section{Taxonomic part}

1. Hypoxylaceae DC. in Lamarck \& de Candolle, Fl. franç., Edn 3 (Paris) 2: 280 (1805), emend. M. Stadler \& L. Wendt.

Type genus: Hypoxylon Bull., Histoire des champignons de la France. I: 168 (1791).

= Sphaeria Haller, Historia stirpium indigenarum Helvetiae inchoata: 120 (1768).

= Spermodermia Tode, Fungi Mecklenburgenses Selecti 1: 1 (1790).

= Perisphaeria Roussel (1806).

= Discosphaera Dumort., Commentationes botanicae: 91 (1822).

= Institale Fr., Systema Mycologicum 3: 210 (1829).

= Spermatodermia Wallr., Flora Cryptogamica Germaniae 2: 262 (1833).

= Nodulisporium Preuss, Klotzschii Herbarium Vivum Mycologicum, Editio novo. Century: no. 1272 (1849).

= Pyrenodermium Bonord., Handbuch der allgemeinen Mykologie: 272 (1851).

= Epixylon Füisting, Bot. Ztg.: 309 (1867).

= Euhypoxylon Füisting, Bot. Ztg.: 309 (1867).

= Hypoxylina Starbäck, Arkiv før Botanik 5 (7): 29 (1905).

= Acrostaphylus G. Arnaud ex Subram., Journal of the Indian Botanical Society 35 (4): 482 (1956).

Type species: Hypoxylon fragiforme (Pers.): J. Kickx fil.

Typus: Locality unknown, corticated wood of Fagus, Moug. in Herb. Pers., (L 910, 267-646, Lectotype of Sphaeria fragiformis, selected by Petrini and Müller (1986)).

Epitype of Sphaeria fragiformis Pers., Ann. Bot. (Usteri) 11: 21 (1794), designated here:

Germany, Rhenania-Palatanate, Südpfalz, near Edenkoben, Hilschweiher, Fagus sylvatica, 22 Apr 2007, leg. M. \& Benno Stadler (STMA 07015, KR-M-0048413, MBT 374788), ex-epitype culture MUCL 51264.

Epitypes of two further important species in Hypoxylon are here designated, based on the specimens that were used in the current phylogeny, in order to stabilise the taxonomy of the genus. Especially, H. rubiginosum has been misinterpreted very often in the course of the taxonomic history and was often regarded as a cosmopolitan species, while there is no record of this taxon for the tropics to the best of our knowledge. The specimen selected as epitype showed the same morphology as the type material, and it was even possible to detect their characteristic stromatal metabolites by comparison of the HPLC profiles of the type specimen. These data, as well as other results on the synonymy and geographic distribution of both taxa in the temperate Northern hemisphere, were compiled by Stadler et al. (2008b).
Hypoxylon fuscum (Pers.) Fr., Summa veg. Scand., Sectio Post. (Stockholm): 384 (1849).

Basionym: Sphaeria fusca Pers., Ann. Bot. (Usteri) 11: 22 (1794).

Typus: Locality unknown, corticated rotten wood (L 910, 267-664, holotype of Sphaeria fusca).

Epitype of Sphaeria fusca Pers., Ann. Bot. (Usteri) 11: 22 (1794), designated here:

Germany, North Rhine Westphalia, Haan-Gruiten, Neandertal, Corylus avellana, 21 Apr 2003, leg. H. Wollweber (Ww 3723, M-0065028), ex-epitype culture CBS 113049 (cf. Triebel et al. 2005).

Hypoxylon rubiginosum (Pers.) Fr., Summa veg. Scand., Sectio Post. (Stockholm): 384 (1849).

Basionym: Sphaeria rubiginosa Pers., Syn. meth. fung. (Göttingen) 1: 11 (1801).

Typus: Locality unknown, corticated wood (L 910, 2631194, Lectotype (selected by Miller 1961) of Sphaeria rubiginosa.

Epitype of Sphaeria rubiginosa Pers., Syn. meth. fung. (Göttingen) 1: 11 (1801), designated here: Germany, Rhenania-Palatinate, vicinity of Wachenheim an der Weinstrasse, Poppental, on wood of Fagus sylvatica, 25 Mar 2008, leg. Benno Stadler (STMA 08027, KR-M-0048411, MBT 374767), ex-epitype culture MUCL 52887.

\section{General description of the Hypoxylaceae}

Saprobic on plant material, but many species are endophytes and some species are associated with insect vectors (Pažoutová et al. 2010a, b, 2013). Stromata (if present) erect, glomerate, pulvinate, discoid, effused-pulvinate, hemispherical, spherical or peltate; solitary or confluent, with broad or narrow attachment to the substrate; surface colored or black, pruinose or polished, planar or with perithecial mounds; waxy or carbonaceous tissue immediately beneath surface and between perithecia, with or without $\mathrm{KOH}$-extractable pigments; the tissue below the perithecial layer inconspicuous, conspicuous, or massive, most often dark brown to black, persistent or loculate; interior sometimes conspicuously zonate (Daldinia) or hollow and filled with liquid (Entonaema).

Ascomata (perithecia) embedded in the stroma, spherical, obovoid, tubular, or long tubular, monostichous, with or without carbonaceous stromatal material surrounding individual perithecia.

Ostioles lower than the level of stromatal surface (umbilicate), at the same level of stromatal surface, or higher than the level (papillate) of stromatal surface, with or without discs formed by dehiscence of surrounding tissue.

Asci typically eight-spored, cylindrical, stipitate, persistent; with apical ring discoid, amyloid or infrequently inamyloid, distinct, highly reduced, or apparently lacking. 


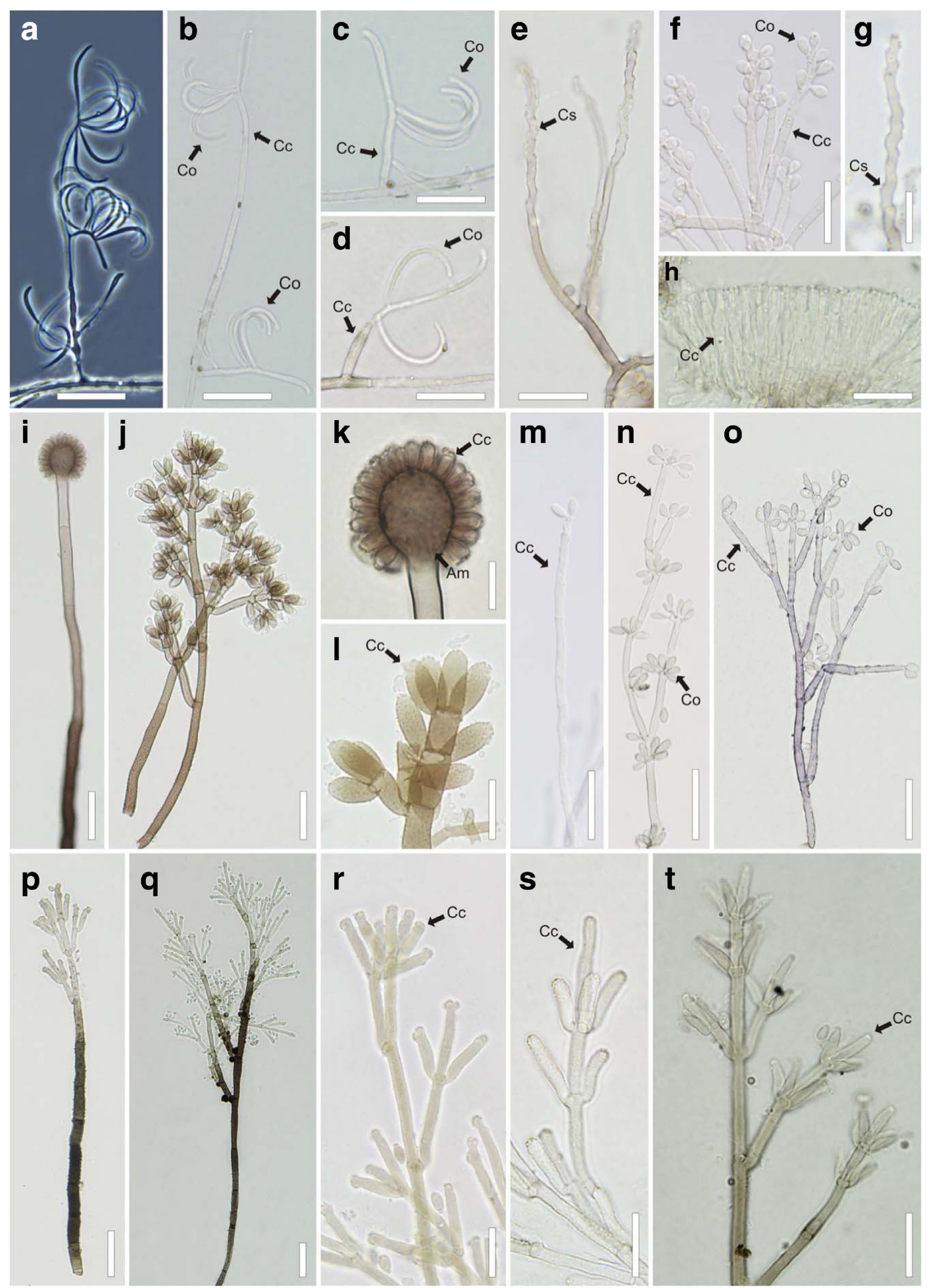


Fig. 3 General morphology of conidial states of Xylariales families treated in this study: a-d: libertella-like anamorph, characteristic of Diatrypaceae and Lopadostomataceae a: conidiophore view with polarised light $\mathbf{b}, \mathbf{c}, \mathbf{d}$ : conidiogenous cells and conidia (from Creosphaeria sassafras, Sir \& Hladki 442). e, f, g, h: geniculosporiumlike anamorph (characteristic of Xylariaceae s. str. and synanamorph of some Lopadostomataceae) e: conidiophore f: geniculate conidiogenous cells and conidia (from Nemania plumbea, EKKRF 1401) g: conidiogenous cell becoming geniculate after producing multiple conidia (from Rosellinia sp., Sir \& Hladki 282) h: palisadic geniculosporium-like anamorph (from Stilbohypoxylon macrosporum, Sir \& Hladki 972; i, k: xylocladium-like anamorph, characteristic of Graphostromataceae. i: conidiophore k: detail of ampullae with conidiogenous cells (from Camillea sp., Sir \& Hladki 856) j, l: nodulisporium-like anamorph with periconiella-like branching patterns, characteristic of Graphostromataceae and some Hypoxylaceae $\mathbf{j}$ : conidiophore l: conidiogenous cells (from Biscogniauxia sp.; Sir \& Hladki 187). m, n, $\mathbf{0}, \mathbf{p}, \mathbf{q}, \mathbf{r}, \mathbf{s}, \mathbf{t}$ : "regular" nodulisporium anamorph with different branching patterns as defined by Ju and Rogers (1996), characteristic of the Hypoxylaceae m: conidiophore single, sporothrix-like (from Hypoxylon lilloi, Sir \& Hladki 739) n, o: conidiophores with virgariella-like branching patterns (n: from Annulohypoxylon sp. STMA 15026; o: from Hypoxylon sp. Sir \& Hladki 002) p: conidiophores with nodulisporium-like branching patterns (from A. subeffusum, Sir \& Hladki 805) q: conidiophore with periconiella-like branching patterns (from H. investiens, Sir \& Hladki 014) r: nodulisporium-like branching patters (from Annulohypoxylon sp. Sir \& Hladki 021a) s, t: periconiella-like branching patterns (s: from H. haematostroma Sir \& Hladki 434; t: from A. yungensis, Sir \& Hladki 291). (Am: ampullae. Cc: conidiogenous cells. Co: conidia. Cs: conidial scar). Scale is indicated by bars $(\mathbf{a}, \mathbf{b}, \mathbf{c}, \mathbf{d}, \mathbf{g}, \mathbf{h}$, $\mathbf{k}, \mathbf{l}, \mathbf{r}, \mathbf{s}, \mathbf{t}: 10 \mu \mathrm{m} ; \mathbf{i}, \mathbf{j}, \mathbf{m}, \mathbf{n}, \mathbf{o}, \mathbf{p}, \mathbf{q}: 20 \mu \mathrm{m})$

Ascospores brown, unicellular in both mature and immature ascospores, ellipsoid or shorty fusoid, inequilateral, slightly inequilateral or nearly equilateral, with acute, narrowly rounded, or broadly rounded ends, in most species bearing a germ slit; perispore dehiscent or indehiscent in $10 \% \mathrm{KOH}$.

Conidiophores mononematous or infrequently synnematous, usually macronematous, hyaline or colored, smooth or roughened, simple or with a dominant main axis that is unbranched or bears one or more major branches.

Conidiogenous cells cylindrical, usually hyaline, one to several on each terminus of conidiophore, with conidiogenous regions at apex that are swollen to various degrees due to successive conidial production. Conidiogenous regions with poroid or, infrequently, denticulate conidial secession scars. Conidia produced sympodially in more or less basipetal succession, subglobose to ellipsoid, usually hyaline, with flattened base indicating former point of attachment to conidiogenous cells.

Notes: This ancient family name was coined originally by de Candolle (cf. de Lamarck and de Candolle 1805) in the sense of an order ("ordo") with the type genus Hypoxylon Bull. and its type species Hypoxylon coccineum (三 Hypoxylon fragiforme) and was only occasionally used by other taxonomists. Under the previous taxonomic concepts, the Hypoxylaceae was, however, never generally accepted among mycologists as a separate family besides the morphologically similar Xylariaceae, but generally regarded as a synonym of the latter family.

Our above definition takes into account the few salient features by which the Hypoxylaceae differ from the Xylariaceae s. str., and the circumscription also includes the "special" features of the genera that are aberrant with respect to their ascal and stromatal morphology. Notably, hollow stromata filled with liquid also occur at least in one member of the Xylariaceae s. str., namely Xylaria mesenterica (Möller) M. Stadler, Læssøe \& J. Fourn. 2008, originally reported by Möller (1901) as an Entonaema (cf. Stadler et al. 2008a). However, all genera formerly assigned to the Xylariaceae with cleistocarpous asci like Phylacia, Rhopalostroma and Thamnomyces belong to the Hypoxylaceae in the current sense. Chlorostroma is accommodated in the Hypoxylaceae due to its similarity to Hypoxylon aeruginosum and the highly similar secondary metabolite profiles (Læssøe et al. 2010).

The assignment of several genera formerly included in the broad concept of the Xylariaceae s. lat. to either of the families follows morphological descriptions, since no molecular phylogenetic data have so far been generated for their type species, and no living ex-type cultures seem to be available. The genera Jumillera and Whalleya (Rogers et al. 1997) are accommodated in the Lopadostomataceae at interim, based on the morphology of their conidial states (which is also supported for Whalleya, based on the comparison of molecular data from the literature). For some other genera of non-stromatic and anamorphic Xylariales, the assignment of the family was made based on DNA-based data, where those have been available. Several genera that are only known from morphological descriptions of the conidial states were accordingly placed in Xylariales incertae sedis. Substantial field work, in particular in tropical countries, remains to be accomplished to settle their phylogenetic affinities. The morphological concept that coincides with the organisation of families in the studied fungi is summarised in Table 2.

\section{Other accepted genera of the Hypoxylaceae}

Annulohypoxylon Y.M. Ju, J.D. Rogers \& H.M. Hsieh, in Hsieh et al., Mycologia 97(4): 855 (2005), emend. M. Stadler, Kuhnert \& L. Wendt.

Type species: Annulohypoxylon truncatum (Schwein.) Y.M. Ju, J.D. Rogers \& H.M. Hsieh 2005. Fig. 5.

See detailed chapter below.

Anthocanalis Daranag., Camporesi \& K.D. Hyde, in Daranagama, Camporesi, Tian, Liu, Chamyuang, Stadler \& Hyde, Fungal Diversity: 10.1007/s13225-015-0329-6, [9] (2015). 
Fig. 4 Illustrations of the different conidiogenous structures treated in this work: a: libertellalike b, c: geniculosporium-like d: xylocladium-like e, f, $\mathbf{g}, \mathbf{h}, \mathbf{i}$ : nodulisporium-like with different branching patterns as defined $\mathrm{Ju}$ and Rogers (1996) e: sporothrixlike to virgariella-like f: virgariella-like g: nodulisporiumlike h: periconiella-like (rather than nodulisporium-like) i: periconiella-like (Cc: conidiogenous cell. Co: conidia). Scale is indicated by bars $(20 \mu \mathrm{m})$
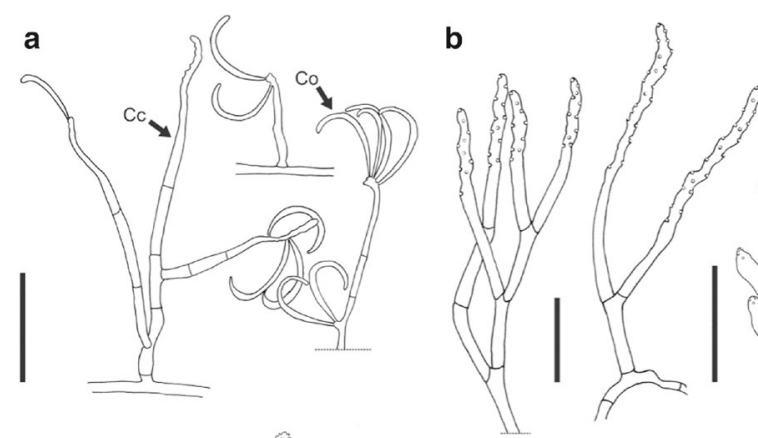

d
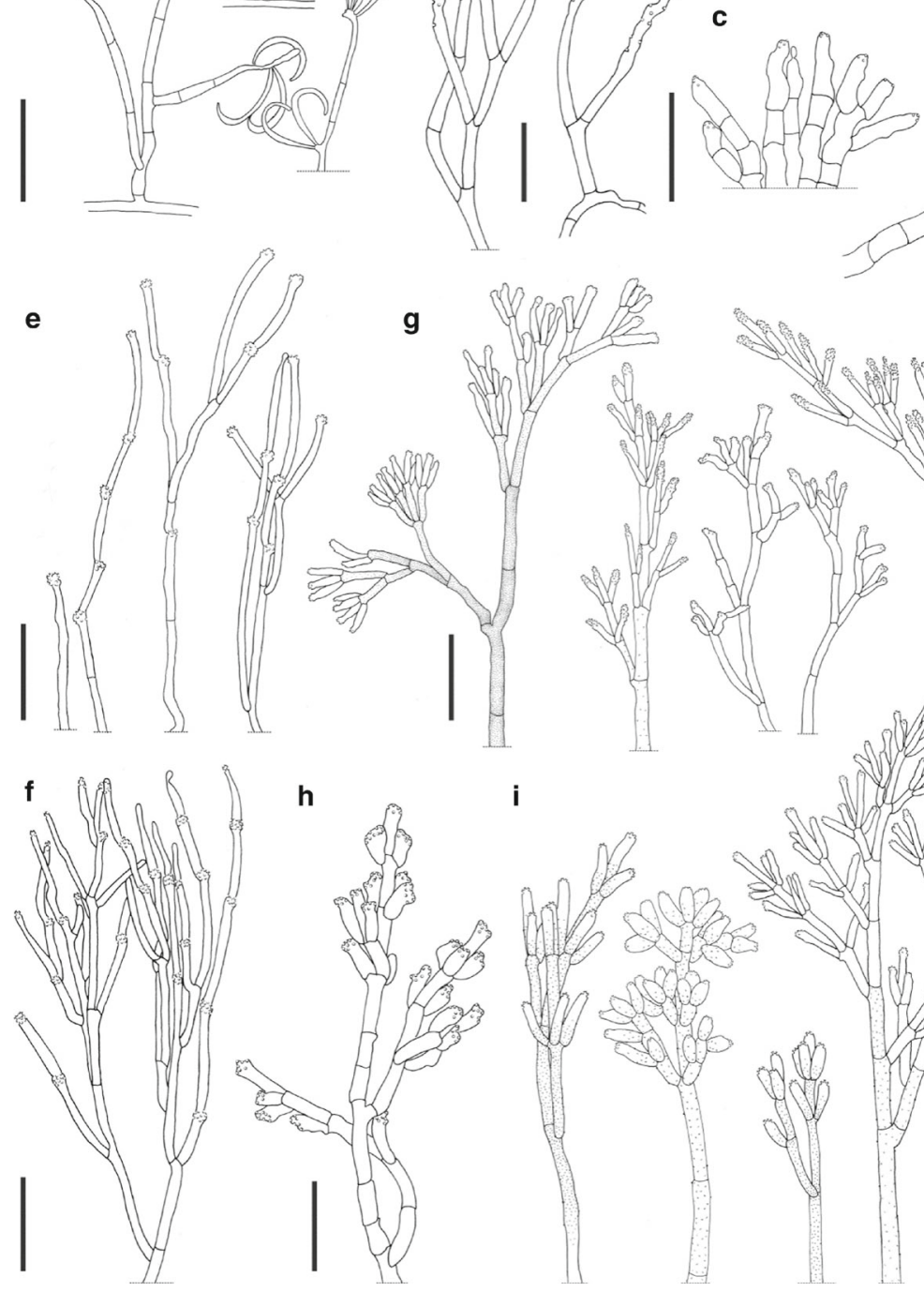

h

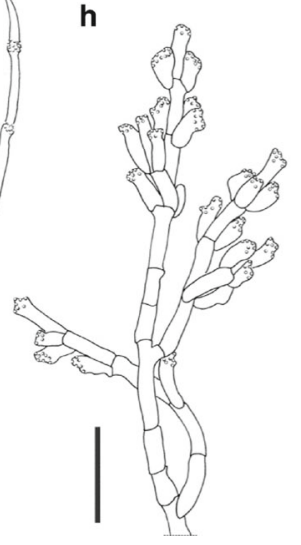

i

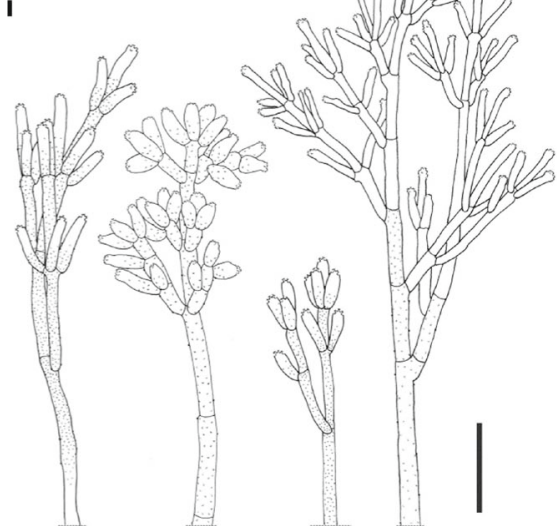

Type species: Anthocanalis sparti Daranag., Camporesi \& K.D. Hyde 2015.

Chlorostroma A.N. Mill., Lar.N. Vassiljeva \& J.D. Rogers, Sydowia 59(1): 142 (2007).

Type species: Chlorostroma subcubisporum A.N. Mill., Lar.N. Vassiljeva \& J.D. Rogers 2007.

Daldinia Ces. \& De Not., Comm. Soc. crittog. Ital. 1(fasc. 4): 197 (1863).

= Annellosporium M.L. Davey, Karstenia 50: 3 (2010).

$=$ Hemisphaeria Klotzsch, Nova Acta Phys.-Med. Acad. Caes. Leop.-Carol. Nat. Cur., Suppl. 1 19: 241 (1843).
$=$ Peripherostoma Gray, Nat. Arr. Brit. Pl. (London) 1:513 (1821).

= Stromatosphaeria Grev., Fl. Edin.: 1xxiii, 355 (1824).

= Versiomyces Whalley \& Watling, Notes R. bot. Gdn Edinb. 45(2): 401 (1989) [1988].

Type species: Daldinia concentrica Ces. \& De Not., Comm. Soc. crittog. Ital. 1(fasc. 4): 197 (1863).

Entonaema A. Möller, Botanische Mittheilungen aus den Tropen 9: 306 (Möller 1901) emend. Stadler et al. (2008a).

Type species: Entonaema liquescens A. Möller, Botanische Mittheilungen aus den Tropen 9: 307 (1901).

Phylacia Lév., Annls Sci. Nat., Bot., sér. 3 3: 61 (1845).

= Henningsina Möller, Bot. Mitt. Trop. 9: 309 (1901). 
Table 2 Salient features of the families of Xylariales treated in this study

\begin{tabular}{|c|c|c|c|}
\hline Family name & Ascospore shape & Asexual morph & Stromatal pigments \\
\hline Diatrypaceae & allantoid & libertella-like & absent \\
\hline Graphostromataceae & $\begin{array}{r}\text { allantoid or } \\
\text { ellipsoid }\end{array}$ & $\begin{array}{l}\text { nodulisporium-like } \\
\text { (mostly of the periconiella type) } \\
\text { or xylocladium-like }\end{array}$ & absent \\
\hline Hypoxylaceae & ellipsoid & nodulisporium-like & mostly present \\
\hline Lopadostomataceae & ellipsoid & $\begin{array}{l}\text { libertella-like or } \\
\text { geniculosporium-like }\end{array}$ & $\begin{array}{l}\text { present (sometimes weak) } \\
\text { or absent }\end{array}$ \\
\hline Xylariaceae s. str. & ellipsoid & geniculosporium-like & mostly absent \\
\hline
\end{tabular}

$=$ Leveillea Fr., Summa veg. Scand., Sectio Post. (Stockholm): 409 (1849).

Type species: Phylacia globosa Lév. 1845.

Pyrenomyxa Morgan, J. Cincinnati Soc. Nat. Hist. 18: 42 (1895) emend. Stadler et al. (2005).

= Pulveria Malloch \& Rogerson 1977.

Type species: Pyrenomyxa invocans Morgan 1895.

Pyrenopolyporus Lloyd, Mycological Writings 5 (50): 706 (1917) emend. M. Stadler \& L. Wendt (Fig. 6).

See separate chapter.

Rhopalostroma D. Hawksw., Kew Bull. 31(3): 422 (1977).

Type species: Rhopalostroma indicum D. Hawksw. \& Muthappa 1977.

Rostrohypoxylon J. Fourn. \& M. Stadler, in Fournier et al. (2010).

Type species: Rostrohypoxylon terebratum J. Fourn. \& M. Stadler 2010.

Ruwenzoria J. Fourn., M. Stadler, Læssøe \& Decock, in Stadler, Fournier, Læssøe, Decock, Peršoh \& Rambold, Mycol. Progr. 9(2): 171 (2010).

Type species: Ruwenzoria pseudoannulata J. Fourn., M. Stadler, Laessøe \& Decock 2010.

Thamnomyces Ehrenb., in Nees von Esenbeck, Horae Phys. Berol.: 79 (1820).

Type species: Thamnomyces chamissonis Ehrenb. 1820.

Thuemenella Penz. \& Sacc., Malpighia 11(11-12): 518 (1898) [1897].

= Chromocreopsis Seaver, Mycologia 2(2): 63 (1910).

Type species: Thuemenella cubispora (Ellis \& Holw.) Boedijn 1964.

Note: This genus is transferred to the Hypoxylaceae because the scarce molecular data available (Miller et al. 2007) point to its affinities with Hypoxlon and the conidial state is said to be nodulisporium-like. The ITS and TUB2 sequences we obtained of the strain studied by Miller et al. (2007) that is deposited with CBS 119807 are 100\% identical to those of Hypoxylon rubiginosum, which is why we have excluded it from our phylogeny and think we need to re-collect and sequence this taxon to get sure about its affinities.

2. Xylariaceae Tul. \& C. Tul. [as "Xylariei"] Select. fung. carpol. (Paris) 2: 3 (1863), emend. M. Stadler \& L. Wendt.

= Clypeosphaeriaceae G. Winter [as "Clypeosphaerieae"], Rabenh. Krypt.-Fl., Edn 2 (Leipzig) 1.2: 554 (1886), fide Jaklitch et al. (2016).

Type genus: Xylaria Hill ex Schrank, Baier. Fl. (München) 1: 200 (1789).

= Acrosphaeria Corda Anleit. Stud. Mykol., Prag: 136 (1842).

= Carnostroma Lloyd, Mycol. Writ. 5 (Syn. Large Pyrenomyc.): 27 (1919).

= Coelorhopalon Overeem, in Overeem \& Weese, Icon. Fung. Malay. 11: 3 (1925).

= Hypoxylon Adans., Fam. Pl. 2: 9, 616 (1763).

= Lichenagaricus P. Micheli, Nov. pl. gen. (Florentiae): 103, tab. 54-55 (1729).

= Moelleroclavus Henn., Hedwigia 41: 15 (1902).

$=$ Penzigia Sacc., in Saccardo \& Paoletti, Atti Inst. Veneto Sci. lett., ed Arti, Sér. 6 6: 406 (1888).

= Porodiscella Viégas, Bragantia 4(1-6): 106 (1944).

= Pseudoxylaria Boedijn, Persoonia 1(1): 18 (1959).

= Sclerodermatopsis Torrend, in Lloyd, Mycol. Writ. 7 (Letter 70): 1231 (1923).

= Spirogramma Ferd. \& Winge, Vidensk. Meddel. Dansk Naturhist. Foren. Kjøbenhavn 60: 142 (1909).

= Xylariodiscus Henn., Hedwigia 38(Beibl.): (63) (1899).

= Xylocoremium J.D. Rogers, Mycologia 76(5): 913 (1984).

= Xylosphaera Dumort., Comment. bot. (Tournay): 91 (1822).

Type species: Xylaria hypoxylon (L.) Grev. 1824.

All remaining genera of the Xylariaceae according to the current concept are listed below. Unless a note is provided, the 
association of these genera with the family in the current sense is corroborated by data on conidiogeneous structures and/or molecular phylogenetic data in previous studies including the respective type species or (where this was not possible) a number of other representatives.

Amphirosellinia Y.M. Ju Y.M. Ju, J.D. Rogers, H.M. Hsieh \& Lar.N. Vassiljeva, Mycologia 96(6): 1393 (2004).

Type species: Amphirosellinia nigrospora Y.M. Ju Y.M. Ju, J.D. Rogers, H.M. Hsieh \& Lar.N. Vassiljeva 2004.

Anthostomella Sacc., Atti Soc. Veneto-Trent. Sci. Nat., Padova, Sér. 4 4: 84 (1875).

= Cryptosordaria De Not. ex Sacc., Syll. fung. (Abellini) 9: 506 (1891).

= Entosordaria Speg., Revta. Fac. Agron. Vet. Univ. nac. La Plata, Ser. 2 6(1): 40 (1910), nom. Inval.

= Maurinia Niessl, Verh. nat. Ver. Brünn 14: 198 (1876).

= Myconeesia Kirschst., Annls mycol. 34(3): 200 (1936).

三Neesiella Kirschst., Annls mycol. 33(3/4): 217 (1935).

= Paranthostomella Speg., Revta. Fac. Agron. Vet. Univ. nac. La Plata, Ser. 2 6(1): 42 (1910).

= Phaeophomatospora Speg., Anal. Mus. nac. B. Aires, Ser. 3 12: 339 (1909).

Type species: Anthostomella tomicoides Sacc. 1875.

Anthostomelloides Tibpromma \& K.D. Hyde, in Tibpromma, Daranagama, Boonmee, Promputtha, Nontachaiyapoom \& Hyde, Turkish Journal of Botany 40: 10.3906/bot-1606-45, [2] (2016).

Type species: Anthostomelloides krabiensis Tibpromma \& K.D. Hyde 2016.

Arthroxylaria Seifert \& W. Gams, in Seifert, Gams \& Louis-Seize, Czech Mycol. 53(4): 299 (2002).

Type species: Arthroxylaria elegans Seifert \& W. Gams 2002.

Ascotricha Berk., Ann. nat. Hist., Mag. Zool. Bot. Geol. 1: 257 (1838).

= Dicyma Boulanger, Rev. gén. Bot. 9: 18 (1897).

= Gonytrichella Emoto \& Tubaki, Trans. Mycol. Soc. Japan 11: 95 (1971).

= Puciola De Bert., Mycotaxon 3(3): 553 (1976).

Type species: Ascotricha chartarum Berk. 1838.

Astrocystis Berk. \& Broome, J. Linn. Soc., Bot. 14(no. 74): 123 (1873) [1875].

Type species: Astrocystis mirabilis Berk. \& Broome 1873 [1875].

Brunneiperidium Daranag., Camporesi \& K.D. Hyde, in Daranagama, Camporesi, Tian, Liu, Chamyuang, Stadler \&
Hyde, Fungal Diversity: 10.1007/s13225-015-0329-6, [19] (2015).

Type species: Brunneiperidium gracilentum Daranag., Camporesi \& K.D. Hyde 2015.

Note: This genus appears very close to Kretzschmaria and certain species of Xylaria in the molecular phylogeny provided by Daranagama et al. (2015).

Clypeosphaeria Fuckel, Jb. nassau. Ver. Naturk. 23-24: 117 (1870) [1869-70].

Type species: Clypeosphaeria mamillana (Fr.) Lambotte 1880.

Note: The molecular data provided by Jaklitsch et al. (2016), where the taxonomic history of this genus is discussed in detail, point toward its being closely related to Anthostomella and the Xylariaceae in the current sense.

Collodiscula I. Hino \& Katum., Bull. Faculty of Agriculture, Yamaguchi University 6: 55 (1955).

= Acanthodochium Samuels, J.D. Rogers \& Nagas., Mycotaxon 28 (2): 457 (1987).

Type species: Collodiscula japonica I. Hino \& Katum. 1955.

Coniolariella Dania García et al., in García et al., Mycol. Res. 110(11): 1285 (2006).

Type species: Coniolariella gamsii (Asgari \& Zare) Dania García, Stchigel \& Guarro 2006.

Note: This genus is close to Rosellinia as inferred from molecular phylogeny (Zare et al. 2010).

Emarcea Duong, Jeewon \& K.D. Hyde, Stud. Mycol. 50(1): 255 (2004).

Type species: Emarcea castanopsidicola Duong, Jeewon \& K.D. Hyde 2004.

Note: The few DNA sequence data available on this genus show high homologies to Nemania and Xylaria species.

Entoleuca Syd., Annls mycol. 20(3/4): 186 (1922).

Type species: Entoleuca callimorpha Syd., in Sydow \& Petrak, Annls mycol. 20(3/4): 186 (1922).

Euepixylon Füisting, Bot. Ztg. 25(no. 39): 309 (1867). Type species: Euepixylon udum (Pers.) Læssøe \& Spooner 1994.

Halorosellinia Whalley, E.B.G. Jones, K.D. Hyde \& Læssøe, in Whalley, Jones, Alias \& Siti Aisyah, Mycol. Res. 104(3): 368 (2000).

Type species: Halorosellinia oceanica (S. Schatz) Whalley, E.B.G. Jones, K.D. Hyde \& Læssøe 2000.

Helicogermslita Lodha \& D. Hawksw., in Hawksworth \& Lodha, Trans. Br. mycol. Soc. 81(1): 91 (1983). 
Type species: Helicogermslita celastri (S.B. Kale \& S.V.S. Kale) Lodha \& D. Hawksw. 1983.

Note: A geniculosporium-like anamorph was reported in the protologue, but no molecular data on the genus are available as yet.

Hypocopra (Fr.) J. Kickx f., Fl. Crypt. Flandres (Paris) 1: 362 (1867).

= Coprolepa Fuckel, Jb. nassau. Ver. Naturk. 23-24: 239 (1870) [1869-70].

Type species: Hypocopra merdaria (Fr.) J. Kickx f. (1867).

Notes: Recently, the first DNA sequences of a member of this genus have become available in the course of a study on the chemistry of Hypocopra rostrata (Jayanetti et al. 2014). The ITS sequence arising from this study (GenBank Acc. No. KM067909) was subjected to a homology search and the results proved beyond doubt that this species has close affinities to Xylaria and Podosordaria.

Hypocreodendron Henn., Hedwigia 36(4): 223 (1897).

= Discoxylaria J.C. Lindq. \& J.E. Wright, Darwiniana 13: 139 (1964).

= Poroniopsis Speg., Revta Mus. La Plata 26: 171 (1922).

Type species: Hypocreodendron sanguineum Henn. 1897.

Kretzschmaria Fr., Summa veg. Scand., Sectio Post. (Stockholm): 409 (1849).

$=$ Ustulina Tul. \& C. Tul., Select. fung. carpol. (Paris) 2: 23 (1863).

= Ascostroma Bonord., Handb. Allgem. mykol. (Stuttgart): 272 (1851).

= Rhopalopsis Cooke, Grevillea 11 (no. 59): 93 (1883).

Type species: Kretzschmaria clavus (Fr.) Sacc. 1883.

Kretzschmariella Viégas, Bragantia 4(1-6): 105 (1944).

Type species: Kretzschmariella culmorum (Cooke) Y.-M. Ju \& J. D. Rogers 1994.

Note: A geniculosporium-like anamorph was reported in the protologue, but no molecular data on the genus are available as yet.

Leprieuria Læssøe, J.D. Rogers \& Whalley, Mycol. Res. 93(2): 152 (1989).

Type species: Leprieuria bacillum (Mont.) Læssøe, J.D. Rogers \& Whalley 1989.

Note: A geniculosporium-like anamorph was reported in the protologue, but no molecular data on the genus are available as yet.

Lunatiannulus Daranag., Camporesi \& K.D. Hyde, Fungal Diversity: 73: 227 (2015).

Type species: Lunatiannulus irregularis Daranagama, Camporesi \& K.D. Hyde 2015.
Note: The phylogenetic affinities of this taxon are apparently with Nemania and other Xylariaceae in the current, restricted sense. It has brown ellipsoid ascospores but differs from the typical Xylariaceae in having a libertella-like conidial state (albeit with relatively short conidia) and an atypical crescent shaped apical apparatus (cf. Daranagama et al. 2015).

Nemania S. F. Gray, Nat. Arr. Brit. Pl. (London) 1: 516 (1821).

$\equiv$ Geniculosporium Chesters \& Greenh., Trans. Br. mycol. Soc. 47(3): 400 (1964).

= Gamosphaera Dumort., Comment. bot. (Tournay): 90 (1822).

$=$ Geniculisynnema Okane \& Nakagiri, Mycoscience 48 (4): 245 (2007).

Type species: Nemania serpens (Pers.) S. F. Gray 1821.

Podosordaria Ellis \& Holw., Bot. Gaz. 24: 37 (1897) emend Rogers et al. (1998).

$\equiv$ Pedisordaria Clem., Gen. fung. (Minneapolis): 29 (1909).

Type species: Podosordaria mexicana Ellis \& Holw. 1897.

Poronia Willd., Fl. Berol. Prodr:: 400 (1787).

Type species: Poronia gleditschii Willd. 1787.

Rosellinia De Not., G. bot. ital. 1(1): 334 (1844).

= Amphisphaerella Henn., Hedwigia 41: 18 (1902).

= Byssitheca Bonord., Abh. naturforsch. Ges. Halle 8: 82, 156 (1864).

= Dematophora $\mathrm{R}$. Hartig, Untersuch. Forstbot. Inst. München 3: 95, 125 (1883).

= Vrikshopama D. Rao \& P.Rag. Rao, Mycopath. Mycol. appl. 23: 289 (1964).

Type species: Rosellinia aquila (Fr.) Ces. \& De Not. 1844.

Note: The recent monograph of this genus by Petrini (2013) suggests that it is still rather heterogeneous and may in the future be further subdivided. The type species, $R$. aquila, as well as various other taxa that have so far been studied for their anamorph morphology or by using molecular data, however, all appear to be members of the Xylariaceae s. str. as understood here.

Sarcoxylon Cooke, Grevillea 12(no. 62): 50 (1883).

[三 Sarcoxylum in Clements and Shear (1931)].

Type species: Sarcoxylon compunctum (Jungh.) Cooke 1885.

Note: This genus is here proven to be xylarioid for the first time by using molecular phylogenetic data, confirming the suspicions by Rogers (1981) from his detailed morphological studies.

Squamotubera Henn., Hedwigia 42(Beibl.): (308) (1903). Type species: Squamotubera leratii Henn. 1903. 
Note: Rogers (1981) described the specimen, originally collected from New Caledonia, which should be regarded as the isotype in $\mathrm{K}$, and the holotype is housed in FH (D. Pfister and G. Tocci pers. comm.). There is evidence that the type species has recently been recovered from both China and Thailand. We are aware of an ongoing study on its pyhlogenetic affinities and will refrain from giving details of this unpublished work. However, from the morphological examination reported by Rogers (1981) there can be no doubt that the affinities of Squamotubera are with Xylaria.

Stilbohypoxylon Henn., Hedwigia 41: 16 (1902).

Type species: Stilbohypoxylon moelleri Henn. 1902.

Note: The anamorph of this genus is very similar to Xylaria, and Stilbohypoxylon is therefore retained in the Xylariaceae where it had been placed tentatively by Hennings, and which is also supported by molecular data.

Vamsapriya Gawas \& Bhat, Mycotaxon 94: 150 (2006) [2005].

Type species: Vamsapriya indica Gawas \& Bhat 2006.

Note: The affinities of this anamorph genus are clearly with Xylaria, as recently revealed from a molecular study (Dai et al. 2015) and hence, is accepted in the Xylariaceae.

Virgaria Nees, Syst. Pilze (Würzburg): 54 (1816) [181617].

= Ascovirgaria J.D. Rogers \& Y.M. Ju 2002.

Type species: Virgaria nigra (Link) Nees 1817.

Wawelia Namysł., Bull. int. Acad. Sci. Lett. Cracovie, Cl. sci. math. nat. Sér. B, sci. nat. 2: 602 (1908).

Type species: Wawelia regia Namysł. 1908.

Note: The anamorph of this genus can be categorised as geniculosporium-like, and it is therefore retained in the Xylariaceae, even though no molecular data are available as now.

\section{Genera excluded from the Xylariaceae in the current sense}

3. Graphostromataceae M.E. Barr, J. D. Rogers \& Y.-M. Ju., Mycotaxon 48: 533 (1993) emend M. Stadler, L. Wendt and Sir.

Emended generic description (modified from Barr et al. 1993).

Stromata on wood of living or dead angiosperm plants, effuse, erumpent from the bark of the host plant, bipartite, consisting of two layers with deciduous entostroma. Ascomata perithecial, immersed in the entostroma. Asci unitunicate, oblong to cylindrical, in spicate arrangement. Paraphyses sparse, elongate, tapering from wide base. Ascospores unicellular, allantoid and hyaline or brown and ellipsoid, at times with appendages, with or without germ slits, without dehiscent perispores. Stromatal pigments absent. Asexual morph of the nodulisporium-type, most often periconiella-like or xylocladium-like.

Type genus: Graphostroma Piroz., Can. J. Bot. 52(10): 2131 (1974).

Type species: Graphostroma platystomum (Schwein.) Piroz. 1974 [as "platystoma"].

The concept of the Graphostromataceae, erected by Barr et al. (1993) for the monotypic genus and species G. platystomum, surprisingly held true in our multigene genealogy. We have added Biscogniauxia and Camillea, as well as Obolarina and Vivantia to this family, even though we realise that many species of the two former, relatively large genera remain to be studied in-depth and that virtually no reference sequence data are available for them in the public domain. However, previous studies on Biscogniauxia using molecular phylogenetic methods (Hsieh et al. 2005; Collado et al. 2001) have always shown the genus to be rather homogeneous and the same holds true for the numerous data on Biscogniauxia spp. in GenBank. Therefore, we do not expect many surprises in the future. Camillea primarily differs from Biscogniauxia by the more complex stromatal anatomy of several species and by its ascospore morphology (pale brown to uncolored, lacking a germ slit) and by the xylocladium-like conidiogeneous structures, which were mostly observed on the stromata. This genus was regarded by Læssøe et al. (1989) and Ju et al. (1998) as closely related to Biscogniauxia, but possibly more evolutionarily advanced. For a detailed treatment of these genera we refer to the papers mentioned above. Molecular data are widely amiss for many taxa of Biscogniauxia and most species of Camillea, and many of their species have never been cultured. Obolarina and Vivantia definitely appear related to Biscogniauxia and each genus only differs from the latter in a single salient morphological character (i.e., ascospore morphology and/or complexity of stromata). Further research using extensive studies on the anamorphic traits and molecular phylogenetic data may be helpful in their segregation. Interestingly, the most salient morphological feature of the species included in this family are the erumpent, bipartite stromata, which are often observed on the surface of still living woody plants. This is a rare case that a "macromorphological" character can be specific for a family in the Ascomycota, but it may be related to the endophytic lifestyle of these fungi. 


\section{Other accepted genera}

Biscogniauxia Kuntze, Revis. gen. pl. (Leipzig) 2: 398 (1891).

= Albocrustum Lloyd, Mycol. Writ. 7(Letter 75): 1353 (1925).

= Kommamyce Nieuwl., Am. Midl. Nat. 4: 375 (1916).

$=$ Nummularia Tul. \& C. Tul., Select. fung. carpol. (Paris) 2: 42 (1863).

= Nummulariella Eckblad \& Granmo, Norw. Jl Bot. 25(2): 9 (1978).

= Numulariola House, N.Y. St. Mus. Bull. 266: 49 (1925).

Type species: Biscogniauxia nummularia (Bull.) Kuntze (1891).

Basionym: Hypoxylon nummularium Bull., Herb. Fr. (Paris): tab. 468, Fig. 4 (1790) [1791].

Lectotype (selected here): Fig. 4 of Bulliard (1791).

Epitype (of Hypoxylon nummularium Bull., Herb. Fr. (Paris): tab. 468, Fig. 4 (1790), designated here): Germany, Rhenania-Palatinate, vicinity of Wachenheim an der Weinstrasse, Poppental, Schlangenweiher, on wood of Fagus sylvatica, 23 Mar 2008, leg. M. Stadler (STMA 08026, KR-M-0048412, MBT 374787), ex-epitype culture MUCL 51395.

Notes: We selected the illustration of Bulliard since we could not find any data in the literature indicating that this species has ever been lectotypified. The location of the epitype is in an area where it is very commonly found in the beech forests. This area used to alternatively belong to France or Germany, during the time when German and French mycologists were proposing different alternative names for this area.

Camillea Fr., Summa veg. Scand., Section Post. (Stockholm): 382 (1849).

= Diatrypeopsis Speg., Anal. Soc. cient. argent. 18(6): 266 (1884).

= Nummularioidea (Cooke \& Massee) Lloyd, Mycological Writings 7 (72): 1281 (1924).

= Xylocladium P. Syd. ex Lindau, Die natürlichen Pflanzenfamilien nebst ihren Gattungen und wichtigeren Arten insbesondere den Nutzpflanzen: I. Tl., 1. Abt.: Fungi (Eumycetes): 494 (1900).

$=$ Jongiella M. Morelet, Bull. Soc. Sci. nat. Arch. Toulon et du Var 196: 7 (1971).

Type species: Camillea leprieurii (Mont.) Mont. (1849).

Obolarina Pouzar, Česká Mykol. 40(1): 7 (1986).

Type species: Obolarina dryophila (Tul. \& C. Tul.) Pouzar 1986.

Vivantia J.D. Rogers, Y.M. Ju \& Cand., Mycol. Res. 100(6): 672 (1996).
Type species: Vivantia guadalupensis J.D. Rogers, Y.M. Ju \& Cand. 1996.

Note: This genus is tentatively assigned to the Graphostromataceae because it has a nodulisporium-like anamorph (reminiscent of the periconiella-like type) and bipartite stromata and does, therefore, match the characteristics of the family better than those of the Hypoxylaceae or the Xylariaceae s. stricto. However, it remains to be studied by molecular phylogenetic methods.

4. Lopadostomataceae Daranagama \& K.D. Hyde [as "Lopadostomaceae", in Senanayake et al., Fungal Divers 73: 1 (2015)].

Creosphaeria Theiss., Beih. bot. Zbl., Abt. 2 27: 396 (1910).

Type species: Creosphaeria sassafras (Schwein.) Y.M. Ju, San Martín \& J.D. Rogers 1993.

Lopadostoma (Nitschke) Traverso, Fl. ital. crypt., 1(2): 169 (1906).

Type species: Lopadostoma turgidum (Pers.) Traverso 1906.

Jumillera J.D. Rogers, Y.M. Ju \& F. San Martín, Mycotaxon 64: 41 (1997).

Type species: Jumillera mexicana J.D. Rogers, Y.M. Ju \& San Martín 1997.

Whalleya J.D. Rogers, Y.M. Ju \& F. San Martín, Mycotaxon 64: 48 (1997).

Type species: Whalleya microplaca (Berk. \& M.A. Curtis) J.D. Rogers, Y.M. Ju \& San Martín 1997.

\section{Xylariales Incertae Sedis}

The segregation of Lopadostomataceae (and as practiced here, Graphostromataceae and Hypoxylaceae) from the Xylariaceae s. lat., makes it difficult (if not impossible) to assign many genera to either of the new families, as neither anamorphic structures nor molecular data exist for this genera. A taxon that is only known from drawings or from old depauperate herbarium, specimens cannot be accommodated any longer in the Xylariaceae based solely on the ascospore morphology.

There had been two choices when interpreting the current phylogeny:

a) reject the concepts brought forward by the recent studies that have revealed the Lopadostomataceae cited in the introduction, based on a polyphasic approach, or 
b) accept these concepts and apply it to the new data that are presented in the current study, although we still have various gaps.

Since we were not inclined to deny the tremendous progress on our understanding of the phylogenetic affinities in this highly complex and diverse group of Ascomycota, we have chosen option b).

Therefore, several genera were expelled from either of the families and placed at interim in Xylariales incertae sedis. We frankly hope that this procedure may point other mycologists toward these genera with unsettled phylogeny, promoting the recollection of fresh material to fill our gaps in the knowledge on the affinities of the Xylariomycetideae. All genera, whose affinities remain still unsettled and which we do not regard to belong to the Xylariaceae s. str., are listed below:

Alloanthostomella Daranag., Camporesi \& K.D. Hyde, in Daranagama, Camporesi, Jeewon, Liu, Stadler, Lumyong \& Hyde, Cryptog. Mycol. 37(4): 518 (2016).

Type species: Alloanthostomella rubicola (Speg.) Daranag., Camporesi \& K.D. Hyde 2016.

Note: This genus was recently segregated from Anthostomella based on molecular phylogenetic data and morphological traits (Daranagama et al. 2016). In their phylogenetic tree, it appeared related to Neoanthostomella and Biscogniauxia, rather than to Xylaria. It differs from Neoanthostomella in lacking pigmented ascospores. However, various xylariaceous and graphostromataceous taxa were not included in this phylogenetic study. We refrain from assigning it to one of the families in the current concept, until additional data have become available.

Appendixia B.S. Lu \& K.D. Hyde, Fungal Diversity Res. Ser. 4: 224 (2000).

Type species: Appendixia closterium (Berk. \& M.A. Curtis) B.S. Lu \& K.D. Hyde 2000.

Note: The anamorph of this genus is unknown and no molecular data are available.

Barrmaelia Rappaz, Mycol. Helv. 7(1): 130 (1995).

Type species: Barrmaelia rhamnicola Rappaz 1995.

Notes: The taxonomic position of this genus is unclear. No anamorph data are available and Jaklitsch et al. (2014) sequenced the ITS and LSU and found it to differ from Lopadostoma s. str. (which is now accommodated in a different family) as well as from the Xylariaceae s. str.

Biporispora J.D. Rogers, Y.M. Ju \& Cand., Nova Hedwigia 68(3-4): 421 (1999).
Type species: Biporispora europaea J.D. Rogers, Y.M. Ju \& Cand. 1999.

Notes: The type species of this monotypic genus is apparently a parasite of the stromata of Hypoxylon macrocarpum Pouz. The assignment to the Xylariaceae was tentative, based on the ascospore morphology, which was, however, regarded by the authors as atypical for the family. No data on anamorphic structures or molecular phylogeny are available. Recently generated, yet unpublished DNA sequence data actually point toward a placement of Biporispora in the Chaetosphaeriales (A. N. Miller, pers. comm.).

Camporesia W.J. Li \& K.D. Hyde, in Li et al., Fungal Diversity 78: 10.1007/s13225-016-0366-9, [113] (2016).

Type species: Camporesia sambuci W.J. Li \& K.D. Hyde 2016.

Notes: This genus was recently erected based on a single cultured specimen and the placement in the Xylariaceae was based on DNA sequence data, where it appeared in the hypoxyloid clade (Li et al. 2016). However, the morphology does not match any known xylariaceous taxon. The teleomorph is unknown, while the anamorph is coelomyceteous and the conidia are not typical for Xylariaceae or Hypoxylaceae at all. The extype culture was only grown on PDA (rather than on the conventional media used for sporulation) where the coelomyceteous structures found in the type material were not observed again (as is usually the case, e.g. in Xylariales spp. featuring libertella-like anamorphic stages) and it was not examined at all for comparison with cultures of other taxa that have similar phylogenetic characteristics. We strongly suspect that it may constitute a contaminant and think that more collections should be made available for verification.

Cannonia Joanne E. Taylor \& K.D. Hyde, Mycol. Res.103(11): 1398 (1999).

Type species: Cannonia australis (Speg.) Joanne E. Taylor \& K.D. Hyde 1999.

Note: The anamorph of this genus is unknown and no molecular data are available. The asci do not match any known xylariaceous taxon. They are claviform, short-pedicellate, evanescent and lack an apical apparatus. It is quite common to find only free ascospores as usually no intact asci can be observed (Trierveiler-Pereira et al. 2012). These authors already discussed that Carlos Spegazzini originally had placed it in Ceratostoma Fr., a genus generally possessing asci with an evanescent wall. Taylor \& Hyde (1999) compared features of the Coniochaetaceae and Xylariaceae to place Cannonia in the latter family, but molecular phylogenetic data are definitely needed to clarify the phylogenetic affinities of this genus. 
Cerillum Clem., in Clements \& Shear, Gen. fung., Edn 2 (Minneapolis): 280 (1931).

Type species: Cerillum paradoxa (Har. \& Pat.) Clem. 1931.

Note: The anamorph of this genus is unknown and no molecular data are available. It is regarded tentatively as a synonym of Engleromyces, whose affinities are likewise unknown (cf. Stadler et al. 2013).

Chaenocarpus Rebent., Prodr. fl. neomarch. (Berolini): 350 (1804).

= Cryptothamnium Wallr., Beitr. Bot.: 76 (1842).

Type species: Chaenocarpus setosus (Roth) Rebent. 1804.

Note: The anamorph of this genus is unknown and no molecular data are available.

Cyanopulvis J. Fröhl. \& K.D. Hyde, Fungal Diversity Res. Ser. 3: 308 (2000).

Type species: Cyanopulvis australiensis J. Fröhl. \& K.D. Hyde 2000.

Note: The anamorph of this genus is unknown and no molecular data are available.

Calceomyces Udagawa \& S. Ueda, Mycotaxon 32: 448 (1988).

Type species: Calceomyces lacunosus Udagawa \& S. Ueda 1988.

Note: The current study, in which the ex-type strain of this monotypic genus is included, revealed a phylogenetic placement outside the major clades, close to Creosphaeria (Lopadostomataceae). A subsequent study including more representatives of the latter family and non-stromatic Xylariales should be carried out for comparison to shed more light on its affinities.

Diamantinia A.N. Mill., Læssøe \& Huhndorf, Sydowia 55(1): 94 (2003).

Type species: Diamantinia citrina A.N. Mill., Læssøe \& Huhndorf 2003.

Note: The anamorph of this genus (which has been referred to as a member of the Xylariaceae and was in fact, until recently, listed under this family in public databases) is unknown and no molecular data are available, except for a LSU sequence (GenBank Acc. No. AY346278) that proved to be only of little use for our current phylogenetic study. The authors have clearly stated that they prefer to place it in Xylariales incertae sedis and we agree.

Durotheca Læssøe, Srikitik., Luangsa-ard \& M. Stadler, IMA Fungus 4(1): 62 (2013).

Type species: Durotheca depressa Læssøe \& Srikitik. 2013.
Note: For data on the phylogenetic position of this genus see Notes to Theissenia, with which Durotheca is obviously closely related. The anamorph of $D$. comedens was described by $\mathrm{Ju}$ et al. (2003) to be nodulisporium-like, but they observed rather long slender conidia that are somewhat reminiscent of scolecospores. Interestingly, the stromata of Durotheca comedens were found to contain lepraric acids, which is indicative of chemotaxonomic affinities to Chlorostroma and Hypoxylon aeruginosum (Læssøe et al. (2013).

Engleromyces Henn., Bot. Jb. 28(3): 327 (1900).

三Stromne Clem., Gen. fung. (Minneapolis): 44 (1909).

= Colletomanginia Har. \& Pat., C. r. hebd. Séanc. Acad. Sci., Paris 142: 225 (1906).

Type species: Engleromyces goetzei Henn. 1900.

Note: The anamorph of this genus is unknown and no molecular data are available.

Fasciatispora K.D. Hyde, Trans. Mycol. Soc. Japan 32(2): 265 (1991).

Type species: Fasciatispora nypae K.D. Hyde 1991.

Notes: The few sequence data of this genus show high homologies to Barrmaelia followed by Lopadostoma species. However, only a LSU sequence (GenBank Acc. No. KP744484) is available from material assigned to the type species. Further work must be carried out to demonstrate its affinities.

Gigantospora B.S. Lu \& K.D. Hyde, Nova Hedwigia 76(1-2): 202 (2003).

Type species: Gigantospora gigaspora B.S. Lu \& K.D. Hyde 2003.

Note: The anamorph of this genus is unknown and no molecular data are available.

Guestia G.J.D. Sm. \& K.D. Hyde, Fungal Diversity 7: 107 (2001).

Type species: Guestia gonetropospora G.J.D. Sm. \& K.D. Hyde 2001.

Note: The anamorph of this genus is unknown and no molecular data are available.

Induratia Samuels, E. Müll. \& Petrini, Mycotaxon 28(2): 482 (1987).

Type species: Induratia apiospora Samuels, E. Müll. \& Petrini 1987.

Note: A nodulisporium-like anamorph was reported from the type species of this genus in the protologue, but it has ascospores reminiscent of the Apiosporaceae 
and neither a living culture nor molecular data are available.

Leptomassaria Petr., Annls mycol. 12(5): 474 (1914).

Type species: Leptomassaria simplex (Nitschke ex G.H. Otth) Petr. 2014.

Note: This genus is reminiscent of Anthostomella, but its anamorphic structures are not known and no molecular data are available.

Neoanthostomella D.Q. Dai \& K.D. Hyde, in Dai, Phookamsak, Wijayawardene, Li, Bhat, Xu, Taylor, Hyde \& Chukeatirote, Fungal Diversity: 10.1007/s13225-016-03678, [84] (2016).

Type species: Neoanthostomella pseudostromatica D.Q. Dai \& K.D. Hyde 2016.

Note: The phylogenetic position of the type species of this monotypic genus is close to that of Pyriformiascoma. It has typical xylarioid ascospores and its asci are lacking an amyloid apical apparatus, but no anamorphic structures were observed (Dai et al. 2016). It seems to be distinct from Anthostomella s. str. and is here retained in the Xylariaceae.

Nipicola K.D. Hyde, Cryptogamic Botany 2(4): 330 (1992).

Type species: Nipicola carbospora K.D. Hyde 1992.

Note: The anamorph of this genus is unknown and no molecular data are available.

Occultitheca J.D. Rogers \& Y.M. Ju, Sydowia 55(2): 359 (2003).

Type species: Occultitheca costaricensis J.D. Rogers \& Y.M. Ju 2003.

Note: The anamorph of this genus is unknown and no molecular data are available.

Ophiorosellinia J.D. Rogers, A. Hidalgo, F.A. Fernández \& Huhndorf, Mycologia 96(1): 172 (2004).

Type species: Ophiorosellinia costaricensis J.D. Rogers, A. Hidalgo, F.A. Fernández \& Huhndorf 2004.

Note: The anamorph of this genus is unknown and no molecular data are available.

Paramphisphaeria F.A. Fernández, J.D. Rogers, Y.M. Ju, Huhndorf \& Umaña, Mycologia 96(1): 175 (2004).

Type species: Paramphisphaeria costaricensis F.A. Fernández, J.D. Rogers, Y.M. Ju, Huhndorf \& Umaña 2004.

Note: The anamorph of this genus is unknown and no molecular data are available.
Paucithecium Lloyd, Mycol. Notes (Cincinnati) 7(4): 1200 (1923).

Type species: Paucithecium rickii Lloyd 1923.

Note: The anamorph of this genus is unknown and no molecular data are available.

Pandanicola K.D. Hyde, Sydowia 46(1): 35 (1994).

Type species: Pandanicola calocarpa (Syd. \& P. Syd.) K.D. Hyde 1994.

Note: The anamorph of this genus is unknown and no molecular data are available.

Poroleprieuria M.C. González, Hanlin, Ulloa \& Elv. Aguirre, Mycologia 96(3): 676 (2004).

Type species: Poroleprieuria rogersii M.C. González, Hanlin, Ulloa \& Elv. Aguirre 2004.

Note: The anamorph of this fungus is unknown, and if it were found to be geniculosporium-like, it would possibly have to be synonymised with Leprieuria.

Pyriformiascoma Daranag., Camporesi \& K.D. Hyde, Fungal Diversity, 73:203-238 (2015).

Type species: Pyriformiascoma trilobatum Daranag., Camporesi \& K.D. Hyde 2015.

Note: DNA sequences derived from the type species of this genus were reported to be basal in the phylogeny by Daranagama et al. (2015) with focus on Anthostomella. The data available on the simple conidiogeneous structures are reminiscent of the "sporothrix-like" conidiogeneous structures defined by Ju and Rogers (1996) and suggest that it is ancestral. It is not clear, whether it represents a separate lineage, or whether it can be categorised in one of the existing families. We think that more specimens need to be collected and studied before a final conclusion can be reached.

Pseudoanthostomella Daranag., Camporesi \& K.D. Hyde, in Daranagama, Camporesi, Jeewon, Liu, Stadler, Lumyong \& Hyde, Cryptog. Mycol. 37(4): 527 (2016).

Type species: Pseudoanthostomella pini-nigrae Daranag., Camporesi \& K.D. Hyde 2016.

Note: This genus was recently segregated from Anthostomella based on molecular phylogeny and morphological traits and like Alloanthostomella, it showed affinities to Biscogniauxia, rather than to Xylaria. However, various xylariaceous and graphostromataceous taxa were not included in this phylogenetic study. It is characterised by an amyloid ascal apparatus and morphologically differs from the genus Anthostomelloides (which is clearly a member of the Xylariaceae based on molecular data) by the lack of a central periphysate ostiolar canal. In the phylogenetic tree, it appeared related to Neoanthostomella and Biscogniauxia, rather than to 
Xylaria. We refrain from assigning it to one of the families in the current concept, until additional data have become available.

Spirodecospora B.S. Lu, K.D. Hyde \& W.H. Ho, Fungal Diversity Res. Ser. 1: 170 (1998).

Type species: Spirodecospora melnikii (Lar.N. Vassiljeva) K.D. Hyde \& Mel'nik, in Mel'nik \& Hyde (2003).

Note: The anamorph of this genus is unknown and no molecular data are available.

Striatodecospora D.Q. Zhou, K.D. Hyde \& B.S. Lu, Mycotaxon 76: 142 (2000).

Type species: Striatodecospora bambusae D.Q. Zhou, K.D. Hyde \& B.S. Lu 2000.

Note: The anamorph of this genus is unknown and no molecular data are available.

Stromatoneurospora S.C. Jong \& E.E. Davis, Mycologia 65(2): 459 (1973).

Type species: Stromatoneurospora phoenix (Kunze) S.C. Jong \& E.E. Davis 1973.

Note: According to the protologue, and in particular with respect to the morphology of its asci and ascospores (which are lacking germ slits; however, this also applies to a number of other xylarialean species), this genus may tentatively be assigned to the xylarioid Xylariales, but might represent yet another phylogenetic lineage within the Sordariomycetes. Studies on fresh material, possibly including a morphological characterisation of the anamorph and molecular phylogenetic data are needed to settle its affinities.

Theissenia Maubl., Bull. Soc. mycol. Fr. 30(1): 52 (1914).

Type species: Theissenia pyrenocrata (Theiss.) Maubl. 1914.

Notes: This genus appears heterogeneous even after the segregation of Durotheca by Læssøe et al. (2013) with respect to both teleomorph and anamorph morphology. The phylogeny of Ju et al. (2007) based on protein coding genes suggests affinities to both Biscogniauxia (Graphostromataceae) and Whalleya (Lopadostomataceae). Further studies will show whether Theissenia, which has been regarded as a basal or even doubtful member of the Xylariaceae s. lat., can be assigned to one of the aforementioned families or whether the genus and the related Durotheca will have to be elevated to a family of their own. From a phylogenetic point of view, it cannot be retained in the Xylariaceae and was also found to be quite distant to the taxa that are here regarded as Hypoxylaceae.

Xylocrea Möller, Bot. Mitt. Trop. 9: 397 (1901).

Type species: Xylocrea piriformis Möller 1901.
Note: Contrary to previous reports in the literature, the type is extant in B, where it was discovered in 2007 (M.S. personal observations, confirmed by J. Fournier). However, the stromata were soaked in ethanol for over a hundred years; no spores were found in the depauperate stroma, and even DNA extraction proved futile. The detailed description by Möller (1901) could point toward this genus being close to Xylaria or Sarcoxylon, but as no data on anamorphic structures were reported, we cannot safely assign it to any of the families treated herein. However, there is no doubt that $X$. pyriformis belongs to the Xylariales.

Xylotumulus J.D. Rogers, Y.M. Ju \& Hemmes, Sydowia 58(2): 291 (2006).

Type species: Xylotumulus gibbisporus J.D. Rogers, Y.M. Ju \& Hemmes 2006.

Note: The anamorph of this genus is unknown and no molecular data are available.

\section{Sordariomycetes incertae sedis}

Some genera previously treated as Xylariaceae by some authors are excluded here from the Xylariales and treated as Sordariomycetes incertae sedis according to the new polythetic concept:

Fassia Dennis, Bull. Jard. bot. État Brux. 34: 240 (1964).

Type species: Fassia scabrosa Dennis 1964.

Notes: This monotypic genus cannot be accommodated in either of the current families, since neither morphological data of the anamorph, nor molecular phylogenetic data are available, and their teleomorph and ascospore morphology is atypical for the Xylariaceae s. lat. even in the "traditional" definition. We think that its placement in the Xylariales is highly tentative and questionable.

Areolospora S.C. Jong \& E.E. Davis, Norw. J1 Bot. 21(1): 28 (1974).

Type species: Areolospora terrophila S.C. Jong \& E.E. Davis 1974.

Notes: The type species of Areolospora is presently regarded as a synonym of Phaeosporis melasperma (Nyl.) Clem. 1909 (Sordariales), but no cultures and no molecular data are available on this taxon.

Basidiobotrys Höhn., Sitzungsberichte der Kaiserlichen Akademie der Wissenschaften Math-naturw. Klasse Abt. I 118: 420 (1909).

Type species: Basidiobotrys clautriavii (Pat.) Höhn. 1909.

Notes: This genus had been originally proposed to replace Xylocladium, which is an anamorph stage of Biscogniauxia 
and Camillea. Hence, it was listed by Stadler et al. (2013) as a synonym of Xylocladium. However, no ex/type strains and illustrations are available, and there will be no way to relate it to any of the extent genera by modern polythetic methodology. It is actually not even possible to confirm its placement in the Xylariomycetideae and it should, therefore, be abandoned.

Muscodor Worapong, Strobel \& W.M. Hess, Mycotaxon 79: 71 (2001).

Notes: This genus is so far only defined on molecular data and the lack (!) of salient morphological features. We feel that it should be rejected, because the publication did not follow good taxonomic standards (cf. Stadler et al. 2013).

Steganopycnis Syd. \& P. Syd., Annls mycol. 14(5): 370 (1916).

Note: The type material of this genus appears to be lost, and the description is vague. Hence, it is not possible to include it in any xylarialean taxon at this time.

Triplicaria P. Karst., Hedwigia 28: 195 (1889).

Type species: Triplicaria hypoxyloides P. Karst. 1889.

Note: The protologue suggests that the type species of this genus is a synnemata-forming hyphomycete that was assigned to Hypoxylon by some mycologists in the past, but might actually belong to many different genera in the current sense. Even an assignment to one of the Xylariales families in the current definition will never be possible and it is, therefore, suggested to abandon the genus name.

\section{Division of Annulohypoxylon and Jackrogersella, gen. nov.}

The genus Annulohypoxylon was erected by Hsieh et al. (2005) to accommodate the former sect. Annulata of Hypoxylon s. Ju and Rogers (1996) based on molecular phylogenetic data inferred from ACT and TUB2 DNA sequences. The segregation was also found in accordance with the morphological concept as inferred from the latter monograph. Concurrently, Quang et al. (2005a) had also provided first evidence that species of Hypoxylon sect. Annulata (i.e. Annulohypoxylon species) have different stromatal secondary metabolites. They reported cohaerins A and B from "Hypoxylon" (=Annulohypoxylon) cohaerens, which were then discovered as the first members of a novel class of azaphilone pigments. Moreover, they also studied several specimens of what is now regarded as Annulohypoxylon, using high performance liquid chromatography with diode array and mass spectrometric detection (HPLC-DAD-MS), showing that none of them contained any of the mitorubrin or daldinin type azaphilones that prevail in many species of Hypoxylon s. str. Later, various other pigments of the cohaerin/multiformin type were discovered from species of
Annulohypoxylon (Quang et al. 2005b, 2006; Surup et al. 2013; Kuhnert et al. 2017). None of them has so far been encountered in another xylariaceous species, let alone any other fungus, even though some yet unidentified metabolites with cohaerin-like UV/visible spectra were detected in the stromata of certain species of Hypoxylon (cf. H. pulicicidum, Bills et al. 2012). A recent extensive study by Kuhnert et al. (2016) embarked on these data. Numerous type and authentic specimens of Annulohypoxylon including several new and recently erected species were studied in-depth using a more sophisticated HPLC-DAD-MS methodology. In addition, they combined published data from GenBank and newly generated DNA sequences and provided an updated phylogeny of the genus. Interestingly, the results confirmed that the species in which the cohaerin/multiformin type azaphilones had been detected showed a morphological peculiarity. With the exception of A. michelianum, they all have papillate ostioles. The species of the former group with papillate ostioles that have so far been cultured and sequenced also clustered together in the phylogeny based on TUB2 DNA sequences. In our mind, this segregation of the genus Annulohypoxylon s. Hsieh et al. (2005) - which is confirmed by the current multigene genealogy - into distinctive clades warrants the establishment of a new genus for which we propose the name Jackrogersella.

Below we provide a description of the new genera, followed by an account of the species that remain in Annulohypoxylon according to the current taxonomy and their most important synoynyms. Epitypes have also been designated for two important species, which were concurrently evaluated by molecular phylogeny.

Jackrogersella L. Wendt, Kuhnert \& M. Stadler, gen. nov. MB 819742

Etymology: In honor of Professor Jack D. Rogers, to acknowledge his tremendous accomplishments in Ascomycota taxonomy.

Differs from the genus Annulohypoxylon by containing cohaerin/multiformin type azaphilones as predominant stromatal pigments.

Type species: Jackrogersella multiformis (Fr. . Fr.) L. Wendt, Kuhnert \& M. Stadler, comb nov. Fig. 7

MB 819743

Fig. 5 Annulohypoxylon truncatum (a-d: PH, lectotype of Sphaeria truncata; e-n: EKTX14006, KR-M-0046695, epitype of A. truncatum): a: stromatal habit $\mathbf{b}$ : $\mathrm{KOH}$-extractable pigments $\mathbf{c}, \mathbf{d}$ : stromatal surface showing ostiolar disc e, f: stromatal habit $\mathbf{g}$ : $\mathrm{KOH}$-extractable pigments $\mathbf{h}$ : ostiolar disc i: section through stroma showing perithecia $\mathbf{j}$ : ascospores showing germ slit (arrows) k: asci I: nodulisporium-like anamorph from substrate m: apical apparatus blueing in Melzer's reagent (arrow) n: perispore showing thickened area. Scale is indicated by bars (a, e, f: $3 \mathrm{~mm} ; \mathbf{c}, \mathbf{d}, \mathbf{h}, \mathbf{i}: 1 \mathrm{~mm} ; \mathbf{j}, \mathbf{k}, \mathbf{m}, \mathbf{n}: 10 \mu \mathrm{m} ; \mathbf{l}: 50 \mu \mathrm{m})$ 

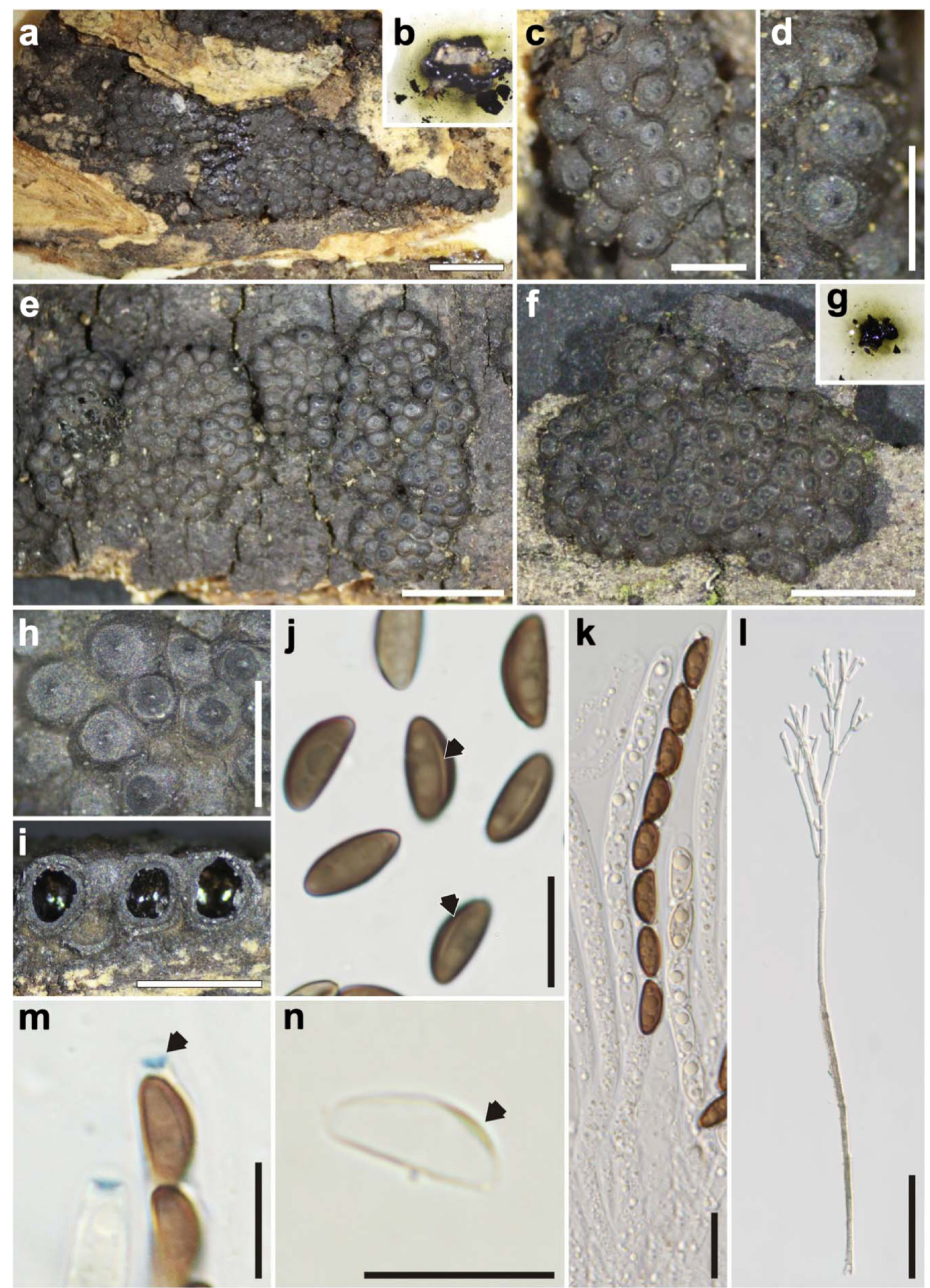

\section{m}
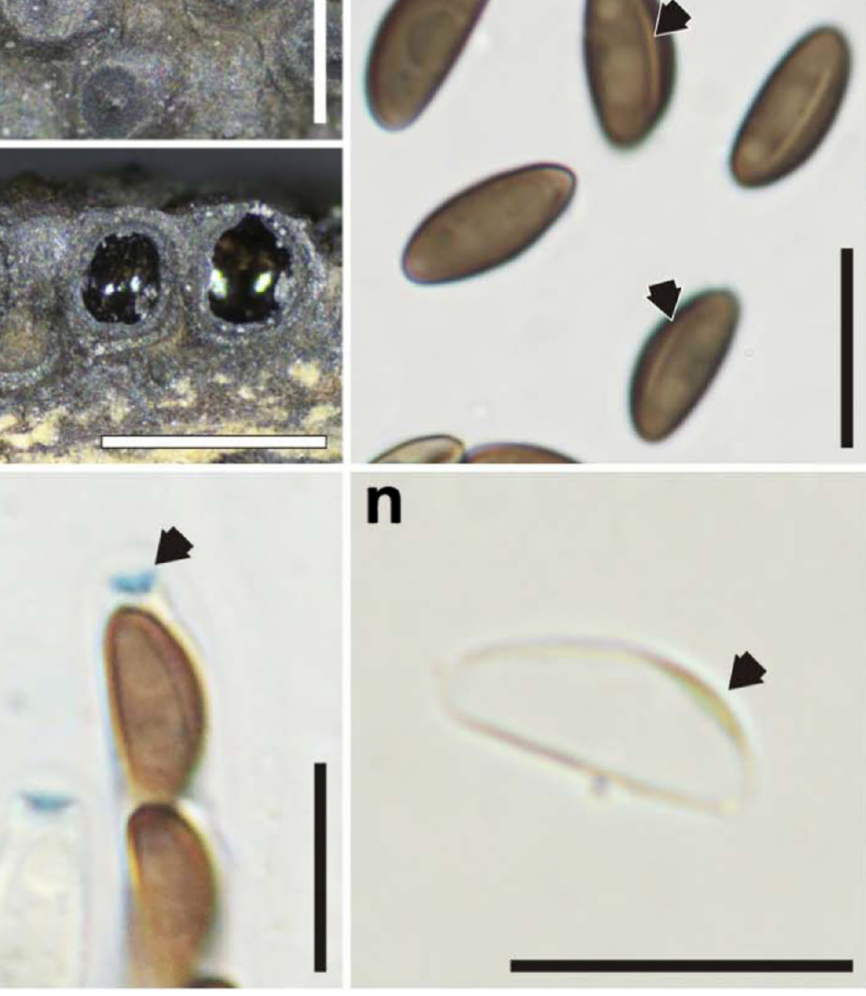

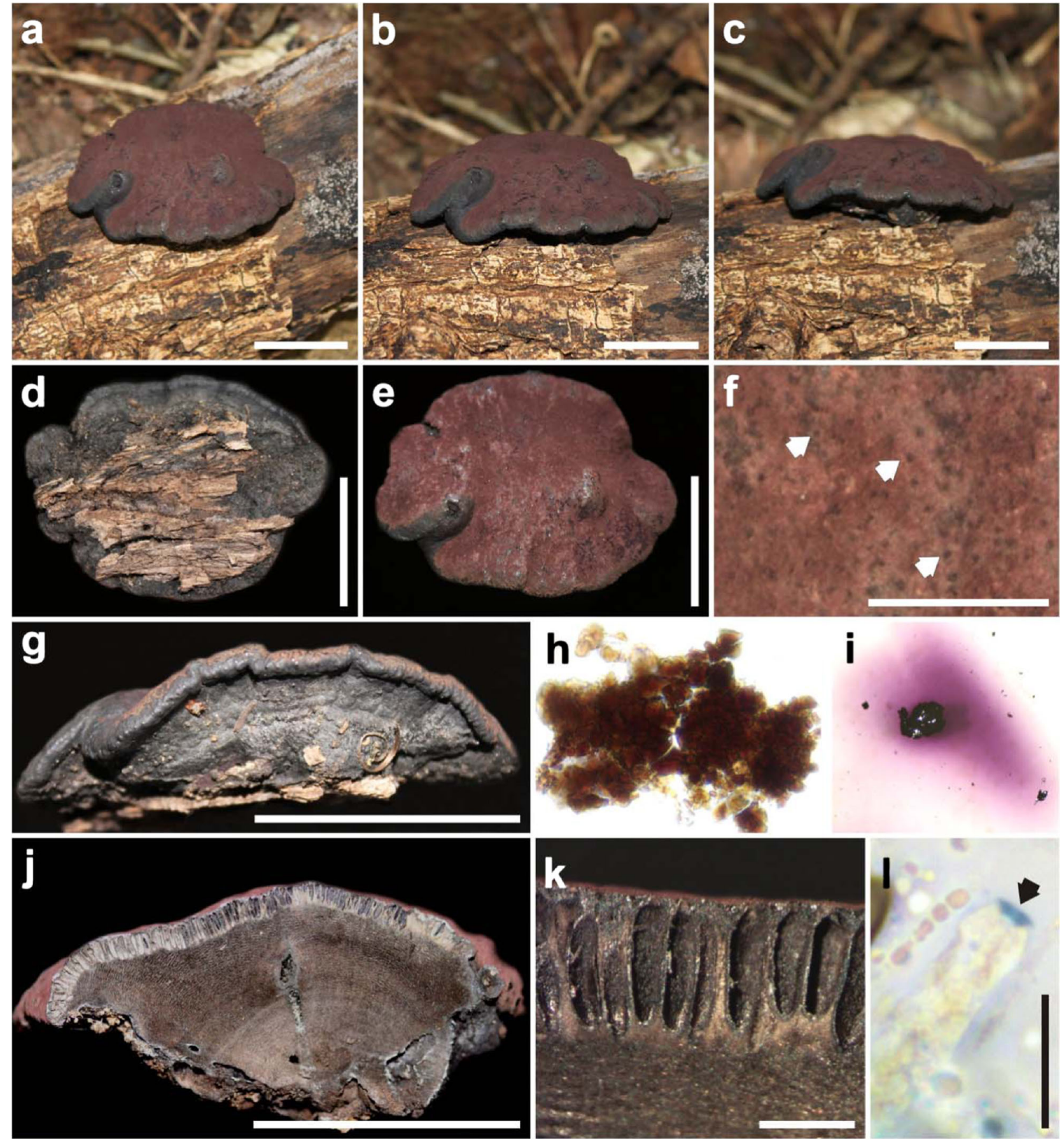

m

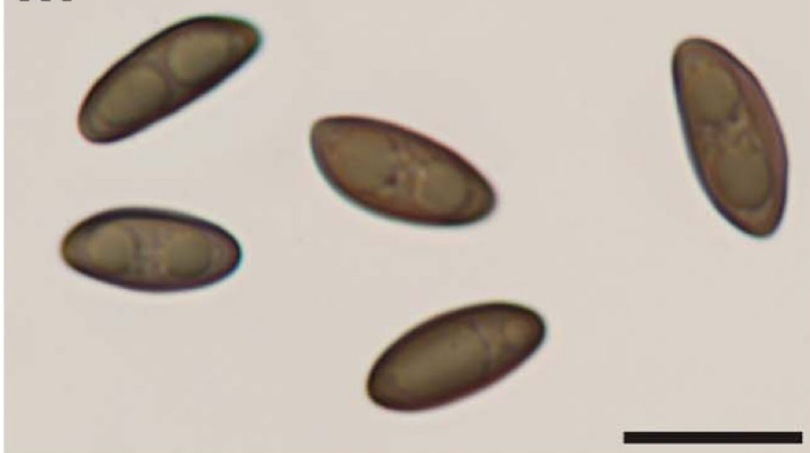

n

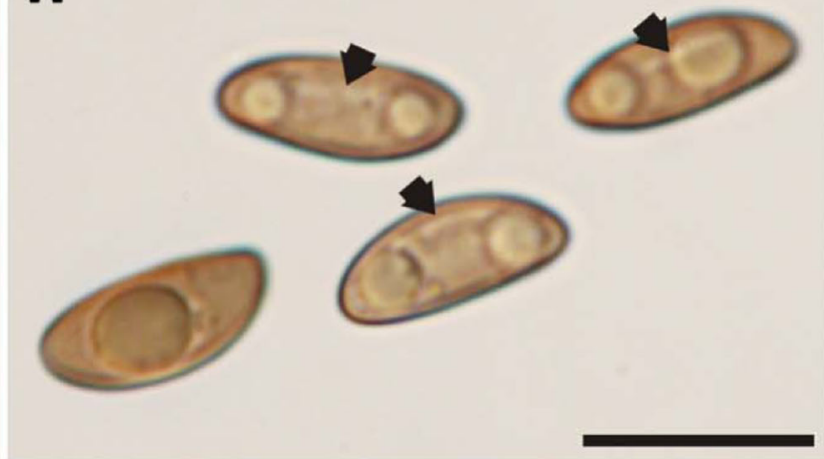


Fig. 6 Pyrenopolyporus hunteri (Sir \& Hladki 016): a, b, c: stromatal habit d: stromata showing ventral surface e: detail of stromatal surface f: detail of stromatal surface showing ostioles (indicated by arrows). g: stromata in lateral view $\mathbf{h}$ : stromatal granules in water $\mathbf{i}: \mathrm{KOH}$-extractable pigments $\mathbf{j}$ : section through stromata showing tissue below perithecia and perithecial layer k: detail of perithecial layer $\mathbf{l}$ : apical apparatus blueing in Melzer's reagent (indicated by arrow) m: ascospores in $10 \% \mathrm{KOH}$ solution $\mathbf{n}$ : ascospores in water showing short germ slit (indicated by arrows). Scale is indicated by bars (a, b, c, d, e, g, j: $3 \mathrm{~cm} ; \mathbf{f}, \mathbf{k}: 1 \mathrm{~mm} ; \mathbf{l}, \mathbf{m}, \mathbf{n}$ : $10 \mu \mathrm{m})$

Basionym: Sphaeria multiformis Fr., Syst. Mycol. II, p 334. 1823.

三 Hypoxylon multiforme (Fr.) Fr. 1849 .

$\equiv$ Annulohypoxylon multiforme (Fr.) Y.M. Ju, J.D. Rogers \& H.M. Hsieh 2005.

= Hypoxylon granulosum Bull. 1791 .

ESphaeria granulosa (Bull.) Sowerby 1803.

三Peripherostoma granulosum (Bull.) Gray 1821.

三 Hypoxylon multiforme var. granulosum (Bull.) Sacc. 1882.

= Sphaeria rubiformis Pers. 1794 .

= Sphaeria rubiformis var. effusa Pers. 1801.

= Hypoxylon multiforme var. effusum (Pers.) Cooke \& Ellis 1876.

= Sphaeria pulvinata R. Hedw. 1802 .

= Sphaeria crustacea Sowerby 1803 .

三 Nemania crustacea (Sowerby) Gray 1821.

三 Hypoxylon crustaceum (Sowerby) Nitschke 1867.

= Sphaeria cinereofusca Schumach. 1803.

= Sphaeria peltata DC. \& Lam. 1805.

= Sphaeria deusta Wahlenb. 1812.

= Stromatosphaeria elliptica Grev. 1824.

= Sphaeria rubiginosa Spreng. 1827 (non Pers.).

= Sphaeria corrugata Fr. 1828.

三 Hypoxylon corrugatum (Fr.) Fr. 1849.

= Sphaeria transversa Schwein. 1832.

三 Hypoxylon transversum (Schwein.) Sacc. 1882.

= Hypoxylon hookeri Berk. ex Cooke 1883 .

= Rosellinia callimorpha P. Karst. 1884.

三 Hypoxylon callimorphum (P. Karst.)

P.M.D. Martin 1967.

= Hypoxylon granulosum var. luxurians Rehm 1905.

= Hypoxylon multiforme var. luxurians (Rehm) Sacc. \& Trotter 1913.

Typus: Sweden, locality unknown, on wood, E. Fries Suec. Exs. 44 (UPS-holotype, K-isotype of Sphaeria multiformis).

Epitype of Sphaeria multiformis Fr., Observ. mycol. (Havniae) 1: 169 (1815), designated here: Germany, North Rhine Westphalia: Haan-Gruiten, Alnus glutinosa, 10 Aug 2004, leg M. Stadler (STMA 04117, KR-M-0048410,
MBT 374766), ex-epitype culture CBS 119016.

\section{Additional accepted taxa:}

Jackrogersella cohaerens (Pers.) L. Wendt, Kuhnert \& M. Stadler, comb nov.

MB819744

Basionym: Sphaeria cohaerens Pers., Neues Mag. Bot. 1: 82 (1794).

三 Hypoxylon cohaerens (Pers.) Fr. 1849.

$\equiv$ Annulohypoxylon cohaerens (Pers.) Y.M. Ju, J.D. Rogers \& H.M. Hsieh 2005.

= Sphaeria spondylina Fr. 1823.

三 Hypoxylon spondylinum (Fr.) Fr. 1849 .

$\equiv$ Nummularia spondylina (Fr.) Sacc. 1882.

= Sphaeria turbinulata Schwein. 1832.

三 Hypoxylon turbinulatum (Schwein.) Berk. 1875.

= Hypoxylon bagnisii Sacc. 1877 .

= Hypoxylon cohaerens var. tenuior Ces. 1879.

= Hypoxylon cohaerens var. minor Sacc. 1882 .

= Hypoxylon atrorufum Ellis \& Everh. 1892.

= Hypoxylon rutilum var. ericae 1924 .

Typus: Locality unknown, wood, (L 910, 270-92, ex Persoon herb.), Lectotype selected by Miller (1961).

Epitype of Sphaeria cohaerens Pers., Neues Mag. Bot. 1: 82 (1794), designated here: Austria, Lower Austria Prov., Mauerbach, Nature reserve Kartause, Fagus sylvatica, 17 July 2005, leg. M. Stadler (STMA 05161, KR-M-0039298), ex-epitype culture CBS 119126.

Jackrogersella gombakensis (M.A. Whalley, Y.M. Ju, J.D. Rogers \& Whalley) L. Wendt, Kuhnert \& M. Stadler, comb. nov.

MB 819776

Basionym: Hypoxylon gombakense M.A. Whalley, Y.M. Ju, J.D. Rogers \& Whalley, Mycotaxon 74(1): 137 (2000).

三Annulohypoxylon gombakense (M.A. Whalley, Y.M. Ju, J.D. Rogers \& Whalley) Y.M. Ju, J.D. Rogers \& H.M. Hsieh, Mycologia 97(4): 859 (2005).

Jackrogersella ilanensis (Y.M. Ju \& J.D. Rogers) L. Wendt, Kuhnert \& M. Stadler, comb. nov. MB 819773

Basionym: Hypoxylon ilanense Y.M. Ju \& J.D. Rogers, Mycotaxon 73: 371 (1999).

三Annulohypoxylon ilanense (Y.M. Ju \& J.D. Rogers) Y.M. Ju,

J.D. Rogers \& H.M. Hsieh, Mycologia 97(4): 859 (2005).

Typus: Taiwan, I-lan Co., Ta-Tung, Chi-lan Shan, wood, 11 Oct. 1996, Y.-M. Ju 85,101,101 (WSP-holotype).

Jackrogersella minutella (Syd. \& P. Syd.) L. Wendt, Kuhnert \& M. Stadler, comb. nov.

MB 819749

Basionym: Hypoxylon minutellum Syd. \& P. Syd., Annls mycol. 8(1): 37 (1910).

$\equiv$ Annulohypoxylon minutellum (Syd. \& P. Syd.) Y.M. Ju, J.D. Rogers \& H.M. Hsieh, Mycologia 97(4): 859 (2005). 

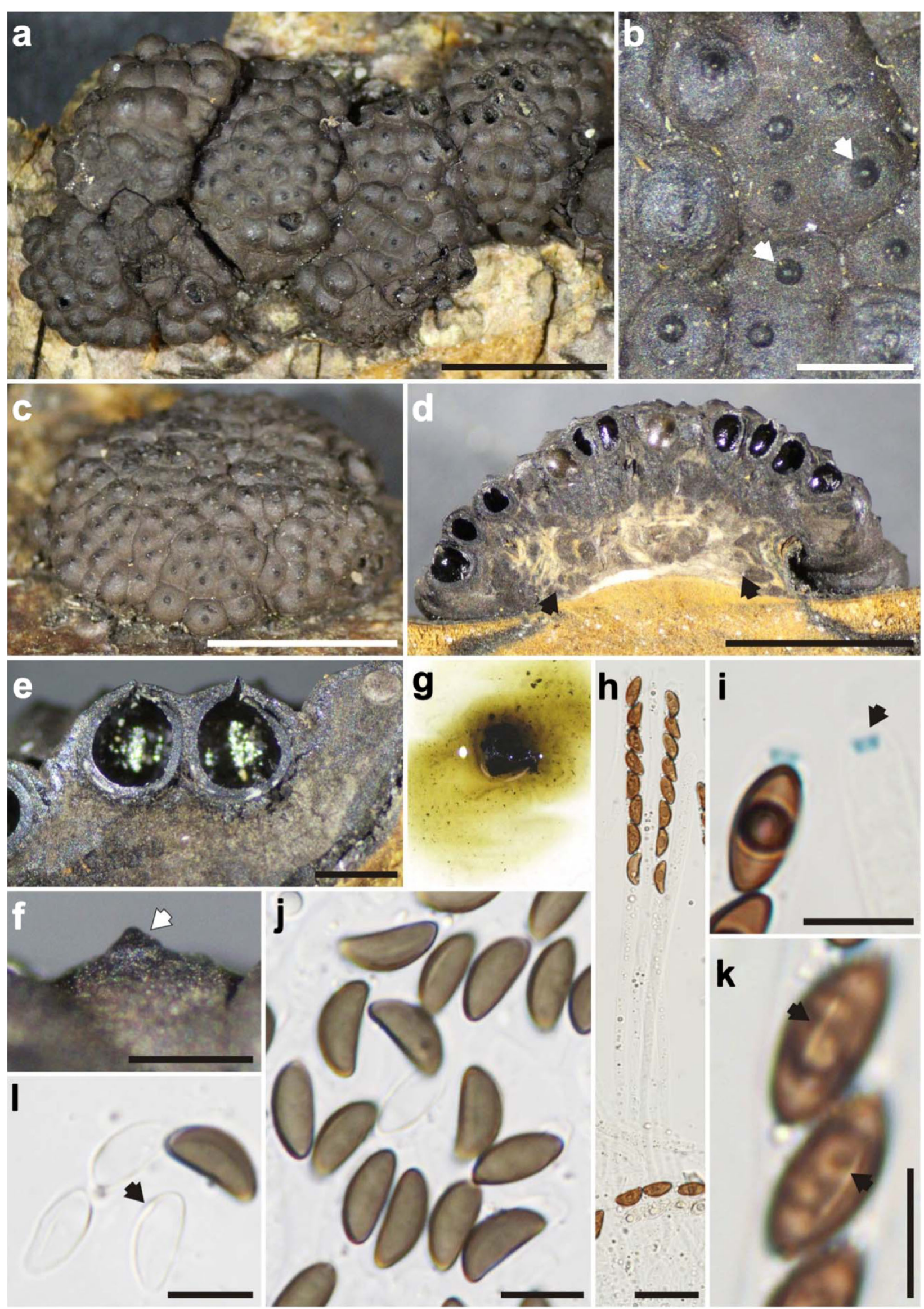
Fig. 7 Jackrogersella multiformis (STMA 05230): a, c: stromata habit b: stromatal surface showing ostiolar papillae (arrows) d: section through stroma showing tissue below perithecia (arrows) and perithecial layer e: detail of perithecia $\mathbf{f}$ : detail of ostiolar papilla $\mathbf{g}$ : $\mathrm{KOH}$-extractable pigments h: asci i: amyloid apical ring $\mathbf{j}$ : ascospores $\mathbf{k}$ : ascospores showing germ slit l: perispores showing thickening (arrow). Scale is indicated by bars (a, c, d: $3 \mathrm{~mm} ; \mathbf{b}, \mathbf{e}, \mathbf{f :} 0.5 \mathrm{~mm} ; \mathbf{h :} 20 \mu \mathrm{m} ; \mathbf{i}, \mathbf{j}, \mathbf{k}, \mathbf{l}: 10 \mu \mathrm{m})$

= Hypoxylon cohaerens var. microsporum J.D. Rogers \& Cand., Mycologia 72(4): 826 (1980).

Typus: (fide Sydow and Sydow 1910) Philippines, Luzon Island, Benguet Prov., on bark, June 1909, Mc Gregor 8721.

Jackrogersella multiformis var. alaskensis (Y.M. Ju \& J.D. Rogers) L. Wendt, Kuhnert \& M. Stadler, comb nov.

MB 819775

Basionym: Hypoxylon multiforme var. alaskense Y.M. Ju \& J.D. Rogers, Mycol. Mem. 20: 219 (1996).

$\equiv$ Annulohypoxylon multiforme var. alaskense (Y.M. Ju \& J.D. Rogers) Y.M. Ju, J.D. Rogers \& H.M. Hsieh, Mycologia 97(4): 859 (2005).

Typus: USA, Alaska, P.W. Island, Kasaan Bay, corticated wood of Alnus sitchensis, 1 Aug. 1950, leg. J.A. Klein 43 (WSP 26287 - holotype).

Jackrogersella nothofagi (Y.M. Ju \& J.D. Rogers) L. Wendt \& M. Stadler, comb. nov.

MB 819745

Basionym: Hypoxylon nothofagi Y.M. Ju \& J.D. Rogers, Mycol. Mem. 20: 221 (1996).

三Annulohypoxylon nothofagi (Y.M. Ju \& J.D. Rogers) Y.M. Ju, J.D. Rogers \& H.M. Hsieh, Mycologia 97(4): 861 (2005).

Typus: New Zealand, Bay of Plenty, off Tauranga Road, Mangorewa Gorge, wood of Nothofagus menziesii, 20 Mar. 1963, leg. J. M. Dingley (PDD 21889 - holotype; WSP 69630 - isotype).

Notes: The genus Jackrogersella comprises the group of species formerly included in Hypoxylon sect. Annulata s. Ju and Rogers (1996) and Annulohypoxylon that have papillate ostioles and are lacking very conspicuous ostiolar disks. As can be seen in Fig. 8, some of these species such as J. gombakensis and J. ilanensis do have ostioles encircled by a disk, but they show similar secondary metabolite profiles as the remainder of Jackrogersella and also clustered with those in the phylogeny of Kuhnert et al. (2016). Notably, ostiolar disks are not exclusively found in the genus Annulohypoxylon, but even occur in other xylariaceous genera such as Hypoxylon (e.g. H. monticulosum Mont.) and Ruwenzoria (Stadler et al. 2010c).

The most salient feature to discriminate the new genus from Annulohypoxylon is, therefore, a chemotaxonomic trait: It is characterised by the specific occurrence of the unique cohaerin/multiformin type azaphilones while apparently lacking daldinone $\mathrm{A}$, truncatone and other binaphthalenes that occur in many species of Annulohypoxylon s. str. as stromatal pigments. Interestingly, the binaphthalene derivative hinnulin may eventually turn out to be recognised as a chemotaxonomic bridging character, because it occurs in J. minutella, as well as A. purpureopigmentum (cf. Kuhnert et al. 2017). In our phylogeny, A. michelianum formed a separate, distinct clade that nevertheless clustered apart from Annulohypoxylon. Another new genus may have to be coined for this species, if the results of the molecular phylogeny will be confirmed during the course of further studies. The anamorph states of various species in the Jackrogersella clade have for instance never been evaluated, and also the information on their secondary metabolites produced in culture is incomplete. One species, J. nothofagi remains to be cultured and studied indepth on its phylogenetic affinities and its metabolite profiles, since the data on the specimens we have at hand are still inconclusive.

\section{Dichotomous key to the species of Jackrogersella and Annulohypoxylon}

1a. Ostioles slightly papillate, encircled by an inconspicuous disc, stromata effused pulvinate ..........................................2 1b. Ostioles papillate not encircled by a disc, stromata peltate, pulvinate to peltate, or effused pulvinate ................................4 2a. Perithecial mounds $1 / 2$ exposed to entirely exposed, ascospores 5.5-6 $\times 2.5-3 \mu \mathrm{m}$ J. ilanensis 2b. Perithecial mounds $1 / 4$ to $2 / 3$ exposed, ascospores greater than $11 \mu \mathrm{m}$ long and greater than $4 \mu \mathrm{m}$ broad .......................3 3a. Stromata surface more or less whitish, becoming blackish, ascospores $11-15 \times 4.5-5.5 \mu \mathrm{m}$, with perispore not dehiscent in $\mathrm{KOH}$ .A. michelianum

3b. Stromata surface dark reddish brown, ascospores 13$15 \times 5-6 \mu \mathrm{m}$, with perispore dehiscent in $\mathrm{KOH}$ J. gombakensis

4a. Stromata effused-pulvinate with inconspicuous perithecial mounds to planar, surface dark vinaceous or brown vinaceous, up to $1 \mathrm{~mm}$ thick, ascospores 7-9.9 $\times 3.5-5 \mu \mathrm{m}$ J. nothofagi

4b. Stromata pulvinate to peltate, often constricted at base, with inconspicuous to conspicuous perithecial mounds, surface blackish, $1.5 \mathrm{~mm}$ to $7 \mathrm{~mm}$ thick

.5

5a. Ascospores (10-)12-15(-17) × 6-7(-9) $\mu \mathrm{m}$ J. multiformis var. alaskensis

5b. Ascospores less than $12 \mu \mathrm{m}$ long ...6 6a. Ascospores 6.5-8.5 × 3-4 $\mu \mathrm{m}$, stromata with hinnulin A as chemotaxonomic marker compounds, Quercus, Castanea, and Erica arborea as host known. J. minutella 6b. Ascospores larger; stromata with BNT and cohaerin D or multiformin B as chemotaxonomic marker compounds, on different hosts 

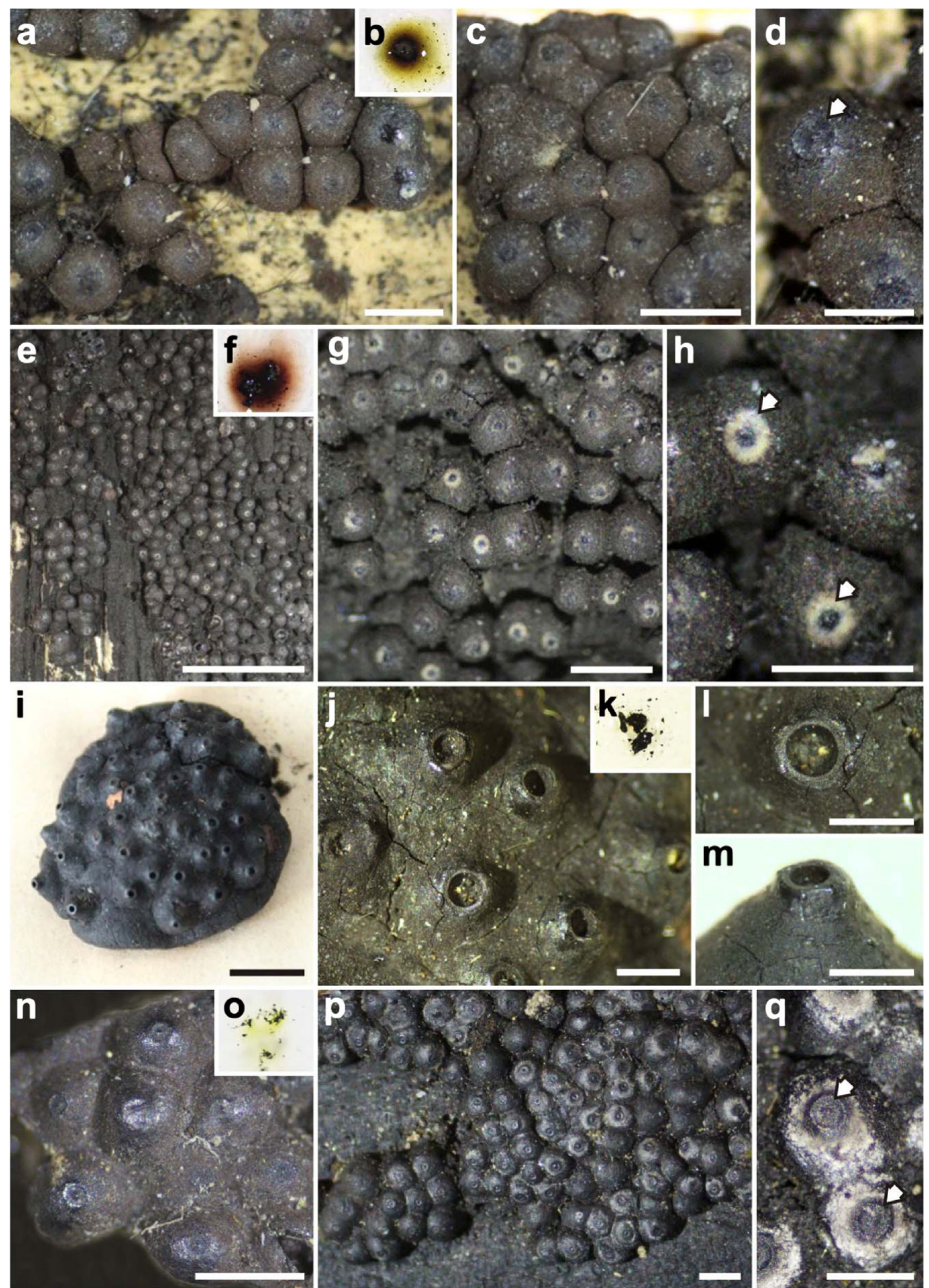

Fig. 8 Annulohypoxylon and Jackrogersella spp.: a, b, c, d: Jackrogersella gombakense (holotype, WSP 69847). e, f, g, h: J. ilanense (holotype, WSP 69730). i, j, k, l, m: A. hians (holotype, $\mathrm{K}(\mathrm{M})$ 123,168). n, o, p, q: A. michelianum (n, o: type, BPI 716551; p, q: STMA 16011). a, e, i, p: Stromatal habit b, f, k, o: KOH-extractable pigments. $\mathbf{c}, \mathbf{g}, \mathbf{j}, \mathbf{n}$ : Details of stromatal surface with perithecial mounds and ostiolar discs. $\mathbf{d}, \mathbf{h}, \mathbf{l}, \mathbf{q}$ : Ostiolar discs in close-up (arrows). m: Lateral view of an ostiolar disc. Scale is indicated by bars $(\mathbf{a}, \mathbf{c}, \mathbf{g}, \mathbf{j}, \mathbf{l}$, $\mathbf{m}, \mathbf{n}, \mathbf{p : ~} 1 \mathrm{~mm}$. d, h, q: $0.5 \mathrm{~mm}$. e, i: $5 \mathrm{~mm}$ ) 
7a. Apparently restricted to Fagus, ascospores 9$11(-12) \times 4-5 \mu \mathrm{m}$, germ slit spore-length. J. cohaerens

7b. Mainly associated with Alnus, Betula and Corylus, widespread; ascospores $8.5-12.9 \times 3.5-5 \mu \mathrm{m}$ with germ slit less than spore-length .J. multiformis

\section{Emended description of Annulohypoxylon}

The segregation of Jackrogersella affords an emendation of the concept of Annulohypoxylon, which is given further below.

Annulohypoxylon Y.-M. Ju, J.D. Rogers \& H.-M. Hsieh, Mycologia 97(4): 855 (2005) emend L. Wendt, Sir, Kuhnert \& M. Stadler.

Type species: Annulohypoxylon truncatum (Starbäck) Y.M. Ju, J.D. Rogers \& H.M. Hsieh 2005.

$\equiv$ Hypoxylon truncatum (Schwein: Fr.) J. H. Miller, Trans. Brit. Mycol. Soc. 17: 130. 1932.

$\equiv$ Sphaeria truncata Schwein., Schriften Naturf. Ges. Leipzig 1: 44. 1822; Schwein.: Fr., Syst. Mycol. II, p. 442.1823; non Bolton, 1789; nec (Pers.: Fr.) Fr., 1823.

$\equiv$ Hypoxylon annulatum (Schwein.: Fr.) Mont. var. truncata (Schwein.: Fr.) Starb., Bih. Kongl. Svenska Vetensk-Akad. Handl. 27, 3: 8. 1901.

$\equiv$ Sphaeria truncatula Schwein., Trans. Amer. Philos. Soc., n. ser., 4: 210.1832; non Fr: Fr., 1832 [nom. rejie., ICBN Arts. 13.1 (d) \& 63.1].

= Sphaeria annulata Schwein.: Fr. var. depressa Fr.: Fr., Elench. Fung. II, p. 64.1828.

$\equiv$ Hypoxylon annulatum (Schwein.: Fr.) Mont. var. depressum (Fr.: Fr.) Mont., Ann. Sci. Nat. Bot., ser. II, 13: 352. 1840; [nom. inval., ICBN Art. 43].

Emended generic description (modified from Hsieh et al. 2005).

Sexual morph. Stromata effused-pulvinate, pulvinate, glomerate, discoid, hemispherical, or spherical, solitary or confluent, attached to substrate with a broad base; surface light- or dull-colored, usually blackened with age, pruinose or polished, planar or with inconspicuous to conspicuous perithecial mounds; waxy or carbonaceous tissue immediately beneath surface and between perithecia, with $\mathrm{KOH}$ extractable pigments in most cases; the tissue below the perithecial layer inconspicuous, conspicuous, or relatively large, dark brown to black, persistent. Perithecia spherical, obovoid, or less frequently tubular, monostichous, with carbonaceous stromatal layer surrounding individual perithecia. Ostioles higher than the level of stromatal surface, with the ostiolar openings papillate to conical papillate, with conspicuous to hardly noticeable discs formed by dehiscence of surrounding tissue. Asci eight-spored, cylindrical, stipitate, persistent, with apical ring discoid, amyloid or infrequently inamyloid, distinct. Ascospores light- to dark-colored, unicellular in both mature and immature ascospores, ellipsoid or shortly fusoid, inequilateral, slightly inequilateral or nearly equilateral, with acute, narrowly rounded, or broadly rounded ends, with a germ slit spore-length to much less than spore-length on the convex side or less frequently on the flattened (side; absent in A. macrosporum;) perispore dehiscent or indehiscent in $10 \%$ $\mathrm{KOH}$, when dehiscing, with a thickened area visible at the position of ca. 1/3 ascospore length on the same side as the germ slit; epispore smooth. Asexual morph. Anamorph produced on young stromata, or in artificial culture, conidiophores mononematous, usually macronematous, hyaline or colored, smooth or roughened, with nodulisporium-like or rarely periconiella-like branching patterns (as defined in $\mathrm{Ju}$ and Rogers 1996), with holoblastic conidiogenesis.

\section{Other currently accepted species of Annulohypoxylon}

Annulohypoxylon albidiscum J.F. Zhang, J.K. Liu, K.D. Hyde \& Z.Y. Liu 2016.

Annulohypoxylon annulatum (Schwein.) Y.M. Ju, J.D. Rogers \& H.M. Hsieh 2005.

$\equiv$ Sphaeria annulata Schwein.1825.

$\equiv$ Hypoxylon annulatum (Schwein.) Mont. 1850.

= Sphaeria marginata Schwein. 1832.

$\equiv$ Hypoxylon marginatum Berk. 1860.

= Hypoxylon vernicosum Ellis \& Everh. 1897.

= Hypoxylon marginatum var emarginata Theiss. 1909.

= Hypoxylon circumscribum Lloyd 1924.

Annulohypoxylon apiahynum (Speg.) Hladki \& A.I. Romero 2009.

Annulohypoxylon archeri (Berk.) Y.M. Ju, J.D. Rogers \& H.M. Hsieh 2005.

$\equiv$ Hypoxylon archeri Berk. 1859 .

Annulohypoxylon areolatum (Sacc.) Sir \& Kuhnert 2016. $\equiv$ Rosellinia areolata Sacc.1913.

= Annulohypoxylon bovei var. microsporum (J.H. Mill.)

Y.M. Ju, J.D. Rogers \& H.M. Hsieh 2005.

$\equiv$ Hypoxylon bovei Speg. var. microsporum J. H. Miller 1961.

= Hypoxylon marginatum (Schwein.) Berk. var. mammiforme Rehm 1916.

= Hypoxylon chalybeum Berk. \& Broome var. effusum Sacc.1928.

Annulohypoxylon atroroseum (J.D. Rogers) Y.M. Ju, J.D. Rogers \& H.M. Hsieh 2005. 
Fig. 9 Characteristic secondary metabolites of Annulohypoxylon vs. Jackrogersella: Compounds in blue have so far not been found in any other organism but are ubiquitous in Jackrogersella. Compounds in red are frequently or exclusively encountered in Annulohypoxylon, but are apparently absent in Jackrogersella. The only common stromatal metabolite of both genera, and of many other Hypoxylaceae is BNT (printed in violet). Hinnulin (likewise printed in violet) is an apparently specific metabolite that was found in stromata of

A. purpureopigmentum and J. minutella<smiles>O=C1CC2C(=C3CCC(=O)C4CC(=O)c5c(O)ccc2c5C34O)c2cccc(O)c21</smiles><smiles>O=C1C=C(c2ccc(O)c3c(O)cccc23)[C@H](O)c2cccc(O)c21</smiles>
daldinone $\mathrm{A}$<smiles>C=CC(C)(C)c1[nH]c2ccccc2c1C1=C(O)C(=O)C(c2c[nH]c3ccccc23)=C(OC)C1=O</smiles>

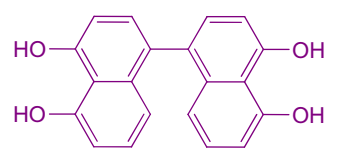

BNT<smiles>O=C1C=C(O)C(=O)c2c1ccc(-c1ccc(O)c3c(O)cccc13)c2O</smiles>

hinnulin $\mathrm{A}$

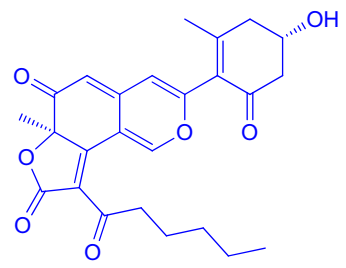

minutellin $B$

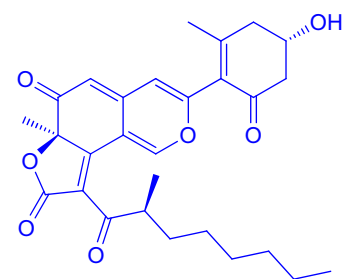

cohaerin D

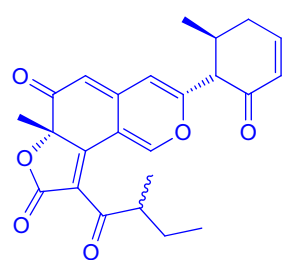

multiformin B
三 Hypoxylon atroroseum J.D. Rogers 1981.

Annulohypoxylon bahnphadengense J. Fourn. \& M. Stadler 2010.

Annulohypoxylon bovei (Speg.) Y.M. Ju, J.D. Rogers \& H.M. Hsieh 2005.

E Hypoxylon bovei Speg. 1887 .

= Hypoxylon ophthalmidium Mont. 1850 .

= Hypoxylon annulatum var. patagoniensis Henn. 1900 .

= Rosellinia moelleriana Henn. 1902.

= Hypoxylon marginatum var mammiforme Rehm 1916.

= Hypoxylon chalybaeum var. effusum Sacc. 1928.

Annulohypoxylon caravellense J. Fourn. \& Lechat 2016.

Annulohypoxylon discophorum (Penz. \& Sacc.) Y.M. Ju, J.D. Rogers \& H.M. Hsieh 2005.

Annulohypoxylon elevatidiscum (Y.M. Ju, J.D. Rogers \& H.M. Hsieh) Y.M. Ju, J.D. Rogers \& H.M. Hsieh 2005.

Annulohypoxylon fulvum J. Fourn. \& Lechat 2016.

Annulohypoxylon hemicarpum Jad. Pereira, J.D. Rogers \& J.L. Bezerra 2010.
Annulohypoxylon leptascum (Speg.) Y.M. Ju, J.D. Rogers \& H.M. Hsieh 2005.

$\equiv$ Hypoxylon leptascum Speg. 1889.

Annulohypoxylon macrosporum (Y.M. Ju \& J.D. Rogers) Sir \& Kuhnert 2016 .

$\equiv$ Annulohypoxylon leptascum var. macrosporum (Y.M. Ju \& J.D. Rogers) Y.M. Ju, J.D. Rogers \& H.M. Hsieh 2005.

Annulohypoxylon macrodiscum Jad. Pereira, J.D. Rogers \& J.L. Bezerra 2010.

Annulohypoxylon maeteangense J. Fourn. \& M. Stadler 2010.

Annulohypoxylon massivum Sir \& Kuhnert 2016.

Annulohypoxylon microcarpum (Penz. \& Sacc.) Y.M. Ju, J.D. Rogers \& H.M. Hsieh 2005.

三 Hypoxylon microcarpum Penz. \& Sacc. 1898.

Annulohypoxylon microdiscum (Y.M. Ju, J.D. Rogers \& H.M. Hsieh) Sir \& Kuhnert 2016.

三 Annulohypoxylon moriforme var. microdiscum (Y.M. Ju \& J.D. Rogers) Y.M. Ju, J.D. Rogers \& H.M. Hsieh 2005. 
Fig. 10 Characteristic secondary metabolites of Pyrenopolyporus (red and green) and some other metabolites that occur in Daldinia, Hypoxylon, and other genera of the Hypoxylaceae. Compounds in brown are typical of Daldinia and allies. 5methylmellein occurs in Hypoxylon and Pyrenopolyporus, but is apparently lacking in Daldinia and allied genera (cf. Bitzer et al. 2008). 8-methoxy-1naphtol is found in Daldinia and Pyrenopolyporus. Compounds depicted in the yellow highlighted square are found in stromata, while the other metabolites are produced by the mycelial cultures<smiles>COc1cccc2cccc(O)c12</smiles>

8-methoxy-1naphthol<smiles>Cc1cc(=O)c2c(O)cccc2o1</smiles>

5-hydroxy-2methyl-chromone<smiles>CCCC(=O)C1=C(O)CC(O)CC1=O</smiles>
Ab-5046-A

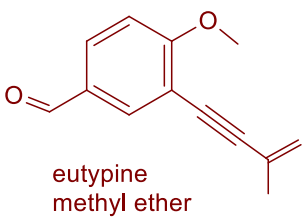<smiles>O=C1CC(O)C(O)c2cccc(O)c21</smiles>

3-hydroxyisosclerone<smiles>Cc1ccc(O)c2c1CC(C)OC2=O</smiles><smiles>CC(C)=CCc1ccc2[nH]cc(C3=C(O)C(=O)C(c4c[nH]c5ccc(CC=C(C)C)cc45)=C(O)C3=O)c2c1</smiles><smiles>Oc1cccc2c(-c3ccc(O)c4c(O)cccc34)ccc(O)c12</smiles>

BNT

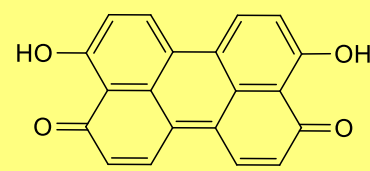

4,9-dihydroxyperylene3,10-quinone<smiles>O=C1C[C@H]2c3ccc(O)c4c3[C@H](CCC4=O)[C@H]2c2cccc(O)c21</smiles><smiles>O=C1C(c2ccc(O)c3c(O)cccc23)=CC(=O)c2c(O)cccc21</smiles>

Stromatal metabolites
Annulohypoxylon moriforme (Henn.) Y.M. Ju, J.D. Rogers \& H.M. Hsieh 2005.

三 Hypoxylon moriforme Henn. 1896.

= Hypoxylon effusum var. viridarii Sacc. 1921.

= Hypoxylon heveae P. Joly 1965.

Annulohypoxylon moriforme var. macrosporum Hladki \& A.I. Romero 2009.

Annulohypoxylon nitens (Ces.) Y.M. Ju, J.D. Rogers \& H.M. Hsieh 2005.

$\equiv$ Rosellinia nitens Ces. 1872

三 Hypoxylon nitens (Ces.) Y.M. Ju \& J.D. Rogers 1996.

= Hypoxylon chalybaeum Berk. \& Broome 1873.

= Hypoxylon chalybaeum var. congestum Ces. 1879 .

= Hypoxylon chalybaeum var. minor Ces. 1879 .

Annulohypoxylon nouraguense J. Fourn. \& Lechat 2016.

Annulohypoxylon orientale Lar.N. Vassiljeva \& S.L. Stephenson 2014.
Annulohypoxylon pouceanum (Berk. \& Cooke) Y.M. Ju, J.D. Rogers \& H.M. Hsieh 2005.

三 Hypoxylon pouceanum Berk. \& Cooke 1883 .

Annulohypoxylon pseudostipitatum (Y.M. Ju \& J.D. Rogers) Y.M. Ju, J.D. Rogers \& H.M. Hsieh 2005.

$\equiv$ Hypoxylon pseudostipitatum Y.M. Ju \& J.D. Rogers 1996.

Annulohypoxylon purpureonitens (Y.M. Ju \& J.D. Rogers) Y.M. Ju, J.D. Rogers \& H.M. Hsieh 2005.

三 Hypoxylon purpureonitens Y.M. Ju \& J.D. Rogers 1996.

Annulohypoxylon pyriforme (Y.M. Ju \& J.D. Rogers) Y.M. Ju, J.D. Rogers \& H.M. Hsieh 2005.

三 Hypoxylon pyriforme Y.M. Ju \& J.D. Rogers 1996.

Annulohypoxylon ramulorum J. Fourn. \& Lechat 2016.

Annulohypoxylon splendens J. Fourn. \& Lechat 2016. 


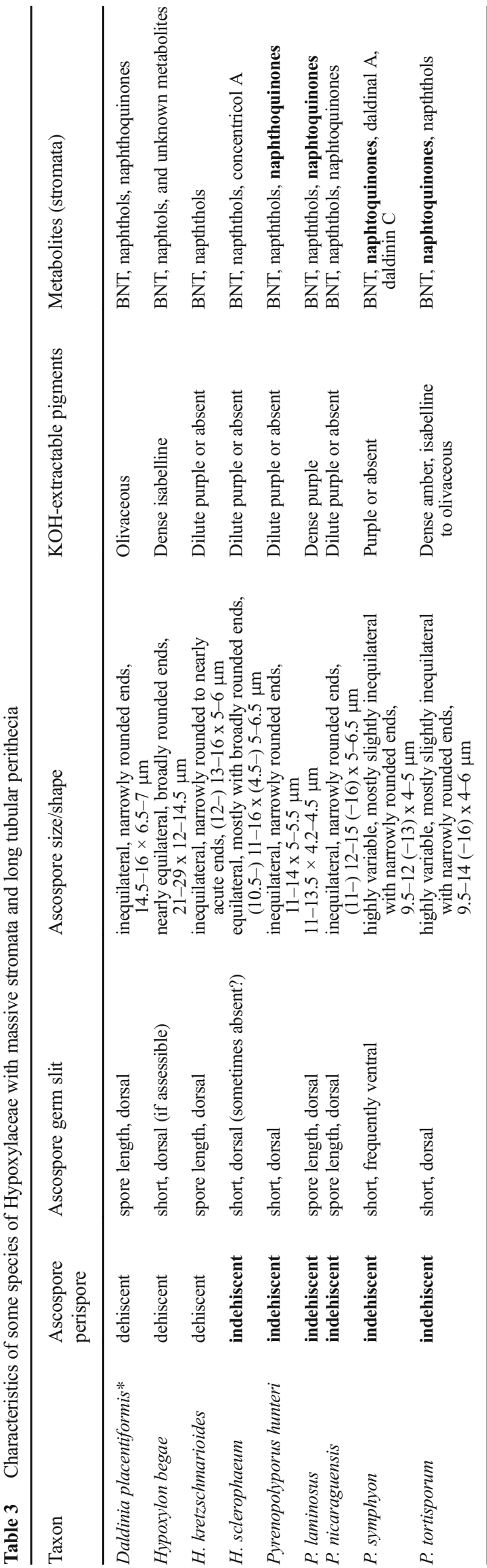

Annulohypoxylon squamulosum (Y.M. Ju, J.D. Rogers \& H.M. Hsieh) Y.M. Ju, J.D. Rogers \& H.M. Hsieh 2005.

Annulohypoxylon stygium (Lév.) Y.M. Ju, J.D. Rogers \& H.M. Hsieh 2005.

$\equiv$ Sphaeria stygia Lév. 1846 .

$\equiv$ Hypoxylon stygium (Lév.) Sacc. 1882.

$\equiv$ Nummularia stygia (Lév.) Lloyd 1924.

= Sphaeria osculosa Pers. 1827.

= Hypoxylon stigmoideum Ces. 1879 .

= Hypoxylon platystomum Ellis \& Everh. 1892.

= Nummularia rufa Ellis \& Everh. 1893.

= Hypoxylon bogoriense Höhn. 1909 .

= Nummularia annulata Rehm 1913.

= Hypoxylon punctatum Petch 1924 .

Annulohypoxylon subeffusum (Speg.) Hladki \& A.I. Romero 2009.

Annulohypoxylon subnitens J. Fourn. \& Lechat 2016.

Annulohypoxylon substygium Sir \& Kuhnert 2016.

Annulohypoxylon thailandicum Daranag. \& K.D. Hyde 2015. ${ }^{1}$

Annulohypoxylon thouarsianum (Lév.) Y.M. Ju, J.D. Rogers \& H.M. Hsieh 2005.

三Sphaeria thouarsiana Lév. 1846.

$\equiv$ Daldinia thouarsiana (Lév.) Sacc. 1882.

三 Hemisphaeria thouarsiana (Lév.) Kuntze 1898.

三 Hypoxylon thouarsianum (Lév.) Lloyd 1919.

= Hypoxylon malleolus Berk. \& Ravenel 1875 .

$\equiv$ Daldinia malleola (Berk. \& Ravenel) Kauffman 1930.

= Hypoxylon occidentale Ellis \& Everh. 1894.

= Hypoxylon amaniense Henn. 1905.

= Hypoxylon gilletianum Sacc. 1906 .

$\equiv$ Hypoxylon thouarsianum var. gilletianum (Sacc.) J.H. Mill. 1961.

= Hypoxylon africanum Van der Byl 1928 .

Annulohypoxylon thouarsianum var. macrosporum (San Martín, Y.M. Ju \& J.D. Rogers) Y.M. Ju, J.D. Rogers \& H.M. Hsieh 2005.

$\equiv$ Hypoxylon thouarsianum var. macrosporum San Martín, Y.M. Ju \& J.D. Rogers 1996.

Annulohypoxylon urceolatum (Rehm) Y.M. Ju, J.D. Rogers \& H.M. Hsieh 2005.

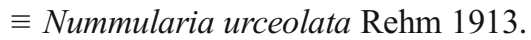

${ }^{1}$ The type material of this species seems to be lost (cf. Kuhnert et al. 2016). 
$\equiv$ Hypoxylon urceolatum (Rehm) Y.M. Ju \& J.D. Rogers 1996.

= Hypoxylon olivaceum Petch 1924.

= Hypoxylon denudatum Petch 1924 .

Annulohypoxylon violaceopigmentum Sir \& Kuhnert 2016.

Annulohypoxylon viridistratum Sir \& Kuhnert 2016.

Annulohypoxylon yungensis Sir, Kuhnert, Hladki \& A.I. Romero 2016.

Taxa of Annulohypoxylon with doubtful affinities (Fig. 9)

Annulohypoxylon hians (Berk. \& Cooke) Y.M. Ju, J.D.

Rogers \& H.M. Hsieh 2005.

$\equiv$ Hypoxylon hians Berk. \& Cooke 1883.

= Hypoxylon rostratum Lloyd 1920.

Note: After re-examination of the type material, we believe that this species does not really fit into the concept of Annulohypoxylon by Hsieh et al. (2005) because the morphology of the ostiolar discs (Fig. 8) seems to be quite different. However, it still resembles Annulohypoxylon more than any other xylariaceous genus. As no information on the conidial state and no molecular data are available, we prefer to retain it ad interim in Annulohypoxylon.

Annulohypoxylon purpureopigmentum Jad. Pereira, J.D. Rogers \& J.L. Bezerra 2010.

Notes: This species was included in the phylogeny of Kuhnert et al. (2016) based on material from French Guiana, whereas the holotype is from Brazil. The phylogeny revealed that its ITS sequence was located on a branch well outside the clade comprising what is here regarded as Jackrogersella, whereas the TUB2 sequence was nested inside the "Jackrogersella clade" (i.e. the clade comprising the species that are moved to the new genus), but on a rather long branch. Since the French Guianean specimen, as well as the holotype, were not found to contain cohaerins or multiformins as stromatal pigments, it is maintained in Annulohypoxylon for the time being, but its taxonomy needs further study.

Annulohypoxylon michelianum (Ces. \& De Not.) Y.M. Ju, J.D. Rogers \& H.M. Hsieh 2005.

Notes: This species (for a recent treatment see Rubio \& De la Pena 2016) occupies a separate clade in our phylogeny, chemotaxonomically belongs to Jackrogersella and its stromatal metabolites are the same as in the latter genus. A new genus would actually be justified from the outcome of our molecular phylogeny. However, we did so far not find any morphological trait to segregate it from either Annulohypoxylon or Jackrogersella. We also were unable to observe any conidiogeneous structures in the two cultures we obtained, both of which did not dfferentiate much. For these reasons, we maintain it in Annulohypoxylon for the time being, until the phylogenetic position has been verified by additional studies.

\section{Resurrection of Pyrenopolyporus}

The current phylogeny revealed a sister clade Py of Daldinia and allies that was comprised of three representatives of a peculiar group of tropical xylariaceous fungi that are characterised by massive, peltate to discoid stromata and long tubular perithecia and have been assigned to Hypoxylon sclerophaeum by Miller (1961). Ju and Rogers (1996) segregated this species complex and resurrected various species that had been lumped by Miller (1961) under the aforementioned name. Various mycologists previously discussed that these species might represent intermediate forms to the genus Daldinia, whose species mostly differ in having stromata with conspicuous internal concentric zones (cf. Theissen 1909, Ju et al. 1997, Stadler et al. 2014a). Indeed, there are two species in the latter genus that deviate from typical Daldinia with respect to their stromatal anatomy: Daldinia placentiformis (Stadler et al. 2014) and the recently described D. korfii (Sir et al. 2016b).

These species show close similarities with respect to their stromatal morphology to Daldinia placentiformis, but deviate in their ascospore morphology and, where this is known, also in their anamorphic branching pattern and the production of secondary metabolites in their stromata and cultures (Bitzer et al. 2008). For instance, cultures of what is here regarded as Pyrenopolyporus have a characteristic virgariella-like conidial stage and produce cochliodinol and 8-methoxy-1-naphtol but no chromones, eutypinols and phytotoxic lactones of the " $\mathrm{Ab}$ 5046" type, which are characteristic for Daldinia and other taxa included in clade $\mathbf{D}$ of the current phylogenetic tree. The characteristic metabolites from their stromata and cultures are depicted in Fig. 10. We have also checked the stromata of several specimens and found that they contain BNT, hypoxylone (Bodo et al. 1983) and yet unidentified metabolites that are not present in $D$. placentiformis, which mainly contains daldinone A. One of the species included in this group, H. polyporus, has previously been validly described as Pyrenopolyporus hunteri by Lloyd (1917), meaning that the name is available. We think that it is better to resurrect this genus, rather than erect a new one; in particular as the name Pyrenopolyporus matches very well the macroscopic appearance of these fungi, whose stromata indeed resemble a polyporaceous basidiomycete. An account of morphological features of Pyrenopolyporus species and morphologically similar representatives of Hypoxylon and Daldinia is given in Table 3.

Pyrenopolyporus Lloyd, Mycological Writings 5 (50): 706 (1917), emend L. Wendt, Sir \& M. Stadler 
Differs from the genera Daldinia and Hypoxylon by producing cochliodinol in its cultures. Differs from the genus Daldinia by having ascospores with indehiscent perispores that are not broadly ellipsoid with rounded ends and by forming stromata with a homogeneous context and long tubular perithecia at the same time. Differs from all other genera of the Hypoxylaceae by having massive stromata with long tubular perithecia that are lacking conspicuous ostiolar rings.

Sexual morph. Stromata discoid, peltate, hemispherical, convex on top, centrally attached to substrate, sessile or with a short and broadly attached central base, with crenate to entire margins, separate to coalescent; surface colored, planar or with inconspicuous to conspicuous perithecial mounds; granules black or colored immediately beneath surface, with or without $\mathrm{KOH}$-extractable pigments, the tissue below the perithecia layer massive, soft-textured. Perithecia long tubular. Ostioles lower than the stromatal surface or slightly higher than the stromatal surface, umbilicate. Asci eight-spored, cylindrical, stipitate, persistent to evanescent, with apical ring discoid to cuneate, amyloid, distinct. Ascospores light- to dark-colored, unicellular in both mature and immature ascospores, ellipsoid-inequilateral, ellipsoid, slightly inequilateral, highly variable or irregularly shaped, narrowly rounded ends, with straight to rarely slightly sigmoid germ slit much less than spore-length or nearly spore-length or spore-length, on the convex side rarely in flattened side; perispore indehiscent in $10 \% \mathrm{KOH}$, epispore smooth. Asexual morph. Anamorph produced in artificial culture; conidiphores mononematous, usually macronematous, generally hyaline, smooth or finely roughened, with virgariella-like branching patterns (as defined in Ju and Rogers 1996; so far only observed in Pyrenopolyporus hunteri and P. nicaraguensis), with holoblastic conidiogenesis.

Type species: Pyrenopolyporus hunteri Lloyd, Mycol. Writ. 5 (Letter 49): 705 (1917).

= Hypoxylon polyporus (Starbäck) Y.M. Ju \& J.D. Rogers [as “polyporum"], Mycol. Mem. 20: 171 (1996).

$\equiv$ Penzigia polyporus Starbäck, Ark. Bot. 5(no. 7): 32 (1905).

Typus: Ghana, Coomassee, T. Hunter as Nummularia suborbicularis var. cookeana, in Lloyd herb. no. 10732 (BPI 715054 - holotype of Pyrenopolyporus hunteri).

Epitype (designated here): Ivory Coast, Akriba, Foret de Bianco 23 July 2000, A. Verbeken \& Solange M. Verbeken (GENT 2000-32, MBT 374768), ex-epitype culture MUCL 52673.

Further specimens examined: Argentina, Jujuy, Quinta near Laguna de la Brea, R.E. Fries 81 (S - type of Penzigia polyporus). Jujuy province, dept. Ledesma, Calilegua Natinal Park, La Lagunita trail, 11 May 2012, Sir \& Hladki 016 (LIL). Australia, Endeavor River, Persiel, ex herb. M.C. Cooke as
H. placentiforme, $\mathrm{K}(\mathrm{M})$ 142,628. Brazil, Rio Grande do Sul, J. Rick in Lloyd herb. no. 11323, as H. broomeianum, det. Miller (1961) as H. sclerophaeum and Ju and Rogers (1996) as $H$. polyporum (BPI 716342). Exact locality unknown, J. Rick as Ustulina sp. in Lloyd herb. no. 10735, det. Miller (1961) as H. sclerophaeum and Ju and Rogers (1996) as H. polyporum (BPI 716359). Democratic Republic of Congo, Distr. Forestier Central: Parc National Albert (800 m), 29 Oct 1955, G. F. de Witte A2836, det. Ju and Rogers (1996) as H. polyporum (BR-Myc 035818,25). Distr. Ecuateur: Koli, Eala, primary forest, 1930, P. Staner 499, det. Dennis as H. sclerophaeum and Ju and Rogers (1996) as H. polyporum (BR-Myc 035819,26); Exact locality unknown, "Congo-Kinshasa, Mar. 1972, J. Rameloo 41/JRZ (GENT); "Congo Belge", de Witte 250, det. Dennis as H. sclerophaeum, K(M) 14,437. Malaysia, Sabah, Ulu Segama, Damum Valley, on rotten log, 25 Nov 1985, B. M. Spooner 154, as H. sclerophaeum, K(M) 13,560. Nicaragua, Ometepe, wood, Feb 1893, B. Shimek, Cent. Amer. Fung. 26A, det. Ju and Rogers (1996) as H. polyporum (NY). Philippines, Laguna (Luzon Island), Mt. Maquiling, near Los Baños, Dec 1913, C. F. Baker, Fung. Malay. 542, det. Miller (1961) as H. sclerophaeum and Ju and Rogers (1996) as H. polyporum "BPI 591029" [BPI 591399; duplicate in K(M) 140,164]; Mt. Maquiling, wood, Dec 1913, C. F. Baker 4308 as H. placentiforme, det. Ju and Rogers (1996) as H. polyporum (S); same locality, Diplodiscus paniculatus, 10 Oct 1920, V. Marlao in herb O. Reinking, det. J. H. Miller as H. sclerophaeum (BPI 591400); Rizal, Sep 1915, H. S. Yates in Lloyd herb. no. 11503 (BPI 716657). USA, Florida: Winter Park, 22 Jan 1945, C. L. Shear as H. sclerophaeum (BPI 591412). US Virgin Islands, Saint John: Cinnamon Bay (Ruins), Loop Trail, branch of wood, 28 Jan 1994, D. J. Lodge STJ 157, as H. polyporum.

\section{Additional accepted species in Pyrenopolyporus}

Pyrenopolyporus laminosus (J. Fourn., Kuhnert \& M. Stadler) M. Stadler, Kuhnert \& L. Wendt, comb. nov.

MB 819738

Basionym: Hypoxylon laminosum J. Fourn., Kuhnert \& M. Stadler, Fungal Diversity 64: 189 (2014).

Type: French West Indies, Martinique, Schoelcher, rivière Case Navire, at base of dead standing culms of bamboo, 28 Aug 2010, J. Fournier MJF10181 (LIP, ex-type culture MUCL 53305 and CBS 129032).

Pyrenopolyporus nicaraguensis (Ellis \& Everh.) M. Stadler, Kuhnert \& L. Wendt, comb. nov. $\quad$ MB819737

Basionym: Hypoxylon nicaraguense Ellis \& Everh., in Smith, Bull. Lab. Nat. Hist. Iowa State Univ. 2: 407 (1893).

= Ustulina decipiens $\mathrm{Rehm}$, ined. (fide Ju and Rogers 1996). 
Type: Nicaragua, Castillo Viejo, 02 Mar 1893, B. Shimek, Cent. Amer. Fung. 26B, (NY, Lectotype;BPI 590953, isolectotype).

Pyrenopolyporus symphyon (Möller) M. Stadler, Kuhnert \& L. Wendt, comb. nov.

MB 819740

Basionym: Hypoxylon symphyon Möller, Bot. Mitt. Trop. 9: 308 (1901).

Type: Brazil, Sta. Catharina, Blumenau, June 1892, A. Möller, (S).

Pyrenopolyporus tortisporus (Y.M. Ju \& J.D. Rogers) M. Stadler, Kuhnert \& L. Wendt, comb. nov. $\quad$ MB 819739

Basionym: Hypoxylon tortisporum Y.M. Ju \& J.D. Rogers, Mycol. Mem. 20: 196 (1996).

Type: Indonesia, North Sulawesi, Dumoga-Bone Natl. Park, vic. of "Camp 1440", Oct 1985, G. J. Samuels 2095 (NY - holotype; BO; WSP 69643 -isotypes).

Notes: The "new" old genus was resurrected and segregated from its allies based on a combination of molecular phylogenetic and chemotaxonomic traits that helped substantially to interpret its salient morphological features. However, this group of hypoxyloid pyrenomycetes actually has been regarded as an intermediate form between Hypoxylon and Daldinia for a very long time (cf. Bitzer et al. 2008). The peculiar secondary metabolite profiles with cochliodinol production in the cultures discriminate it from Daldinia, where the current generic concept includes species that have massive stromata with long tubular perithecia that are lacking the typical internal concentric zones on which the latter genus was originally based. Cochliodinol was also not detected in various species of Hypoxylon and allies studied previously (Bitzer et al. 2008). However, the ITS-based phylogeny of the aforementioned studies did not yet provide conclusive data that would justify the segregation of Pyrenopolyporus from Hypoxylon. This has now been accomplished as additional data from the studies of Kuhnert et al. (2014a) and Sir et al. (2016a, b) became available.

The genus Pyrenopolyporus may be amended in the future as there are various species in Hypoxylon that do not form the characteristic discoid or peltate stromata that are characteristic for the genus, but appear similar in their micromorphological features. These species (e.g. H. sclerophaeum) are only known from old stromatal collections. Their conidiogeneous structures remain to be studied, and no DNA sequence data are available for these species as yet. They will need to be collected and cultured to allow for an assessment of their anamorphic morphology and their phylogenetic position. On the other hand, there are other species in Hypoxylon with massive stromata and long tubular perithecia, which seem to belong to different lineages in the Hypoxylaceae. This concerns Hypoxylon kretzschmarioides, one of the species that is morphologically similar (cf. Ju and Rogers
1996). A re-examination of the holotype material has revealed that the perispore is dehiscent and it also did not show the characteristic HPLC profile that is common in all species of Pyrenopolyporus (J. Fournier \& M.S., unpublished). In accordance with its purple stromatal pigments, BNT was detected as a major stromatal metabolite, but no hypoxylone was found. Possibly, H. kretzschmarioides, which shows strong morphological similarities to Daldinia placentiformis, will eventually be transferred to the sister genus Daldinia. Another widely unknown species with massive stromata is Hypoxylon begae Y.M. Ju \& J.D. Rogers. A culture of the latter has been included in the molecular phylogeny by Hsieh et al. (2005) where it showed affinities to $H$. anthochroum rather than to what is here regarded as Pyrenopolyporus.

\section{Dichotomous key to the species of Pyrenopolyporus}

1a. Ascospores highly variable in shape, ellipsoid to slightly ellipsoid-inequilateral ............................................................ 2 1b. Ascospores less variable in shape, ellipsoidinequilateral ......................................................... 3 2a. KOH-extractable pigments purple, ascospores with straight germ slit less than spore length frequently on the more flattened side P. symphyon

2b. KOH-extractable pigments without purple shades, ascospores with straight to slightly sigmoid germ slit much less than spore length on the more convex side .........P. tortisporus 3b. Ascospores pale brown to light brown, with straight germ slit much less than spore-length .....

..P. hunteri

3a. Ascospores brown to dark brown, with a straight germ slit spore-length

4a. Perithecia $0.8-1.5 \mathrm{~mm}$ high, ascospores (11.5)12$15(-16) \times 5-6.5 \mu \mathrm{m}$..................................... nicaraguensis 4b. Perithecia 0.75-0.9 mm high, ascospores 11-13.5 × 4.2$4.5 \mu \mathrm{m}$ P. laminosus

\section{Discussion}

The present study attempted to segregate the large and heterogeneous family Xylariaceae based on polyphasic taxonomic methodology, and to provide a concept that will be feasible to include the numerous non-stromatic taxa that are now being recognised to have close phylogenetic affinities to the "Large Pyrenomycetes" that were historically the first members of the Xylariales known to science. Our molecular phylogeny agrees with the results of several concurrent studies focusing on different taxa. It ultimately proves that the traditional segregation of families in the Xylariomycetideae based on ascal and ascospore morphology as major discriminative criteria is artificial. This could actually have 
been predicted, since many xylariaceous taxa have an aberrant ascal and ascospore morphology, anyway. Examples are the lack of amyloid ascal plugs in many species of Hypoxylon that are otherwise morphologically very similar to the "typical" members of the genus, and the "cleistocarpous" genera Phylacia, Pyrenomyxa, Rhopalostroma, and Thamnomyces.

The current classification should be stable and allows more easily to place new taxa in one of the families that have been defined in a phylogenetic context. It will of course be necessary to (re-) collect, culture and sequence many taxa that are only known from old descriptions and herbarium material in order to verify their phylogenetic position. In some cases, (in particular for Hypoxylon and Daldinia and their respective relatives) a lot of work remains to be done. For instance, it will be necessary to sample further taxa and even generate sequence data of other DNA loci in order to attain a higher resolution. In any case, the use of a combination of protein coding genes and rDNA has been a great advantage in connecting the phylogeny with historical morphological concepts.

Acknowledgements This project has received funding from the European Union's Horizon 2020 research and innovation programme (RISE) under the Marie Skłodowska-Curie grant agreement No 645701, Project acronym "GoMyTri"; lead beneficiaries JJL and MS). LW gratefully acknowledges a PhD stipend from the Hannover School for Biomolecular Drug Research (HSBDR). The German Academic Exchange Service (DAAD) and the Argentina Ministerio de Ciencia, Tecnología e Innovación Productiva are gratefully acknowledged for an academic exchange grant to AIH and EBS. We gratefully acknowledge support from the curators of various international herbaria, above all, B, BPI, FH, LIL, LPS, K, M, NY, S and WSP, who provided important specimens for the present study. We are deeply indebted to Markus Scholler (KR) for realising international loan transactions on our behalf and to all our co-authors of previous papers on the Xylariaceae from which the majority of the strains, selected for the current study, has been derived. Manfred Rohde is thanked for SEM recordings. Philine Wotsch and Anke Skiba are thanked for expert technical assistance.

Open Access This article is distributed under the terms of the Creative Commons Attribution 4.0 International License (http:// creativecommons.org/licenses/by/4.0/), which permits unrestricted use, distribution, and reproduction in any medium, provided you give appropriate credit to the original author(s) and the source, provide a link to the Creative Commons license, and indicate if changes were made.

\section{References}

Barr ME, Rogers JD, Ju YM (1993) Revisionary studies in the Calosphaeriales. Mycotaxon 48:529-535

Bills GF, Gonzalez-MenendezV MJ, Platas G, Fournier J, Persoh D, Stadler M (2012) Hypoxylon pulicicidum sp. nov. (Ascomycota, Xylariales), a pantropical insecticide-producing endophyte. PLoS One 7:e46687

Bitzer J, Læssøe T, Fournier J, Kummer V, Decock C, Tichy HV, Piepenbring M, Peršoh D, Stadler M (2008) Affinities of Phylacia and the daldinoid Xylariaceae, inferred from chemotypes of cultures and ribosomal DNA sequences. Mycol Res 112:251-270
Bodo B, Tih RG, Davoust D, Jacquemin H (1983) Hypoxylone, a naphthyl naphthoquinone pigment from the fungus Hypoxylon sclerophaeum. Phytochemistry 22:2579-2581

Bulliard P (1791) Histoire des champignons de la France. Paris, 384 pp

Castresana J (2000) Selection of conserved blocks from multiple alignments for their use in phylogenetic analysis. Mol Biol Evol 17:540-552

Clements FE, Shear CL (1931) The genera of fungi. H.W. Wilson, New York

Collado J, Platas G, Peláez F (2001) Identification of an endophytic Nodulisporium sp. from Quercus ilex in central Spain as the anamorph of Biscogniauxia mediterranea by rDNA sequence analysis and effect of different ecological factors on distribution of the fungus. Mycologia 93:875-886

Dai DQ, Bahkali AH, Li QR, Bhat DJ, Wijayawardene NN, Li WJ, Chukeatirote E, Zhao RL, Xu JC, Hyde KD (2016) Vamsapriya (Xylariaceae) re-described, with two new species and molecular sequence data. Cryptogam Mycol 35:339-357

Dai DQ, Phookamsak R, Wijayawardene NN, Li WJ, Bhat DJ, Xu JC, Taylor JE, Hyde KD, Chukeatirote E (2015) Bambusicolous fungi. Fungal Div. 82:1-105

Daranagama DA, Camporesi E, Liu XZ, Stadler M, Lumyong S, Hyde KD (2016) Taxonomic rearrangement of Anthostomella (Xylariaceae) based on multigene phylogenies and morphology. Cryptogam Mycol 37:509-538

Daranagama DA, Camporesi E, Tian Q, Liu X, Chamyuang S, Stadler M, Hyde KD (2015) Anthostomella is polyphyletic comprising several genera in Xylariaceae. Fungal Divers 73:203-238

Daranagama DA, Liu XZ, Chamung S, Stadler M, Hyde KD (2014) A multigene genealogy reveals the phylogenetic position of Rhopalostroma lekae. Phytotaxa 186:177-187

Darriba D, Taboada GL, Doallo R, Posada D (2012) jModelTest 2: more models, new heuristics and parallel computing. Nat Methods 9:772

de Lamarck JB, de Candolle AP (1805) Flore française, vol 5, edn 3 (Paris) 2:280

Dennis RWG (1961) Xylarioideae and Thamnomycetoideae of Congo. Bull Jard Bot Brux 31:109-154

Eriksson OE, Winka K (1997) Supraordinal taxa of Ascomycota. Myconet 1:1-16

Fournier J, Flessa F, Peršoh D, Stadler M (2011) Three new Xylaria species from southwestern Europe. Mycol Prog 10:33-52

Fournier J, Stadler M, Hyde KD, Duong LM (2010) The new genus Rostrohypoxylon and two new Annulohypoxylon species from Northern Thailand. Fungal Divers 40:23-36

Gardes M, Bruns TD (1993) ITS primers with enhanced specificity for basidiomycetes - application to the identification of mycorrhizae and rusts. Mol Ecol 2:113-118

Glass NL, Donaldson GC (1995) Development of primer sets designed for use with the PCR to amplify conserved genes from filamentous ascomycetes. Appl Environ Microbiol 61:1323-1330

Guindon S, Gascuel O (2003) A simple, fast and accurate method to estimate large phylogenies by maximum likelihood. Syst Biol 52: 696-704

Hsieh HM, Ju YM, Rogers JD (2005) Molecular phylogeny of Hypoxylon and closely related genera. Mycologia 97:844-865

Hsieh HM, Lin CR, Fang MJ, Rogers JD, Fournier J, Lechat C, Ju YM (2010) Phylogenetic status of Xylaria subgenus Pseudoxylaria among taxa of the subfamily Xylarioideae (Xylariaceae) and phylogeny of the taxa involved in the subfamily. Mol Phylogenet Evol 54:957-969

Huelsenbeck JP, Ronquist F (2001) MRBAYES: Bayesian inference of phylogenetic trees. Bioinformatics 17:754-755

Jaklitsch WM, Fournier J, Rogers JD, Voglmayr H (2014) Phylogenetic and taxonomic revision of Lopadostoma. Persoonia 32:52-82

Jaklitsch WM, Gardiennet A, Voglmayr H (2016) Resolution of morphology-based taxonomic delusions: Acrocordiella, Basiseptospora, Blogiascospora, Clypeosphaeria, Hymenopleella, 
Lepteutypa, Pseudapiospora, Requienella, Seiridium and Strickeria. Persoonia 37:82-105

Jaklitsch WM, Voglmayr H (2012) Phylogenetic relationships of five genera of Xylariales and Rosasphaeria gen. nov. (Hypocreales). Fungal Divers 52:75-98

Jayanetti DR, Yue Q, Bills GF, Gloer JB (2014) Hypocoprins A-C: new sesquiterpenoids from the coprophilous fungus Hypocopra rostrata. J Nat Prod 78:396-401

Johannesson H, Laessøe T, Stenlid J (2000) Molecular and morphological investigation of the genus Daldinia in Northern Europe. Mycol Res 104:275-280

Ju YM, Hsieh HM, Ho MC, Szu DH, Fang MJ (2007) Theissenia rogersii sp. nov. and phylogenetic position of Theissenia. Mycologia 99: 612-662

Ju YM, Rogers JD (1996) A revision of the genus Hypoxylon. Mycologia memoir no. ${ }^{\circ} 20$. APS Press, St. Paul 365 pp

Ju YM, Rogers JD (2002) The genus Nemania (Xylariaceae). Nova Hedwigia 74:75-120

Ju YM, Rogers JD, Hsieh HM (2003) The genus Theissenia: $T$. pyrenocrata, $T$. cinerea sp. nov., and T. eurima sp. nov. Mycologia 95:109-116

Ju YM, Rogers JD, San Martín F (1997) A revision of the genus Daldinia. Mycotaxon 61:243-293

Ju YM, Rogers JD, San Martin F, Granmo A (1998) The genus Biscogniauxia. Mycotaxon 66:1-98

Ju YM, San Martín F, Rogers JD (1993) Three xylariaceous fungi with scolecosporous conidia. Mycotaxon 47:219-228

Katoh M, Kuma M (2002) MAFFT: a novel method for rapid multiple sequence alignment based on fast Fourier transform. Nucleic Acids Res 30:3059-3066

Kearse M, Moir R, Wilson A, Stones-Havas S, Cheung M, Sturrock S, Buxton S, Cooper A, Markowitz S, Duran C, Thierer T, Ashton B, Mentjies P, Drummond A (2012) Geneious basic: an integrated and extendable desktop software platform for the organization and analysis of sequence data. Bioinformatics 28:1647-1649

Koukol O, Kelnarová I, Černý K (2015) Recent observations of sooty bark disease of sycamore maple in Prague (Czech Republic) and the phylogenetic placement of Cryptostroma corticale. For Pathol 45:21-27

Kuhnert E, Fournier J, Peršoh D, Luangsa-ard JJD, Stadler M (2014a) New Hypoxylon species from Martinique and new evidence on the molecular phylogeny of Hypoxylon based on ITS rDNA and $\beta$ tubulin data. Fungal Divers 64:181-203

Kuhnert E, Sir EB, Lambert C, Hyde KD, Hladki AI, Romero AI, Rohde M, Stadler M (2016) Phylogenetic and chemotaxonomic resolution of the genus Annulohypoxylon (Xylariaceae) including four new species. Fungal Divers. doi:10.1007/s13225-016-0377-6 in press

Kuhnert E, Surup F, Halecker S, Stadler M (2017) Minutellins A - D, azaphilones from the stromata of Annulohypoxylon minutellum (Xylariaceae). Phytochemistry. doi:10.1016/j.phytochem.2017.02. 014 in press

Kuhnert E, Surup F, Sir EB, Lambert C, Hyde KD, Hladki AI, Romero AI, Stadler M (2015) Lenormandins A - G, new azaphilones from Hypoxylon lenormandii and Hypoxylon jaklitschii sp. nov., recognised by chemotaxonomic data. Fungal Divers 71:165-184

Læssøe T, Rogers JD, Whalley AJ (1989) Camillea, Jongiella and lightspored species of Hypoxylon. Mycol Res 93:121-155

Læssøe T, Srikitikulchai P, Fournier J, Köpcke B, Stadler M (2010) Lepraric acid derivatives as chemotaxonomic markers in Hypoxylon aeruginosum, Chlorostroma subcubisporum and C. cyaninum, sp. nov. Fungal Biol 114:481-489

Læssøe T, Srikitikulchai P, Luangsa-ard JJD, Stadler M (2013) Theissenia reconsidered, including molecular phylogeny of the type species T. pyrenocrata and a new genus Durotheca (Xylariaceae, Ascomycota). IMA Fungus 4:57-69
Li GJ, Hyde KD, Zhao RL et al (2016) Fungal diversity notes 253-366: taxonomic and phylogenetic contributions to fungal taxa. Fungal Divers 78:1-273

Li QR, Kang JC, Hyde KD (2015) Two new species of the genus Collodiscula (Xylariaceae) from China. Mycol Prog 14:52

Liu YL, Whelen S, Hall BD (1999) Phylogenetic relationships among ascomycetes: evidence from an RNA polymerase II subunit. Mol Biol Evol 16:1799-1808

Lloyd CG (1917) Synopsis of some genera of the large pyrenomycetes. Mycological notes 50. Mycol Writ 5:701-716

Maharachchikumbura SSN, Hyde KD, Jones EBG, McKenzie EHC, Bhat J, Hawksworth DL, Dayarathne M, Huang SK, Norphanphoun C, Senanayake IC, Perera RH, Shang Q, Xiao Y, D'souza MJ, Hongsanan S, Jayawardena RS, Daranagama DA, Konta S, Goonasekara ID, Zhuang WY, Jeewon R, Phillips AL, Abdel-Wahab MA, Al-Sadi AM, Bahkali AH, Boonmee S, Boonyuen N, Cheewangkoon R, Dissanayake AJ, Kang J, Liu JK, Liu XZ, Liu ZL, Pang KL, Phookamsak R, Promputtha I, Suetrong S, Wen T, Wijayawardene NN (2016) Families of Sordariomycetes. Fungal Divers 79:1-317

Miller AN, Vasilyeva LN, Rogers JD (2007) Chlorostroma subcubisporum gen. et sp. nov. and notes on the systematic position of Thuemenella cubispora. Sydowia 59:138-147

Miller JH (1961) A monograph of the world species of Hypoxylon. Univ. Georgia Press, Athens $158 \mathrm{p}$

Möller A (1901) Phycomyceten und Ascomyceten. Untersuchungen aus Brasilien. Bot Mitt Tropen 9:1-319

O'Donnell K (1993) Fusarium and its near relatives. In: Reynolds DR, Taylor JW (eds) The fungal holomorph: mitotic, meiotic and pleomorphic speciation in fungal systematics. $\mathrm{CAB}$ International, Wallingford, UK, pp 225-233

O’Donnell K, Cigelnik E (1997) Two divergent intragenomic rDNA ITS2 types within a monophyletic lineage of the fungus Fusarium are nonorthologous. Mol Phylogenet Evol 7:103-116

Otto A, Laub A, Wendt L, Porzel A, Schmidt J, Palfner G, Becerra J, Krüger D, Stadler M, Wessjohann L, Westermann B, Arnold N (2016) Chilenopeptins A and B, peptaibols from the Chilean Sepedonium aff. chalcipori KSH 883. J Nat Prod 79:929-938

Pažoutová S, Follert S, Bitzer J, Keck M, Surup F, Šrůtka P, Holuša J, Stadler M (2013) A new endophytic insect-associated Daldinia species, recognised from a comparison of secondary metabolite profiles and molecular phylogeny. Fungal Divers 60:107-123

Pažoutová S, Srutka P, Holuša J, Chudickova M, Kolarik M (2010a) The phylogenetic position of Obolarina dryophila (Xylariales). Mycol Prog 9:501-507

Pažoutová S, Šrůtka P, Holuša J, Chudíčková M, Kolař́k M (2010b) Diversity of xylariaceous symbionts in Xiphydria woodwasps: role of vector and a host tree. Fungal Ecol 3:392-401

Pelaez F, Gonzalez V, Platas G, Sanchez-Ballesteros J (2008) Molecular phylogenetic studies within the family Xylariaceae based on ribosomal DNA sequences. Fungal Divers 31:111-134

Petrini LE (2013) Rosellinia - a world monograph. Bibliotheca Mycologica, Band 205. J. Cramer

Petrini LE, Müller E (1986) Haupt-und Nebenfruchtformen europäischer Hypoxylon-Arten (Xylariaceae, Sphaeriales) und verwandter Pilze. Benteli Verlag

Quang DN, Hashimoto T, Nomura Y, Wollweber H, Hellwig V, Fournier J, Stadler M, Asakawa Y (2005a) Cohaerins A and B, azaphilones from the fungus Hypoxylon cohaerens, and comparison of HPLCbased metabolite profiles in Hypoxylon sect. Annulata. Phytochemistry 66:797-809

Quang DN, Hashimoto T, Stadler M, Radulović N, Asakawa Y (2005b) Antimicrobial azaphilones from the fungus Hypoxylon multiforme. Planta Med 71:1058-1062 
Quang DN, Stadler M, Fournier J, Tomita A, Hashimoto T (2006) Cohaerins $\mathrm{C}-\mathrm{F}$, four azaphilones from the xylariaceous fungus Annulohypoxylon cohaerens. Tetrahedron 62:6349-6354

Rogers JD (1979) The Xylariaceae: systematic, biological and evolutionary aspects. Mycologia 71:1-42

Rogers JD (1981) Sarcoxylon and Entonaema (Xylariaceae). Mycologia 73:28-61

Rogers JD, Ju YM (1996) Entoleuca mammata comb. nov. for Hypoxylon mammatum and the genus Entoleuca. Mycotaxon 59:441-448

Rogers JD, Ju YM, San Martín F (1997) Jumillera and Whalleya, new genera segregated from Biscogniauxia. Mycotaxon 64:39-50

Rogers JD, Ju YM, San Martín González F (1998) Podosordaria: a redefinition based on cultural studies of the type species, P. mexicana, and two new species. Mycotaxon 67:61-72

Rubio E, De la Peña S (2016) Annulohypoxylon michelianum, una rara especie laurícola recolectada en el noroeste español. Ascomycete.org 8:25-29

Saitou N, Nei M (1987) The neighbor-joining method: a new method for reconstructing phylogenetic trees. Mol Biol Evol 4:406-425

Sánchez-Ballesteros J, González V, Salazar O, Acero J, Portal MA, Julián M, Rubio V (2000) Phylogenetic study of Hypoxylon and related genera based on ribosomal ITS sequences. Mycologia 92:964-977

Schoch CL, Seifert KA, Huhndorf S et al (2012) Nuclear ribosomal internal transcribed spacer (ITS) region as a universal DNA barcode marker for fungi. Proc Natl Acad Sci U S A 109:6241-6246

Senanayake IC, Maharachchikumbura SSN, Hyde KD, Bhat JD, EBG J, EH MK, Dai DQ, Dagaranagama DA, Dayarathne MC, Goonasekara ID, Konta S, Li WL, Shang QJ, Stadler M, Wijayawardene NN, Xiao XP, Norphanphoun C, Li QR, Liu XZ, Bahkali AH, Kang JC, Wang Y, Wen TC, Wendt L, Xu JC, Camporesi E (2015) Towards unraveling relationships in Xylariomycetidae (Sordariomycetes). Fungal Divers 73:73-144

Sir EB, Kuhnert E, Lambert C, Hladki AI, Romero AI, Stadler M (2016a) New species and reports of Hypoxylon from Argentina recognized by a polyphasic approach. Mycol Prog 15:42

Sir EB, Lambert C, Wendt L, Hladki AI, Romero AI, Stadler M (2016b) A new species of Daldinia (Xylariaceae) from the argentine subtropical montane forest. Mycosphere 7(9):1378-1388. doi:10.5943/ mycosphere/si/4g/2

Stadler M (2011) Importance of secondary metabolites in the Xylariaceae as parameters for assessment of their taxonomy, phylogeny, and functional biodiversity. Curr Res Environ Appl Mycol 1:75-133

Stadler M, Fournier J, Beltrán-Tejera E, Granmo A (2008a) The "red Hypoxylons" of the temperate and subtropical Northern Hemisphere. In: Glawe DA, Ammirati JF (eds) A Festschrift in honor of Professor Jack D. Rogers. North American Fungi 3:73-125

Stadler M, Fournier J, Gardt S, Peršoh D (2010a) The phylogenetic position of Rhopalostroma as inferred from a polythetic approach. Persoonia 25:11-21

Stadler M, Fournier J, Læssøe T, Chlebicki A, Lechat C, Flessa F, Rambold G, Peršoh D (2010b) Chemotaxonomic and phylogenetic studies of Thamnomyces (Xylariaceae). Mycoscience 51:189-207

Stadler M, Fournier J, Læssøe T, Decock C, Peršoh D, Rambold G (2010c) Ruwenzoria, a new genus of the Xylariaceae from Central Africa. Mycol Prog 9:169-179

Stadler M, Fournier J, Læssøe T, Lechat C, Tichy HV, Piepenbring M (2008b) Recognition of hypoxyloid and xylarioid Entonaema species from a comparison of holomorphic morphology, HPLC profiles, and ribosomal DNA sequences. Mycol Prog 7:53-73

Stadler M, Hawksworth DL, Fournier J (2014b) The application of the name Xylaria hypoxylon, based on Clavaria hypoxylon of Linnaeus. IMA Fungus 5:57-66

Stadler M, Hellwig V (2005) Chemotaxonomy of the Xylariaceae and remarkable bioactive compounds from Xylariales and their associated asexual stages. Recent Res Dev Phytochem 9:41-93
Stadler M, Kuhnert E, Peršoh D, Fournier J (2013) The Xylariaceae as model example for a unified nomenclature following the "one fungus-one name" $(1 \mathrm{~F} 1 \mathrm{~N})$ concept. Mycol Int J Fungal Biol 4:5-21

Stadler M, Læssøe T, Fournier J, Decock C, Schmieschek B, Tichy HV, Peršoh D (2014a) A polyphasic taxonomy of Daldinia (Xylariaceae). Stud Mycol 77:1-143

Stadler M, Laessoe T, Vasilyeva L (2005) The genus Pyrenomyxa and its affinities to other cleistocarpous Hypoxyloideae as inferred from morphological and chemical traits. Mycologia 97:1129-1139

Stamatakis A (2006) RAxML-VI-HPC: maximum likelihood-based phylogenetic analyses with thousands of taxa and mixed models. Bioinformatics 22:2688-2690

Stamatakis A (2014) RAxML version 8: a tool for phylogenetic analysis and post-analysis of large phylogenies. Bioinformatics 30:13121313

Stamatakis A, Alachiotis N (2010) Time and memory efficient likelihood-based tree searches on phylogenomic alignments with missing data. Bioinformatics 26:i132-i139

Stielow JB, Lévesque CA, Seifert KA et al (2015) One fungus, which genes? Development and assessment of universal primers for potential secondary fungal DNA barcodes. Persoonia 35:242-263

Surup F, Mohr KI, Jansen R, Stadler M (2013) Cohaerins G-K, azaphilone pigments from Annulohypoxylon cohaerens and absolute stereochemistry of cohaerins $\mathrm{C}-\mathrm{K}$. Phytochemistry 95 : $252-258$

Swofford DL (2002) PAUP*. Phylogenetic analysis using parsimony (*and other methods). version 4. Sinauer Associates, Sunderland, MA

Sydow H, Sydow P (1910) Fungi novi Phillippinenses. Annales Mycologici 8:36-41

Talavera G, Castresana J (2007) Improvement of phylogenies after removing divergent and ambiguously aligned blocks from protein sequence alignments. Syst Biol 56:564-577

Tang AM, Jeewon R, Hyde KD (2007) Phylogenetic relationships of Nemania plumbea sp. nov. and related taxa based on ribosomal ITS and RPB2 sequences. Mycol Res 111:392-402

Tang AM, Jeewon R, Hyde KD (2009) A re-evaluation of the evolutionary relationships within the Xylariaceae based on ribosomal and protein-coding gene sequences. Fungal Divers 34:155-153

Taylor JE, Hyde KD (1999) Cannonia gen. nov., from palms in the Southern Hemisphere. Mycol Res 103:1398-1402

Theissen F (1909) Xylariaceae austro-brasilienses. Zweiter Teil. Annales Mycologici 7:1-18

Triebel D, Peršoh D, Wollweber H, Stadler M (2005) Phylogenetic relationships among Daldinia, Entonaema and Hypoxylon as inferred from ITS nrDNA sequences. Nova Hedwigia 80:25-43

Trierveiler-Pereira L, Agra LANN, Mariana Capdet M, Romero AI (2012) Cannonia australis (Xylariaceae, Ascomycota) found in equatorial Brazil. Darwin 50:170-173

Vilgalys R, Hester M (1990) Rapid genetic identification and mapping of enzymatically amplified ribosomal DNA from several Cryptococcus species. J Bacteriol 172:4238-4246

Whalley AJS, Edwards RL (1995) Secondary metabolites and systematic arrangement within the Xylariaceae. Can J Bot 73(Supplement 1): S802-S810

White TJ, Bruns TD, Lee S, Taylor JW (1990) Amplification and direct sequencing of fungal ribosomal RNA for phylogenetics. In: Innis MA et al (eds) PCR protocols: a guide to methods and applications. Academic, San Diego, pp 315-322

Zare R, Asgari B, Gams W (2010) The species of Coniolariella. Mycologia 102:1383-1388

Zhang N, Castlebury LA, Miller AN, Huhndorf SM, Schoch CL, Seifert KA, Rossman AY, Rogers JD, Kohlmeyer J, Volkmann-Kohlmeyer B, Sung GH (2006) An overview of the systematics of the Sordariomycetes based on a four-gene phylogeny. Mycologia 98: 1076-1087 